Nilton Eufrázio Martinho Moçambique

\title{
Aplicação de Algoritmos de Busca do Ponto de Máxima Potência e controladores lineares e/ou Fuzzy para a regulação da tensão terminal de Painéis Fotovoltaicos
}

Dissertação de Mestrado apresentada à Escola de Engenharia de São Carlos, da Universidade de São Paulo, como requisito para obtenção do Título de Mestre em Ciências, Programa de Engenharia Elétrica.

Área de Concentração: Sistemas Dinâmicos.

Orientador: Prof. Dr. Ricardo Quadros Machado

São Carlos

2012 
AUTORIZO A REPRODUÇÃO E DIVULGAÇÃO TOTAL OU PARCIAL DESTE TRABALHO, POR QUALQUER MEIO CONVENCIONAL OU ELETRÔNICO, PARA FINS DE ESTUDO E PESQUISA, DESDE QUE CITADA A FONTE.

Ficha catalográfica preparada pela Seção de Atendimento ao Usuário do Serviço de Biblioteca EESC/USP

Moçambique, Nilton Eufrázio Martinho

M688a Aplicação de algoritmos de busca do ponto de máxima potência e controladores lineares e/ou Fuzzy para a regulação da tensão terminal de painéis fotovoltaicos / Nilton Eufrázio Martinho Moçambique ; orientador Ricardo Quadros Machado. São Carlos, 2012.

Dissertação (Mestrado - Programa de Pós-Graduação em Engenharia Elétrica e Área de Concentração em Sistemas Dinâmicos)-- Escola de Engenharia de São Carlos da Universidade de São Paulo, 2012.

1. Painel fotovoltaico. 2. MPPT. 3. Controlador Fuzzy. 4. Eletrônica de potência. I. Título. 


\section{FOLHA DE JULGAMENTO}

Candidato: Engenheiro NILTON EUFRÁZIO MARTINHO MOÇAMBIQUE.

Título da dissertação: "Aplicação de algoritmos de busca do ponto de máxima potência e controladores lineares e/ou fuzzy para regulação da tensão terminal de painéis fotovoltaicos".

Data da defesa: 06/06/2012

Comissão Julgadora:

Prof. Dr. Ricardo Quadros Machado (Orientador)

(Escola de Engenharia de São Carlos/EESC)

Prof. Dr. Denizar Cruz Martins

(Universidade Federal de Santa Catarina/UFSC)

Prof. Dr. José Roberto Boffino de Almeida Monteiro

(Escola de Engenharia de São Carlos/EESC)
Resultado:

APRONADO

APROVADO

APROVADO

Coordenador do Programa de Pós-Graduação em Engenharia Elétrica:

Prof. Titular Denis Vinicius Coury

Suplente do Presidente da Comissão de Pós-Graduação em Exercício:

Prof. Titular Denis Vinicius Coury 



\section{Agradecimentos}

A DEUS, Pai Todo Poderoso, pelo dom da vida e por tudo aquilo que ela representa.

À minha dedicada esposa Dina e a nossa amada filha Tchaya pelo amor, carinho e paciência, sobretudo nos momentos de desânimo e pelas palavras de apoio e perseverança, cruciais para a conclusão deste trabalho. Vocês são as minhas fontes de inspiração e o meu porto seguro.

Aos meus queridos pais, Pedro e Margarida, e aos meus queridos irmãos, Miro, Tânia, Anderson e Marcos, pelas críticas, conselhos e ensinamentos incondicionais. Aos meus queridos sobrinhos Pedro e Sara, agradeço por me motivarem a dar sempre o melhor de mim.

Aos meus compatriotas africanos, em particular em São Carlos, obrigado pelas raízes, cultura e momentos de alegria.

Aos meus colegas e amigos do laboratório (LAFAPE e LAC), pelas discussões, esclarecimentos, aprendizados e momentos de descontração. Em especial, agradeço ao Amilcar, Cássio, Fernando, Gian, Giovani, Guido, Renan e Rodolfo por me apoiarem nas mais diversas situações durante o mestrado.

Aos professores e companheiros de graduação da UNESP/Guaratinguéta, Engenharia Elétrica - 2005, instituição na qual tive o privilégio em adquirir toda a base de conhecimento acadêmico.

Aos professores e funcionários da USP/EESC pelas contribuições neste tempo que passei por aqui. Em especial, aos funcionários, técnico de laboratório, Rui Bertho, às secretárias da Pós-Graduação Jussara e Marisa, à Roseli Ribeiro, e ao senhor José.

Ao professor Dr. Ricardo Machado pela confiança em mim depositada, pela paciência e amizade, por todo apoio e sempre além do esperado. Obrigado meu orientador, Ihe devo todo o respeito e consideração.

À professora Vilma de Oliveira, por toda a contribuição, críticas e ensinamentos, que muito influenciaram neste trabalho e na minha formação pessoal. 
À Escola de Engenharia de São Carlos (USP) pelas instalações e serviços oferecidos para desenvolvimento deste trabalho e a TOTAL E\&P Angola por todo apoio financeiro indispensável para a minha manutenção.

Enfim, agradeço a todas as pessoas ou entidades, omitidas ou esquecidas que acreditaram que este trabalho fosse possível. 


\section{SUMÁRIO}

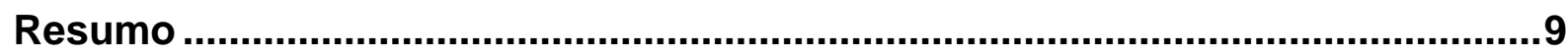

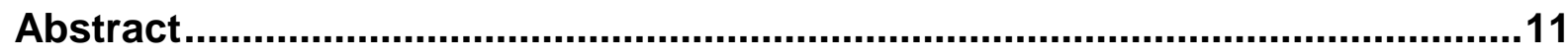

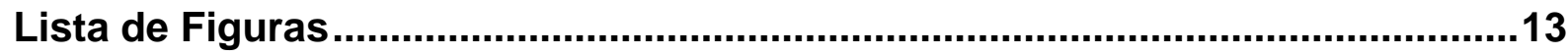

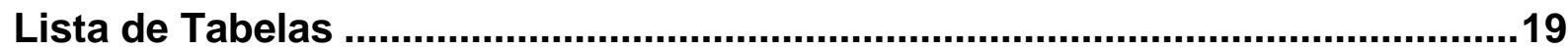

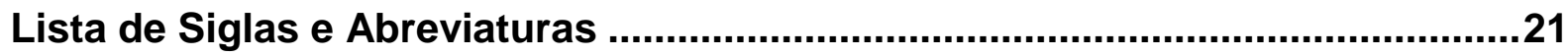

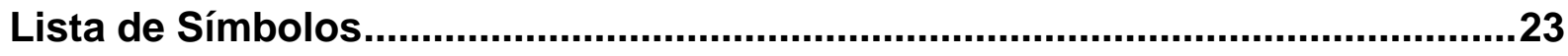

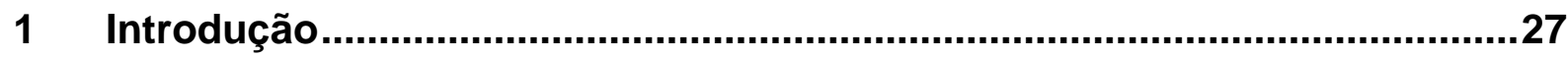

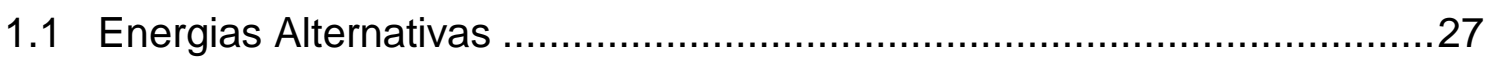

1.2 Cenário da Energia Fotovoltaica no Brasil e no Mundo ...........................29

1.3 Estrutura Mínima para um Sistema Fotovoltaico .....................................31

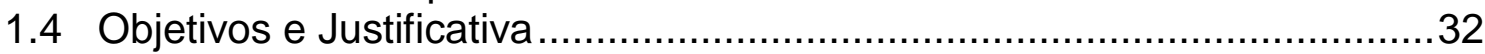

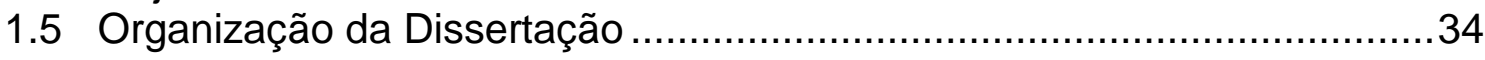

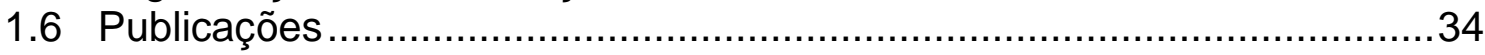

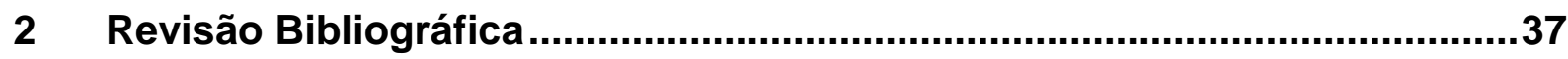

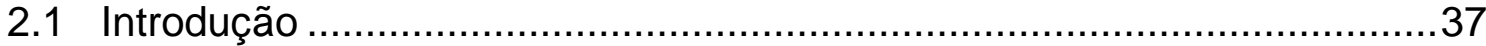

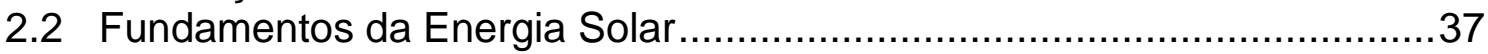

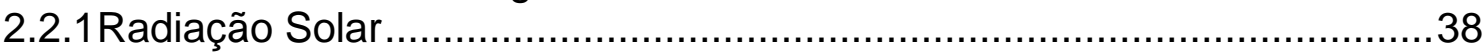

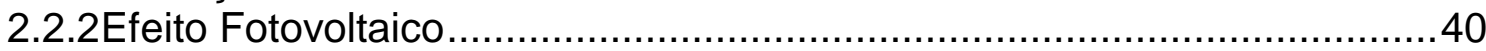

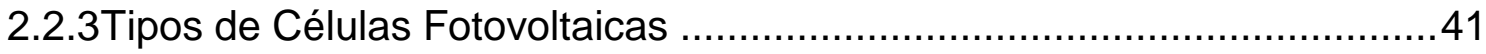

2.3 Modelo Matemático da Célula Fotovoltaica.......................................42

2.3.1 Modelo Generalizado e Modelo Simplificado .........................................43

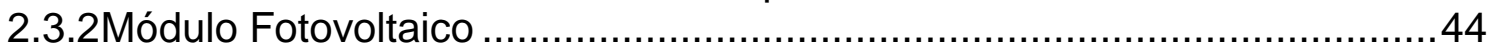

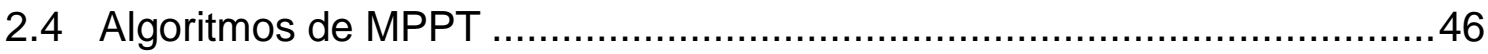

2.4.1 Algoritmos de MPPT Baseados em Modelo .........................................46

2.4.2Algoritmos de MPPT Baseados em Treinamento ................................47

2.4.3Algoritmos de MPPT Heurísticos......................................................4 4

2.4.3.1 Perturbação e Observação ..................................................48

2.4.3.2 Condutância Incremental .....................................................

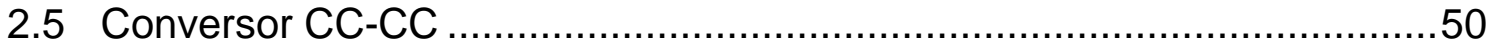

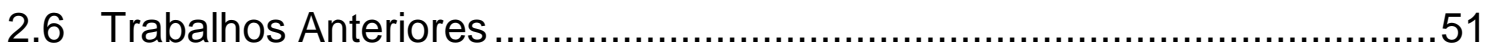

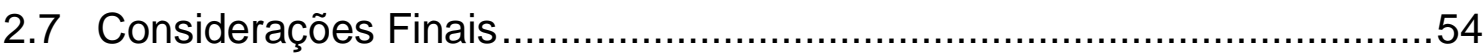

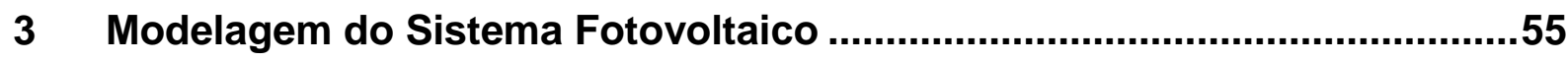

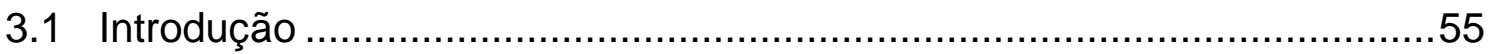

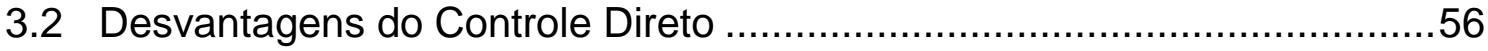

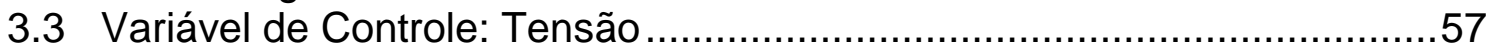

3.4 Especificação do Sistema Fotovoltaico .............................................59

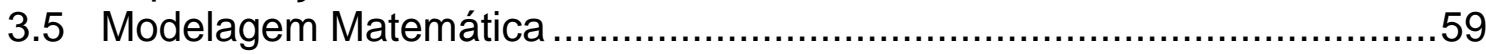

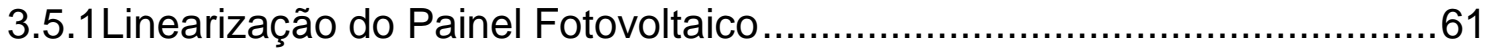


3.5.2Linearização do Sistema Fotovoltaico 62

3.5.3Obtenção da Função de Transferência de Pequenos Sinais por Equação de Espaço de Estados. 64

3.5.4Modelo Circuital CA de Pequenos Sinais .............................................. 66

3.6 Efeito de Elementos Parasitas: Capacitivo e Indutivo............................. 71

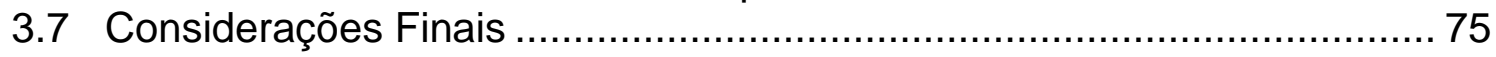

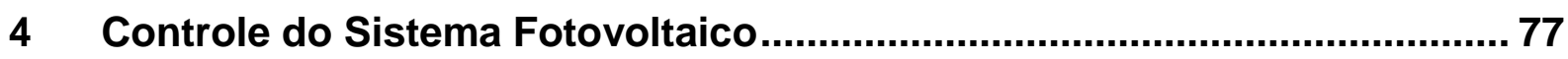

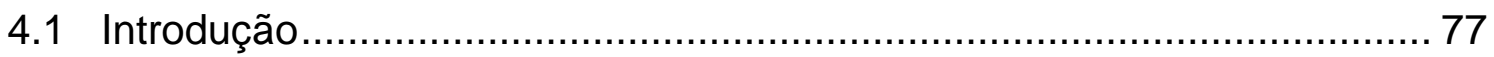

4.2 Controle78

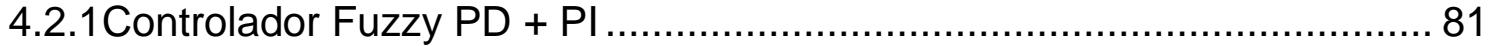

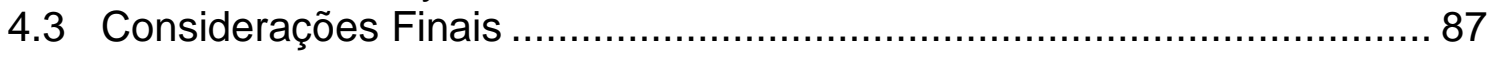

$5 \quad$ Bancada Experimental e Análise de Resultados ...................................... 89

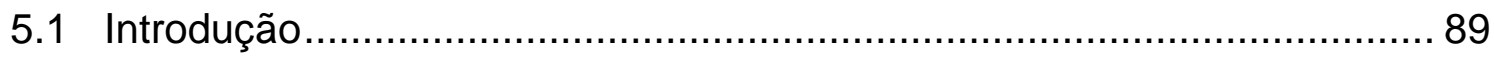

5.2 Descrição da Bancada Experimental ..................................................... 89

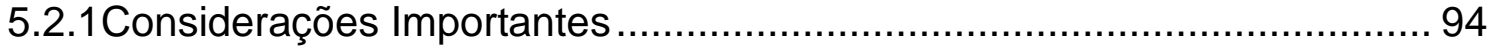

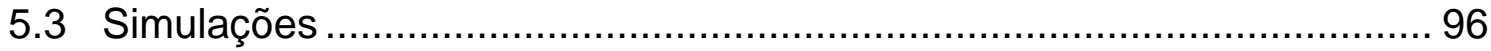

5.3.1Determinação das Condições Iniciais e do Tempo de Amostragem do MPPT

5.3.2Dinâmica do Sistema

5.3.3Rápidas Mudanças nas Condições de Irradiação e Temperatura ........... 100

5.3.4Perturbações na Carga..................................................................... 102

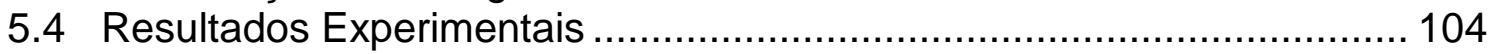

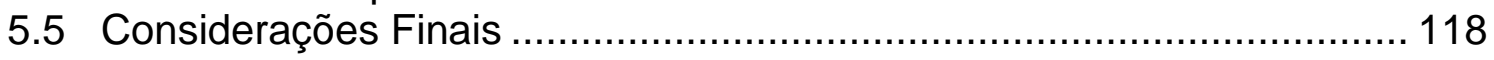

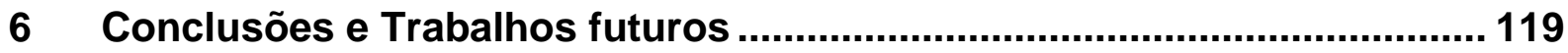

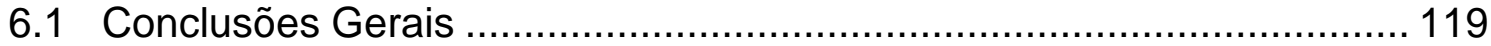

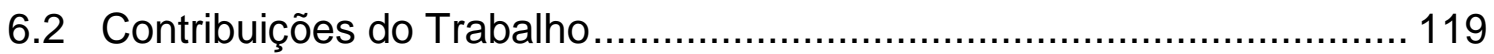

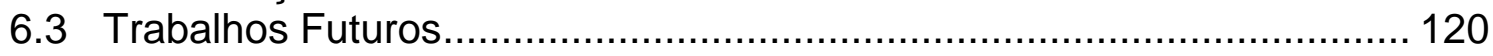

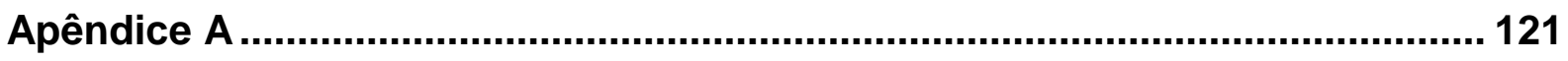

A.1 Curva Estática do Processo com Conversor Elevador de Tensão e Fonte SAS 121

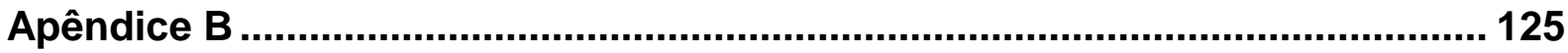

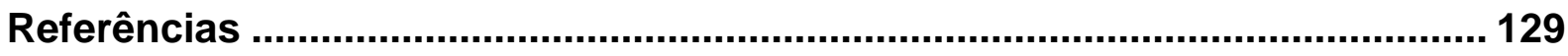




\section{Resumo}

MOCAMBIQUE, N. E. M. (2012). Aplicação de algoritmos de busca do ponto de máxima potência e controladores lineares e/ou Fuzzy para a regulação da tensão terminal de painéis fotovoltaicos. Dissertação (Mestrado) - Escola de Engenharia de São Carlos, Universidade de São Paulo, 2012.

Algoritmos de busca do ponto de máxima potência (MPPT) são largamente utilizados para se obter a potência máxima fornecida em sistemas fotovoltaicos. Apesar de existirem diversas técnicas de MPPT, os métodos heurísticos de busca como o método da perturbação e observação (P\&O) e o método da Condutância Incremental (InC) são os mais usuais por serem simples e confiáveis. Assim, é proposto uma lei de controle com realimentação da tensão de saída de um painel fotovoltaico (PV) de forma a manter o mesmo operando próximo ao ponto de máxima potência, possibilitando com isso uma melhora do desempenho do algoritmo de $\mathrm{P} \& \mathrm{O}$ e $\mathrm{InC}$ inclusive quando o painel PV é submetido a rápidas mudanças na irradiação solar. Além disso, devido às características não lineares dos painéis fotovoltaicos, a utilização de técnicas inteligentes que empregam controladores fuzzy para o controle da tensão terminal do $\mathrm{PV}$, parece ser uma solução viável quando comparada aos controladores clássicos com PI e PID, principalmente, porque tais estruturas de controle proporcionam uma lenta resposta dinâmica e problemas de estabilidade relacionados às oscilações em torno do ponto de máxima potência, decorrente do funcionamento dos algoritmos P\&O e InC.

Palavras Chave: Painel fotovoltaico, MPPT, Controlador Fuzzy, Eletrônica de potência. 



\section{Abstract}

MOCAMBIQUE, N. E. M. (2012). Application of maximum power point tracking algorithms and linear and/or nonlinear fuzzy logic control to regulate the voltage of photovoltaic panels. Dissertation (Master's degree) - Escola de Engenharia de São Carlos, Universidade de São Paulo, 2012.

Maximum power point tracking (MPPT) techniques are widely used to achieve the maximum output power of a photovoltaic (PV) system. Although there are many MPPT techniques, the heuristic search methods such as perturb and observe (P\&O) and incremental conductance $(\mathrm{InC})$ method are the most commonly used because they are simple and reliable in the pursuit of maximum power point. A control law with feedback of the output voltage of a photovoltaic (PV) panel is proposed, in order to maintain it working nearby the maximum power point, enabling an improvement in the performance of the algorithm for $\mathrm{P} \& \mathrm{O}$ and $\operatorname{InC}$ even when the PV array is subjected to rapid changes in solar irradiance. Moreover, due to the nonlinear characteristics of the photovoltaic panels, the technique that employ fuzzy logic control seems to be a viable option when compared with conventional proportional and integral or proportional, integral and derivative controllers, mainly because such control structures provide a slow dynamic response and stability issues related to oscillations around the maximum power point due to operation of $\mathrm{P} \& \mathrm{O}$ and $\mathrm{InC}$ algorithms.

Keywords: Photovoltaic Panel, MPPT, Fuzzy Controller, Power Electronics. 



\section{Lista de Figuras}

Figura 1.2. Taxa média do crescimento anual da energia renovável e da produção de biocombustíveis, 2005-2010.

Figura 1.3. Evolução da capacidade mundial anual de sistemas fotovoltaicos desde 2000 .

Figura 1.4. Cenário da capacidade de sistemas fotovoltaicos instalados no mundo até 2011.

Figura 2.1. Distribuição espectral da luz solar no espaço.. .....................................38

Figura 2.3. Modelo generalizado de uma célula solar...........................................43

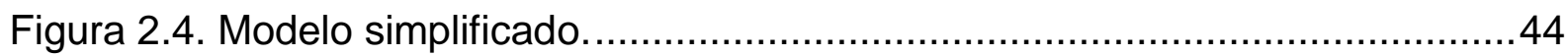

Figura 2.5. Curvas $I-V$ (a) e $P-V$ (b) de um módulo KC130TM PV, para diferentes níveis de irradiação e os pontos notáveis de $\operatorname{PMP}\left(V_{M P}, I_{M P}\right) \mathrm{e}$ $\left(V_{M P}, \mathrm{PMP}\right)$

Figura 2.6. $P-I-V$ características do módulo fotovoltaico KC130TM, para diferentes níveis de irradiação e com os pontos notáveis de PMP ( $V_{M P}, I_{M P}$, PMP)

Figura 3.1. Diagrama do sistema fotovoltaico em estudo......................................56

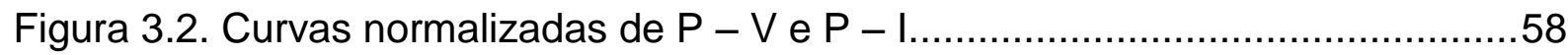

Figura 3.3. Linearização da curva i - v nas proximidades do PMP do módulo solar KC130TM

Figura 3.4. Circuito linear equivalente no ponto de máxima potência.......................62

Figura 3.5. Diagrama esquemático do conversor elevador de tensão. .....................63

Figura 3.6. Circuito geral do sistema fotovoltaico incluindo os efeitos parasitas dos componentes.

Figura 3.7. Circuito de pequenos sinais equivalente para a malha do indutor.

Figura 3.8. Circuito de pequenos sinais equivalente para o nó do capacitor de entrada.

Figura 3.9. Circuito de pequenos sinais equivalente para o nó do capacitor de saída. 
Figura 3.10. Circuito linear equivalente de pequenos sinais do sistema fotovoltaico.68

Figura 3.11. Diagrama de Bode da função de transferência $G_{v d}(s) \ldots \ldots \ldots \ldots \ldots \ldots \ldots \ldots . . . . . . . . . . . .70$

Figura 3.12. Diagrama de Bode da função de transferência $G_{v i}(s) \ldots \ldots \ldots \ldots \ldots \ldots \ldots \ldots \ldots . . . . . . . . . .70$

Figura 3.13. Resposta ao degrau unitário do modelo considerando tensão na saída constante (em azul), modelo considerando carga constante (em verde) e o modelo utilizado (em vermelho). ................................................................... 71

Figura 3.14. Modelo canônico do circuito do conversor elevador de tensão estudado considerando-se os efeitos parasitas do painel fotovoltaico............. 73

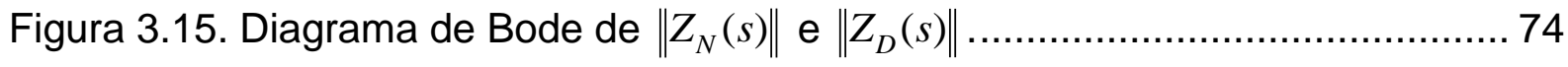

Figura 4.1. Conversor elevador de tensão com controle da tensão de entrada........ 78

Figura 4.2. Diagrama em blocos do conversor CC-CC controlado e com referência

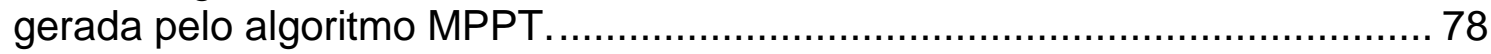

Figura 4.3. Resposta em frequência em malha fechada com realimentação unitária

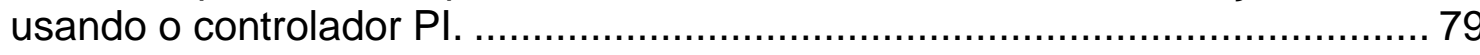

Figura 4.4. Resposta em frequência em malha fechada com realimentação unitária da rejeição a uma perturbação indesejável na entrada da planta. ................... 80

Figura 4.5. Resposta no domínio do tempo da tensão do painel foto voltaico usando o controlador PI para uma referência constante $\mathrm{V}_{\mathrm{REF}}=35 \mathrm{~V}$ (linha pontilhada). Ts $=1 \mu \mathrm{s}$, ripple $=2 \%$.

Figura 4.7. Esquemático do controlador Fuzzy PD+PI do conversor CC - CC. ....... 83

Figura 4.8. Funções de pertinência das variáveis de entrada e saída...................... 84

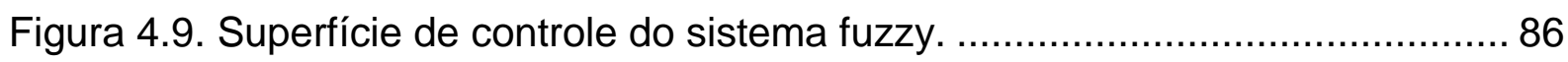

Figura 4.10. Resposta no domínio do tempo da tensão do painel fotovoltaico (linha contínua) usando o controlador Fuzzy PD + PI para uma referência de $\mathrm{V}_{\mathrm{REF}}=35 \mathrm{~V}$ (linha pontilhada). $\mathrm{Ts}=1 \mu \mathrm{s}$, ripple $=0,23 \mathrm{~V}$. 86

Figura 4.11. Resposta no domínio do tempo da tensão do painel fotovoltaico (linha contínua) usando apenas o controlador fuzzy PD para uma referência de $\mathrm{V}_{\mathrm{REF}}=35 \mathrm{~V}$ (linha pontilhada). Ts $=1 \mu \mathrm{s}$, ripple $=0,23 \mathrm{~V}$.

Figura 5.1. Visão geral da bancada experimental: (1) Indutor e capacitor na entrada do conversor. (2) Módulo responsável pelo condicionamento dos sinais analógicos, processamento digital e drivers do chave. (3) Inversor 
trifásico de IGBT's. (4) Carga resistiva. (5) Sinais disponíveis para medição.

(6) Osciloscópio.

Figura 5.2. Painéis fotovoltaicos instalados em suporte móvel.

Figura 5.3. Módulo simulador de matriz solar. Fonte: figura extraída do www.home.agilent.com.

Figura 5.4. (2.1) placa de sensores e condicionamento de sinais analógicos; (2.2) placa de processamento digital; (2.3) placa de acionamento dos drivers e alimentação do sensor hall.

Figura 5.5. Módulo contendo as placas de condicionamento, processamento, acionamento e saídas para medições.

Figura 5.6. Inversor trifásico de IGBT's e carga estática resistiva............................94

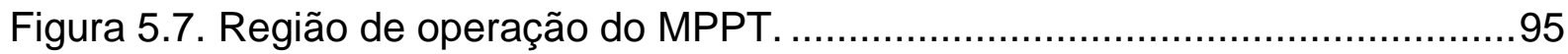

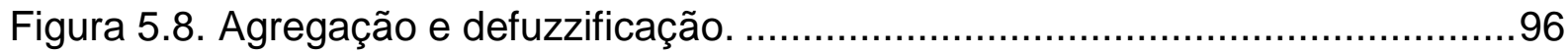

Figura 5.9. Simulações no domínio do tempo para $G=1000 \mathrm{~W} / \mathrm{m}^{2}$ e $T=298,15 \mathrm{~K}$, com passo fixo $=[1,0] V, T_{\alpha}=17 \mathrm{~ms}$. (a) Curva de potência (b) Curva de tensão.

Figura 5.10. Simulações no domínio do tempo para $G=1000 \mathrm{~W} / \mathrm{m}^{2}$ e $T=298,15 \mathrm{~K}$, com passo variável $=[5,01,00,5] \mathrm{V}, T_{\alpha}=17 \mathrm{~ms}$. (a) Curva de potência (b) Curva de tensão

Figura 5.11. Rápidas mudanças na irradiação no instante $0,4 \mathrm{~s}, G=500 \mathrm{~W} / \mathrm{m}^{2}$ (antes de $0,4 \mathrm{~s}$ ) e $G=1000 \mathrm{~W} / \mathrm{m}^{2}$ (depois de 0,4s), $T=298,15 \mathrm{~K}, T_{\alpha}=17 \mathrm{~ms}$ : (a) Curva de potência (b) Curva de tensão.

Figura 5.12. Rápidas mudanças na temperatura no instante $0,35 \mathrm{~s}, t=25^{\circ} \mathrm{C}$ (antes de $0,35 \mathrm{~s}$ ) e $t=75^{\circ} \mathrm{C}$ (depois de $0,35 \mathrm{~s}$ ), $G=1000 \mathrm{~W} / \mathrm{m}^{2}, T_{\alpha}=17 \mathrm{~ms}$ :

(a) Curva de potência (b) Curva de tensão.

Figura 5.13. Simulação do sistema fotovoltaico com fonte de tensão $A C$ $\left(V_{A C}=40 \mathrm{Vpp}, f_{A C}=120 \mathrm{~Hz}\right)$ em série com o barramento CC $\left(V_{O}=150 \mathrm{~V}\right)$, para $G=1000 \mathrm{~W} / \mathrm{m}^{2}, T=298,15 \mathrm{~K}, T_{\alpha}=17 \mathrm{~ms}$ : (a) Curva de potência (b) Curva de tensão

Figura 5.14. Resposta ao degrau na entrada com controlador PI. Ch2: tensão da fonte (5 V/div). Ch4: corrente injetada pela fonte $(900 \mathrm{~mA} / \mathrm{div})$. ChM: potência gerada pela fonte $(30 \mathrm{~W} / \mathrm{div})$. 
Figura 5.15. Resposta ao degrau na entrada com controlador fuzzy. Ch2: tensão da fonte $(5 \mathrm{~V} / \mathrm{div})$. Ch4: corrente injetada pela fonte (1 A/div). ChM: potência gerada pela fonte $(30 \mathrm{~W} / \mathrm{div})$. 106

Figura 5.16. Resposta ao degrau na entrada com controlador fuzzy PD + PI. Ch2: tensão da fonte $(5 \mathrm{~V} / \mathrm{div})$. Ch4: corrente injetada pela fonte (1 $\mathrm{A} / \mathrm{div})$. ChM: potência gerada pela fonte $(30 \mathrm{~W} / \mathrm{div})$. 107

Figura 5.17. Algoritmo P\&O com passo fixo de $0,5 \mathrm{~V}$ : sistema com controlador PI. Ch2: tensão da fonte $(5 \mathrm{~V} /$ div). ChM: potência gerada pela fonte $(30 \mathrm{~W} / \mathrm{div})$. $T_{\alpha}=17 \mathrm{~ms}$. 107

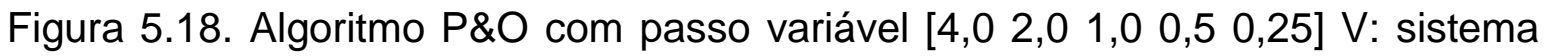
com controlador PI. Ch2: tensão da fonte ( $5 \mathrm{~V} / \mathrm{div})$. ChM: potência gerada pela fonte $(30 \mathrm{~W} / \mathrm{div}) . T_{\alpha}=17 \mathrm{~ms}$. 108

Figura 5.19. Algoritmo InC com passo fixo de $0,5 \mathrm{~V}$ : sistema com controlador PI. Ch2: tensão da fonte $(5 \mathrm{~V} / \mathrm{div})$. ChM: potência gerada pela fonte (30 $\mathrm{W} / \mathrm{div}) \cdot T_{\alpha}=17 \mathrm{~ms}$ 108

Figura 5.20. Algoritmo InC com passo variável [4,0 2,0 1,0 0,5 0,25] V: sistema com controlador PI. Ch2: tensão da fonte (5 V/div). ChM: potência gerada pela fonte $(30 \mathrm{~W} / \mathrm{div}) . T_{\alpha}=17 \mathrm{~ms}$. 109

Figura 5.21. Algoritmo P\&O com passo fixo de $0,5 \mathrm{~V}$ : sistema com controlador fuzzy PD + Pl. Ch2: tensão da fonte ( $5 \mathrm{~V} / \mathrm{div})$. ChM: potência gerada pela

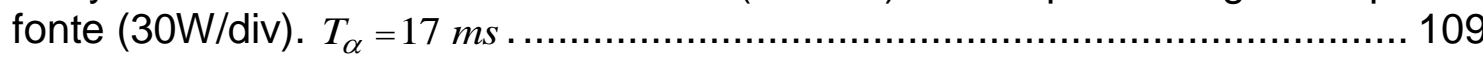

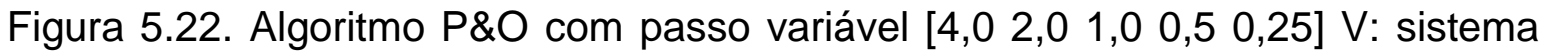
com controlador fuzzy PD+PI. Ch2: tensão da fonte (5 V/div). ChM: potência

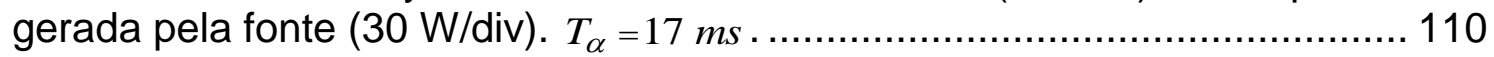

Figura 5.23. Algoritmo InC com passo fixo de $0,5 \mathrm{~V}$ : sistema com controlador fuzzy PI+PD. Ch2: tensão da fonte (5 V/div). ChM: potência gerada pela fonte (30

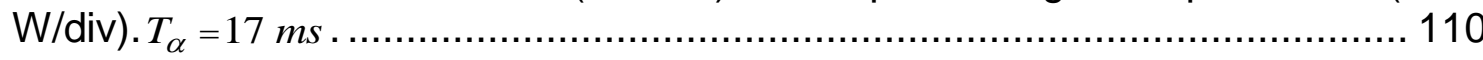

Figura 5.24. Algoritmo InC com passo variável [4,0 2,0 1,0 0,5 0,25] V: sistema com controlador fuzzy PD+PI. Ch2: tensão da fonte (5 V/div). ChM: potência gerada pela fonte $(30 \mathrm{~W} / \mathrm{div}) . T_{\alpha}=17 \mathrm{~ms}$.

Figura 5.25.Câmera infravermelha Ti10 IR Fusion Technology da FLUKE. 112

Figura 5.26. Distribuição térmica dos painéis fotovoltaicos em dia parcialmente nublado. (Vista 1). 113

Figura 5.27. Distribuição térmica dos painéis fotovoltaicos em dia parcialmente nublado. (Vista 2). 
Figura 5.28. Distribuição térmica dos painéis fotovoltaicos em dia com céu claro. .114

Figura 5.29. Distribuição térmica dos painéis fotovoltaicos com inclinações diferentes em um dia parcialmente nublado. ...........................................114

Figura 5.30. Resposta ao degrau na entrada com controlador PI. Ch2: tensão da fonte $(5 \mathrm{~V} / \mathrm{div})$. Ch4: corrente injetada pela fonte (2 A/div). ChM: potência gerada pela fonte $(30 \mathrm{~W} / \mathrm{div})$.

Figura 5.31. Resposta ao degrau na entrada com controlador fuzzy. Ch2: tensão da fonte $(5 \mathrm{~V} / \mathrm{div})$. Ch4: corrente injetada pela fonte $(2 \mathrm{~A} / \mathrm{div})$. ChM: potência gerada pela fonte $(30 \mathrm{~W} /$ div $)$.

Figura 5.32. Resposta ao degrau na entrada com controlador fuzzy PD + PI. Ch2: tensão da fonte (5 V/div). Ch4: corrente injetada pela fonte (2 A/div). ChM: potência gerada pela fonte $(30 \mathrm{~W} / \mathrm{div})$.

Figura 5.33. Algoritmo P\&O com passo fixo de $1,0 \mathrm{~V}$ : sistema com controlador PI. Ch2: tensão da fonte ( $5 \mathrm{~V} / \mathrm{div})$. Ch4: corrente injetada pela fonte $(2 \mathrm{~A} / \mathrm{div})$. ChM: potência gerada pela fonte (30 W/div). $T_{\alpha}=17 \mathrm{~ms}$.

Figura 5.34. Algoritmo $\mathrm{P} \& \mathrm{O}$ com passo fixo de $1,0 \mathrm{~V}$ : sistema com controlador fuzzy PD + Pl. Ch2: tensão da fonte (5 V/div). Ch4: corrente injetada pela fonte (2 A/div). ChM: potência gerada pela fonte (30 W/div) $T_{\alpha}=17 \mathrm{~ms}$

Figura 5.35. Algoritmo InC com passo fixo de 1,0 V: sistema com controlador PI. Ch2: tensão da fonte (5 V/div). Ch4: corrente injetada pela fonte (2 A/div). ChM: potência gerada pela fonte $\left(30 \mathrm{~W} /\right.$ div). $T_{\alpha}=17 \mathrm{~ms}$

Figura 5.36. Algoritmo P\&O com passo fixo de 1,0V: sistema com controlador fuzzy PD + PI. Ch2: tensão da fonte (5 V/div). Ch4: corrente injetada pela fonte (2 A/div). ChM: potência gerada pela fonte (30 W/div) $T_{\alpha}=17 \mathrm{~ms} . \ldots \ldots . .118$

Figura B.1. Teste com o simulador de matriz fotovoltaica, utilizando-se o controlador fuzzy PD+PI e o algoritmo de $\mathrm{P} \& \mathrm{O}$ em regime. Ch2: tensão da fonte $(5 \mathrm{~V} / \mathrm{div})$. Ch4: corrente injetada pela fonte $(900 \mathrm{~mA} / \mathrm{div})$. ChM: potência gerada pela fonte $(30 \mathrm{~W} /$ div $)$.

Figura B.2. Teste com o simulador de matriz fotovoltaica, utilizando-se o controlador fuzzy PD+PI e o algoritmo de InC em regime. Ch2: tensão da fonte (5 V/div). Ch4: corrente injetada pela fonte $(900 \mathrm{~mA} / \mathrm{div})$. ChM: potência gerada pela fonte $(30 \mathrm{~W} / \mathrm{div})$.

Figura B.3. Controle fuzzy PD testado com o simulador de fonte fotovoltaica nas condições de (I): passo fixo e algoritmo de P\&O. (II): passo variável e algoritmo de P\&O. (III): passo fixo e algoritmo de InC. (IV): passo fixo e 
algoritmo de InC. Ch2: tensão da fonte (5 V/div). ChM: potência gerada pela

fonte $(30 \mathrm{~W} /$ div). Escala de tempo de $160 \mathrm{~ms} /$ div. ....................................... 127 


\section{Lista de Tabelas}

Tabela 2.1. Resumo das tecnologias fotovoltaicas comerciais.............................42

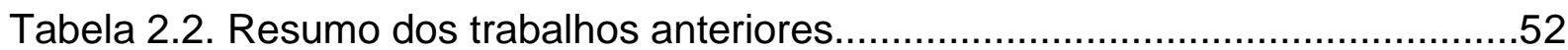

Tabela 3.1. Especificações elétricas do módulo KC130TM em STC. ......................60

Tabela 3.2. Parâmetros do conversor elevador de tensão. .....................................60

Tabela 3.3. Parâmetros do modelo ajustado do conjunto fotovoltaico formado por dois módulos KC130TM conectados série em STC.......................................61

Tabela 4.1. Ganho proporcional e integral do controlador linear............................79

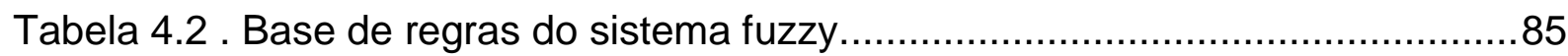

Tabela A.1. Dados obtidos em experimento laboratorial para validação da fonte

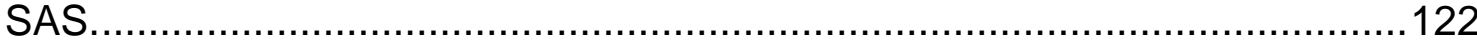





\section{Lista de Siglas e Abreviaturas}

$\begin{array}{ll}\text { A/D } & \text { Conversão Analógico para Digital } \\ \text { AM } & \text { Air Mass } \\ \text { CC } & \text { Corrente Contínua } \\ \text { CA } & \text { Corrente Alternada } \\ \text { DSP } & \text { Digital Signal Processor } \\ \text { InC } & \text { Condutância Incremental } \\ \text { MPPT } & \text { Maximum Power Point Tracking } \\ \text { PD } & \text { Proporcional e Derivativo } \\ \text { PI } & \text { Proporcional e Integral } \\ \text { PMP } & \text { Ponto da Máxima Potência } \\ \text { P\&O } & \text { Perturbação e Observação } \\ \text { PV } & \text { Photovoltaic } \\ \text { PWM } & \text { Pulse Width Modulation } \\ \text { RCC } & \text { Ripple Current Control Algorithm } \\ \text { SAS } & \text { Solar Array Simulator }\end{array}$





\section{Lista de Símbolos}

a Fator de idealidade do diodo.

$A M x$ Massa de ar.

C Capacitância de entrada do conversor $[F]$.

$C_{I} \quad$ Coeficiente de temperatura $\left[\mathrm{V} /{ }^{\circ} \mathrm{C}\right]$.

$C_{V} \quad$ Coeficiente de temperatura $\left[\mathrm{V} /{ }^{\circ} \mathrm{C}\right]$.

$C_{O} \quad$ Coeficiente de temperatura $\left[\mathrm{V} /{ }^{\circ} \mathrm{C}\right]$.

d Razão cíclica instantânea.

$d_{P I} \quad$ Saída do regulador proporcional e integral.

$\delta d \quad$ Saída do controlador fuzzy.

$e \quad$ Erro da tensão fotovoltaica $[V]$.

$\Delta e \quad$ Variação do erro de tensão fotovoltaica $[V]$.

$g \quad$ Tangente na máxima potência $[I / V]$.

$G \quad$ Irradiação fotovoltaica $\left[W / m^{2}\right]$.

$H_{I} \quad$ Ganho do sensor de corrente.

$H_{V} \quad$ Ganho do sensor de tensão.

$i_{L} \quad$ Corrente instantânea do indutor $[A]$.

I Corrente fotovoltaica $[A]$.

$I_{L} \quad$ Corrente média no indutor $[A]$.

$i_{o} \quad$ Corrente instantânea na saída $[A]$.

$I_{O} \quad$ Corrente de saturação reversa $[A]$.

$I_{M P} \quad$ Corrente da máxima potência $[A]$. 
$I_{P V} \quad$ Corrente induzida pela luz $[A]$.

$I_{S C} \quad$ Corrente de curto circuito $[A]$.

$k \quad$ Constante de Boltzmann $\left[1.3806503 \times 10^{-23} \mathrm{~J} / \mathrm{K}\right]$.

$L \quad$ Indutância $[H]$.

$\eta \quad$ Ganho do controlador fuzzy.

$n_{e} \quad$ Fator de normalização do erro.

$n_{\Delta e} \quad$ Fator de normalização da variação do erro.

$N_{P} \quad$ Número de células associadas em paralelo.

$N_{S} \quad$ Número de células associadas em série.

$q \quad$ Carga elementar do elétron $\left[1.60217646 \times 10^{-19} \mathrm{C}\right]$.

$P \quad$ Potência $[W]$.

$P_{M A X} \quad$ Máxima potência $\left[\mathrm{W} / \mathrm{m}^{2}\right]$.

$r_{C} \quad$ Resistência série do capacitor de entrada do conversor $[\Omega]$.

$r_{L} \quad$ Resistência série do indutor $[\Omega]$.

$r_{O N} \quad$ Resistência de condução da chave $[\Omega]$.

$r_{P V} \quad$ Resistência dinâmica $[\Omega]$.

$R_{D} \quad$ Resistência parasita de condução do diodo [ $[\Omega]$.

$R_{E Q} \quad$ Resistência fotovoltaica equivalente $[\Omega]$.

$R_{O} \quad$ Carga nominal do conversor $[\Omega]$.

$R_{S} \quad$ Resistência série equivalente do dispositivo fotovoltaico $[\Omega]$.

$R_{P} \quad$ Resistência paralela equivalente do dispositivo fotovoltaico $[\Omega]$. 
$T$ Temperatura da junção p-n da célula $[K]$.

$T_{S} \quad$ Tempo do chaveamento $[s]$.

$v \quad$ Tensão fotovoltaica instantânea $[V]$.

$v_{C} \quad$ Tensão instantânea do capacitor de entrada $[V]$.

$v_{C_{O}} \quad$ Tensão instantânea do capacitor de saída $[V]$.

$V \quad$ Tensão fotovoltaica $[V]$.

$V_{D} \quad$ Tensão de condução do diodo $[V]$.

$V_{E Q} \quad$ Tensão fotovoltaica equivalente $[V]$.

$V_{M P} \quad$ Tensão de máxima potência $[V]$.

$V_{O} \quad$ Tensão de saída do conversor $[V]$.

$V_{O C} \quad$ Tensão de circuito aberto $[V]$.

$V_{R E F}$ Tensão de referência $[V]$.

$V_{T} \quad$ Tensão térmica $[V]$. 



\section{Introdução}

\subsection{Energias Alternativas}

Pesquisas realizadas nas últimas décadas realçam dois aspectos principais: por um lado, a insustentabilidade das atuais fontes de energia nos diferentes domínios ambiental, econômico e social - e, por outro lado, a necessidade urgente de políticas e ações globais que favoreçam as tecnologias de baixa emissão de carbono. Desse modo, a energia tornou-se tema prioritário nas políticas governamentais de todos os países desenvolvidos ou em vias de desenvolvimento. Como exemplo, recentemente, variações consideráveis nos preços da energia mostraram a sua importância para qualquer atividade econômica e a vulnerabilidade da sociedade aos desequilíbrios no suprimento de combustíveis (INTERNATIONAL ENERGY AGENCY, 2009). Vide Figura 1.1.

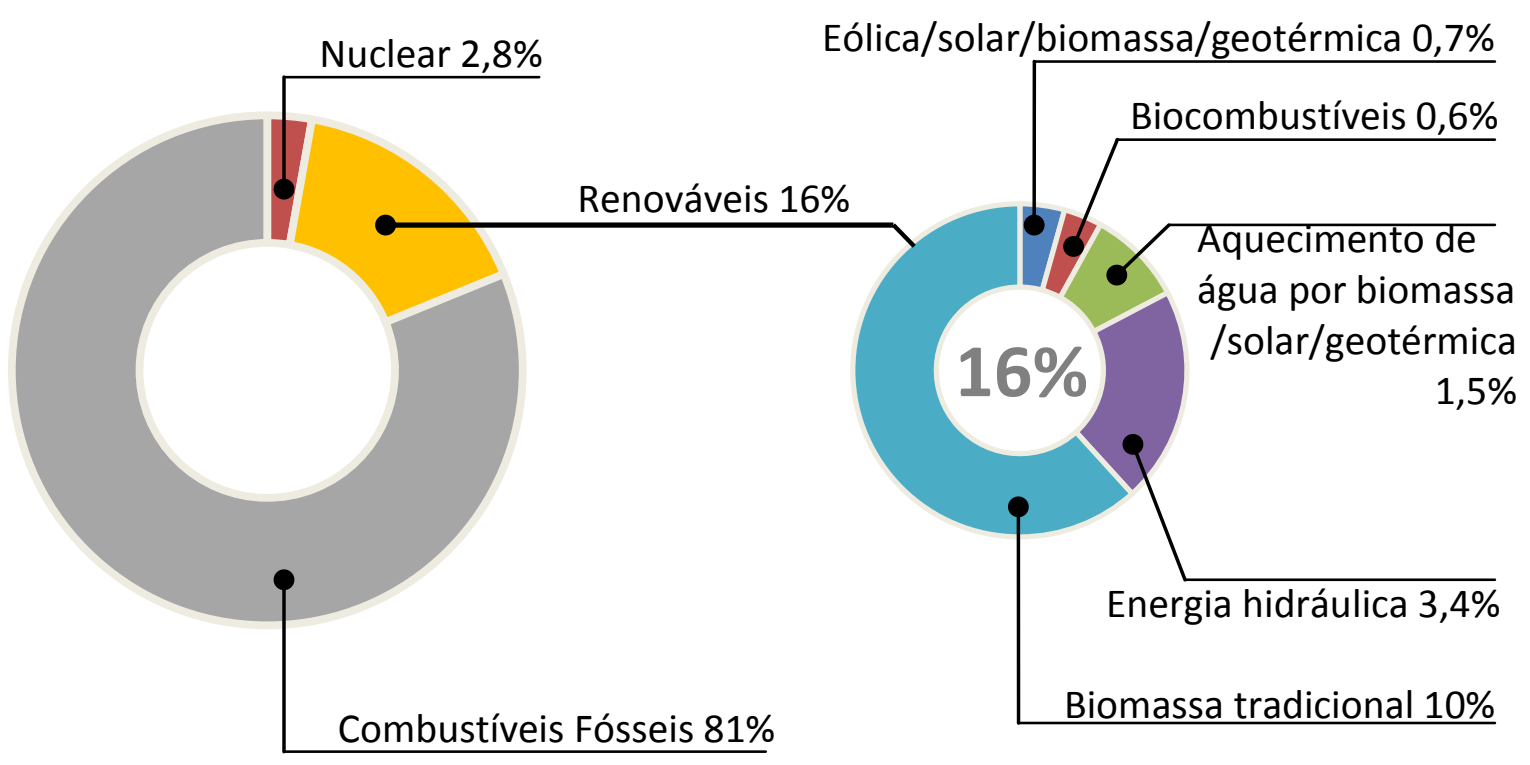

Figura 1.1. Quota da energia renovável no consumo final energético mundial de 2009. Fonte: REN21', (RENEWABLE ENERGY POLICY NETWORK FOR THE 21ST CENTURY, 2011).

\footnotetext{
${ }^{1}$ Renewable Global Status Report.
} 
Além disso, projeções da International Energy Agency (2009) apontam o crescimento populacional, as tendências macroeconômicas, o preço da energia, o desenvolvimento tecnológico e as políticas governamentais, como os principais fatores que impulsionam a demanda e oferta de energia. Segundo a mesma agência, até 2030 a população mundial crescerá em média $1 \%$ ao ano, chegando a 8,2 bilhões de pessoas e a maior parte desse crescimento ocorrerá nas áreas urbanas (INTERNATIONAL ENERGY AGENCY, 2009). Nesse mesmo período, é projetado um aumento de $50 \%$ na proporção de pessoas acima dos 60 anos, o que afetará, inevitavelmente, os níveis e o padrão de uso da energia.

Assim, o status e a eficiência de diferentes tecnologias do setor da energia desempenharão um fator chave na determinação da demanda energética mundial, no uso de combustível, nas emissões de $\mathrm{CO}_{2}$ e nas escolhas dos futuros investimentos. Nesse sentido, tem-se privilegiado a migração para geração de energia sem a emissão de $\mathrm{CO}_{2}$ não somente de maneira eficiente, como também segura. Os acidentes nucleares de 2011 em Fukushima no Japão reforçam esta preocupação.

No grupo das fontes alternativas de energia estão abrigadas a energia eólica, solar, marítima, geotérmica e biomassa (AGÊNCIA NACIONAL DE ENERGIA ELÉTRICA, 2009). Dentre elas, as fontes de energia eólica e solar apresentam-se como as mais promissoras - possuem um grande potencial, atraindo projetos conjuntos de pesquisas e cada vez mais investimentos públicos e privados.

Apesar da participação das fontes alternativas na matriz energética mundial serem, ainda, inexpressiva "[...] a energia solar fotovoltaica é a fonte alternativa que tem recebido mais atenção" (VILLALVA, 2010, p. 2), uma vez que possui a maior taxa de crescimento quando comparada às restantes fontes alternativas (vide Figura 1.2). 


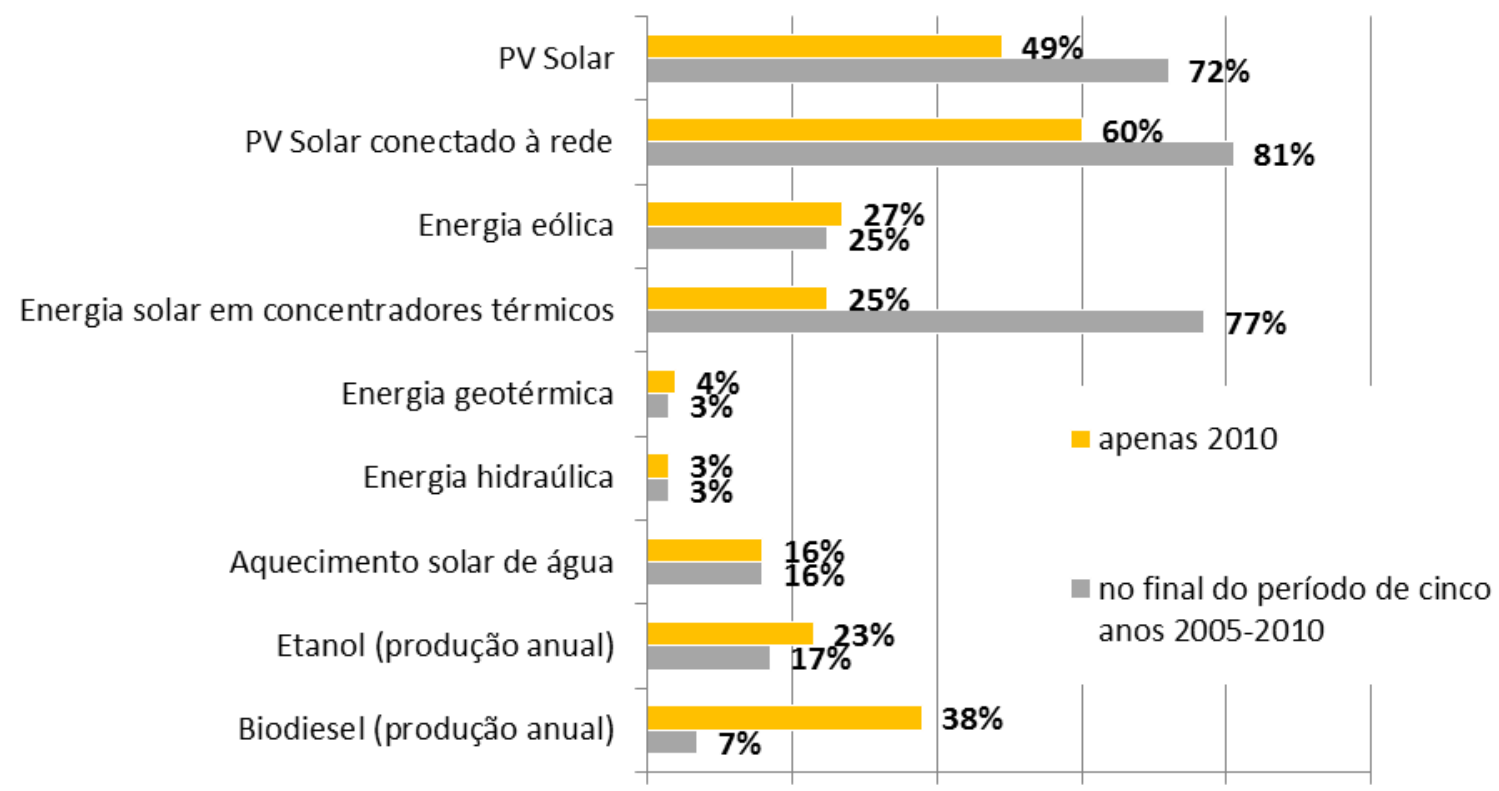

Figura 1.2. Taxa média do crescimento anual da energia renovável e da produção de biocombustíveis, 2005-2010. Fonte: (RENEWABLE ENERGY POLICY NETWORK FOR THE 21ST CENTURY, 2011).

\subsection{Cenário da Energia Fotovoltaica no Brasil e no Mundo}

Segundo a International Energy Agency (2010), em 2010, o mercado de sistemas fotovoltaicos apresentou um forte crescimento, com redução massiva dos custos e sinais da consolidação na indústria. Como exemplo, os preços por watt gerado estiveram na faixa de 4 USD/W a 6 USD/W com tendência a diminuírem.

Em 2011, a European Photovoltaic Industry Association (2012) relata que o mercado mundial de sistemas fotovoltaicos, manteve a sequência de anos de forte crescimento - com aumento de mais de $70 \%$ de novas instalações - mesmo com a crise financeira e econômica mundial (vide Figura 1.3). Com isso, a capacidade de sistemas fotovoltaicos instalados no mundo atingiu, aproximadamente, 67,4 $G W$, tornando-se a terceira mais importante fonte alternativa de energia - logo depois da hidráulica e da eólica. 


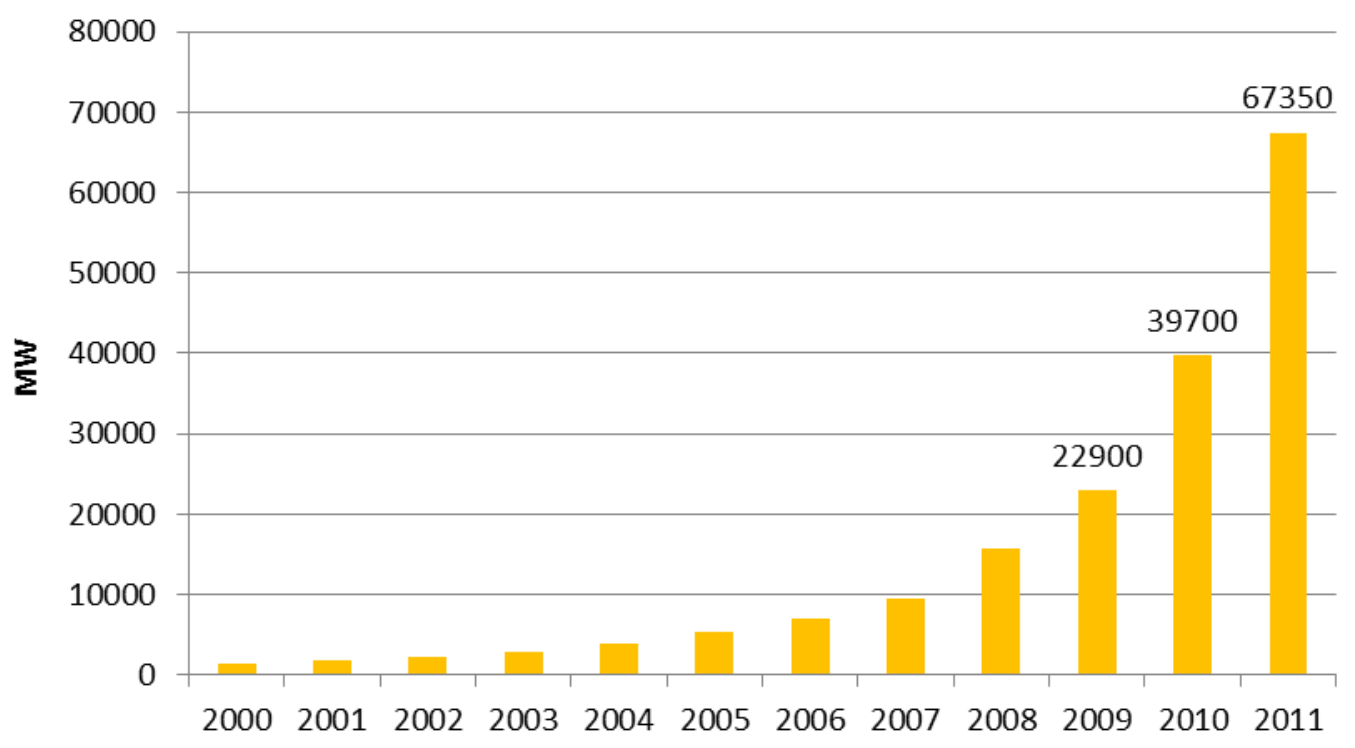

Figura 1.3. Evolução da capacidade mundial anual de sistemas fotovoltaicos desde 2000. Fonte: (EUROPEAN PHOTOVOLTAIC INDUSTRY ASSOCIATION, 2012).

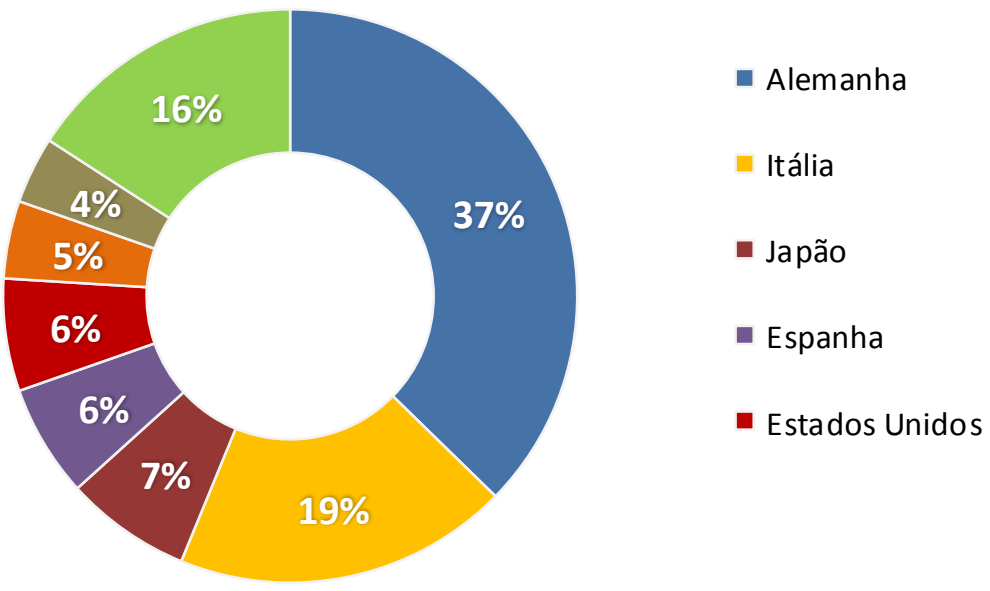

Figura 1.4. Cenário da capacidade de sistemas fotovoltaicos instalados no mundo até 2011. Fonte: (EUROPEAN PHOTOVOLTAIC INDUSTRY ASSOCIATION, 2012).

A Figura 1.4 apresenta o cenário mundial dos sistemas fotovoltaicos no final de 2011.

Por outro lado, em países emergentes e economias em desenvolvimento observou-se que programas de incentivo são subsidiados por agências internas e/ou estrangeiras. Em Angola, por exemplo, um programa com recursos oriundos do Reino Unido obteve relativo sucesso na instalação de pequenas unidades de sistemas 
fotovoltaicos em escolas, clínicas e centros comunitários de várias aldeias (INTERNATIONAL ENERGY AGENCY, 2006).

O Brasil, por sua vez, é privilegiado em termos de radiação solar (AGÊNCIA NACIONAL DE ENERGIA ELÉTRICA, 2009), principalmente, a região do nordeste brasileiro que possui radiação $\left(\mathrm{W} / \mathrm{m}^{2}\right)$ equiparável a do deserto do Saara - onde se situa uma das melhores regiões do mundo neste quesito.

Apesar do alto potencial e de existirem políticas de incentivo, como o Programa de Incentivo às Fontes Alternativas de Energia Elétrica (PROINFA ${ }^{2}$ ) e o Centro Brasileiro para Desenvolvimento da Energia Solar Fotovoltaica (CB - Solar ${ }^{3}$ ), a participação da energia fotovoltaica na matriz energética brasileira ainda é insignificante. Tradicionalmente, a maioria dos projetos é voltada para eletrificação rural e bombeamento de água em pequenos agregados e vilas remotas ou isoladas da rede elétrica convencional (INTERNATIONAL ENERGY AGENCY, 2010). Em 2010, o Brasil totalizou meros $20 \mathrm{MW}$ de capacidade instalada de sistemas fotovoltaicos (INTERNATIONAL ENERGY AGENCY, 2010), dos quais apenas 1\% está conectado à rede elétrica. Geograficamente, cerca de $70 \%$ da capacidade total instalada estão localizados nas regiões Norte, Nordeste e Centro-Oeste (JANUZZI; VARELLA; GOMES, 2009).

\subsection{Estrutura Mínima para um Sistema Fotovoltaico}

O sistema fotovoltaico é composto pelos módulos fotovoltaicos, conversores de potência, armazenadores de energia (baterias e supercapacitores) e todos os acessórios de montagem e componentes de controle.

Um sistema fotovoltaico usa a irradiação solar para convertê-la em energia elétrica. A irradiação solar é a quantidade total de energia solar armazenada em uma área por um período de tempo, sendo proporcional à altitude e, durante o dia, possui

\footnotetext{
2 Programa do Ministério das Minas e Energia, em vigor desde 2004.

3 Parceria da Pontifícia Universidade Católica do Rio Grande do Sul (PUCRS) com o Ministério da Ciência e Tecnologia (MCT), o Estado do Rio Grande do Sul e a Companhia Estadual de Energia Elétrica do Estado de Rio Grande do Sul (CEEE) (JANUZZI; VARELLA; GOMES, 2009).
} 
variação senoidal em função do tempo com amplitude e fase dependentes da estação do ano (MUSSER, 2010).

$\mathrm{Na}$ base de qualquer sistema fotovoltaico estão as células fotovoltaicas que por sua vez são conectadas em série e em paralelo para formarem módulos ou painéis. A International Energy Agency (2010) estabelece quatro principais aplicações para sistemas fotovoltaicos: sistemas fotovoltaicos domésticos isolados da rede (off-grid domestic systems) fornecem energia para localidades isoladas que não estão conectados ao sistema elétrico de distribuição. A energia gerada é, normalmente, usada para iluminação, refrigeração e para outras cargas de baixa potência (tipicamente em torno de $1 \mathrm{~kW}$ ) sendo a tecnologia mais apropriada para responder a demanda energética de comunidades remotas ou isoladas da rede.

Sistemas fotovoltaicos não domésticos e isolados da rede (off-grid nondomestic systems) fornecem energia para aplicações nas quais pequenas quantidades de eletricidade têm um alto valor agregado, tais como sistemas de telecomunicação, bombeamento de água, refrigeração de vacinas e apoio à navegação. O custo comercial dos painéis fotovoltaicos se torna competitivo quando comparado com o de outras fontes de pequeno porte.

Sistemas fotovoltaicos distribuídos e conectados à rede (grid - connected distributed PV systems) fornecem energia para o usuário conectado à rede ou diretamente para a rede elétrica de distribuição. Com diferentes tamanhos, permitem uma instalação diversificada como: nas paredes, fachadas e telhados de prédios públicos e comerciais ou sobre barreiras acústicas nas autoestradas.

Sistemas fotovoltaicos centralizados e conectados à rede (grid - connected centralized systems) desempenham a função de verdadeiras usinas de geração, não estando associadas a usuários particulares. Normalmente, são instalados no solo e independentes de qualquer desenvolvimento nas proximidades.

\subsection{Objetivos e Justificativa}

Com o objetivo de analisar, simular e implementar aplicações fotovoltaicas, é 
necessário um modelo físico capaz de discriminar e quantificar a influência de todos os fatores significativos (KING; BOYSON; KRATOCHVIL, 2004). Embora o efeito elétrico, térmico, espectro solar e ótico devam estar inclusos no modelo, o mesmo deve ser prático e simples (VILLALVA, 2009) o suficiente para permitir tarefas rotineiras em sistemas de potência tais como análise do fluxo de potência, análise harmônica, análise da sensibilidade, casamento de impedância, dentre outros (ORTIZ-RIVERA; PENG, 2005).

Por outro lado, em aplicações de eletrônica de potência envolvendo conversores, é desejável obter-se a maior quantidade de potência fornecida pela fonte fotovoltaica, por isso os conversores buscam, continuamente, o ponto de máxima potência $(P M P)$ através de algoritmos de busca do ponto de máxima potência (MPPT maximum power point tracking). Existem vários algoritmos de MPPT na literatura, por exemplo, métodos envolvendo lógica fuzzy, soluções analíticas e método linear de coordenadas reorientadas, foram propostas respectivamente por Syafaruddin, Karatepe, e Hiyama (2008), Rodriguez e Amaratunga (2007) e Ortiz-Rivera e Peng (2004), uma comparação entre 19 diferentes algoritmos de MPPT é apresentada por Esram e Chapman (2007). Apesar disso, o algoritmo da perturbação e observação (P\&O) é o mais utilizado, por ser simples, barato e fácil de ser implementado. As principais desvantagens deste método é que ao encontrar o $P M P$, em regime permanente, o algoritmo oscila continuamente em torno do $P M P$, fazendo com que o algoritmo se confunda quando ocorrem rápidas mudanças nas condições atmosféricas (FEMIA et al., 2005).

Neste trabalho será analisado, simulado e implementado um circuito fotovoltaico, com conversor CC-CC não isolado do tipo boost (elevador de tensão), operando no modo de condução contínua. O algoritmo de busca será utilizado para estabelecer a tensão de referência de um sistema de controle que regula a tensão terminal dos painéis, empregando controladores fuzzy proporcional derivativo associado a um controlador proporcional-integral (Fuzzy $P D+P l)$.

Assim, este trabalho tem como objetivo aumentar a eficiência na geração fotovoltaica, por meio da diminuição do tempo de resposta do sistema, aperfeiçoando o desempenho do algoritmo de busca. 


\subsection{Organização da Dissertação}

A dissertação está organizada em cinco capítulos principais. No Capítulo 2 são expostos os princípios fundamentais dos fenômenos envolvidos na geração fotovoltaica, estabelece-se o modelo físico do painel fotovoltaico, descrevem-se os algoritmos de busca e apresentam-se a motivação e relevância do trabalho atual em relação aos outros trabalhos encontrados na literatura.

O Capitulo 3 versa sobre a motivação e escolha do sistema de controle, a modelagem e análise matemática do sistema fotovoltaico e, também, sobre os efeitos de elementos parasitas na planta.

O Capitulo 4 descreve detalhadamente o projeto do sistema de controle utilizado.

Já no Capitulo 5 são apresentadas a bancada experimental e analisados os resultados de simulação e experimentais obtidos.

Por fim, considerações gerais, contribuições e sugestões de trabalhos futuros são apresentados no Capitulo 6.

\subsection{Publicações}

No decorrer do período de mestrado, foram publicados os seguintes artigos:

- MOCAMBIQUE, Nilton Eufrázio Martinho; MACHADO, Ricardo Quadros. "Control and Analysis of a PV system operating under nonlinear conditions". In: Brazilian Power Electronics Conference (COBEP), p. 466 - 472, 2011.

- MOCAMBIQUE, Nilton Eufrázio Martinho; MACHADO, Ricardo Quadros; OLIVEIRA, Vilma Alves. "A fuzzy PD-PI control strategy to track the voltage references of photovoltaic arrays". In: Proc. IEEE 9th International Control And Automation Conference (ICCA), p. 1162-1167, 2011. 
- POZZEBON, Giovani; GONCALVES, Amilcar; PENA, Guido; MOCAMBIQUE, Nilton; MACHADO, Ricardo; "Operation of a Three phase Power Converter Connected to a Distribuition System". In: IEEE Transactions on Industrial Electronics, no. 99, (accepted for publication), 2012. 



\section{Revisão Bibliográfica}

\subsection{Introdução}

Neste capítulo descrevem-se objetivamente sobre o material pesquisado referente aos conceitos básicos, tecnologias, modelagem, algoritmos de busca e conversores utilizados em sistemas fotovoltaicos.

Para isso, no $1^{\circ}$ tópico, apresentam-se os fundamentos do efeito fotovoltaico e um breve resumo das tecnologias das células fotovoltaicas que atualmente estão disponíveis comercialmente. Na sequência, abordam-se sobre os modelos físicos das células e módulos fotovoltaicos de forma a se obter uma representação simples, prática e eficaz. No $3^{\circ}$ tópico, são apresentados os principais algoritmos de busca e discutidas as suas principais vantagens e desvantagens de cada algoritmo. Já nos $4^{\circ}$ e $5^{\circ}$ tópicos apresentam-se respectivamente, a descrição do conversor escolhido e a contextualização do presente trabalho em relação aos trabalhos anteriores encontrados na literatura.

\subsection{Fundamentos da Energia Solar}

Para a compreensão dos processos que envolvem a geração de energia elétrica em sistemas fotovoltaicos, nos próximos itens serão abordados os conceitos de radiação solar, efeito fotovoltaico e tecnologias de células fotovoltaicas. 


\subsubsection{Radiação Solar}

A fusão nuclear dos átomos de hidrogênio no núcleo solar, a temperaturas de 15 - 20 milhões de kelvins ( $K$ ) é a responsável pela radiação (calor e luz) no espaço (UNIVERSITAT KASSEL, 2003). A radiação emitida pelo Sol vista da Terra equivale à emitida por um corpo negro ${ }^{4}$ de $6000 \mathrm{~K}$. A equação de Planck descreve a distribuição do comprimento de onda da radiação do corpo negro, estabelecendo relações entre frequência, temperatura e brilho espectral.

O fluxo radiante solar é considerado constante fora da atmosfera terrestre (radiação extraterrestre), tendo um valor médio de 1367 watts por metro quadrado $\left[\mathrm{W} / \mathrm{m}^{2}\right]$ - unidade de intensidade da radiação solar.

Os feixes da radiação solar que chegam à Terra são paralelos, na faixa do visível, entre $0,38 \mu m$ a $0,78 \mu m$ de comprimento de onda (Figura 2.1).

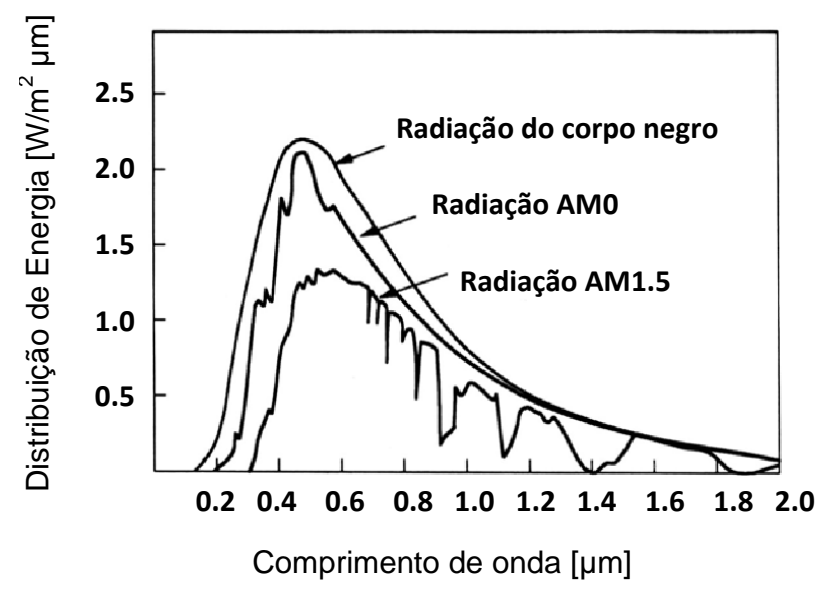

Figura 2.1. Distribuição espectral da luz solar no espaço. Fonte: Möller ${ }^{5}$ (1993 apud VILLALVA, 2010, p. 17).

No entanto, antes de atingir o solo, a intensidade, a distribuição espectral e angular da radiação solar é afetada pelos efeitos da absorção e espalhamento que ocorrem na atmosfera (CRESESB, 2006). Assim, para comparar o desempenho ótico

\footnotetext{
${ }^{4}$ Corpo negro é um emissor e receptor ideal da radiação eletromagnética em todos os comprimentos de onda.

${ }^{5}$ H. J. Moller, " Semiconductors for Solar Cells. Norwood, MA: Artech House, 1993.
} 
de produtos, materiais ou componentes espectralmente sensíveis, tais como as células fotovoltaicas, é necessário estabelecer um padrão de referência da distribuição de espectro solar (AMERICAN SOCIETY FOR TESTING AND MATERIALS, 2008). Com este propósito, é definido o coeficiente de "Massa de $A r$ " ( $A M x)$ - comprimento do percurso relativo do feixe solar através da atmosfera (RIORDAN; HULSTRON, 1990) onde $x$ é a secante do ângulo $(\theta)$ do Sol com relação a zênite no ponto de captação (VILLALVA, 2010), dado por:

$$
x=\frac{1}{\cos \theta}
$$

O coeficiente $A M$ é usado na padronização dos espectros das irradiações. Dentre os diversos padrões, os mais recomendados pela American Society for Testing and Materials (ASTM) são: o espectro global e o espectro normal direto, ambos a AM1.5. O espectro global significa que a irradiação na célula fotovoltaica é o conjunto da irradiação solar diretamente do disco solar somada à irradiação solar difusa (devido às moléculas de ar, aerossóis e vapor de água no céu e no ambiente do entorno pelo solo, vegetação, etc.). Por sua vez, o espectro normal direto, refere-se à irradiação solar direta exclusivamente do disco solar e cujos raios solares são perpendiculares à célula fotovoltaica (RIORDAN; HULSTRON, 1990) (vide Figura 2.2).
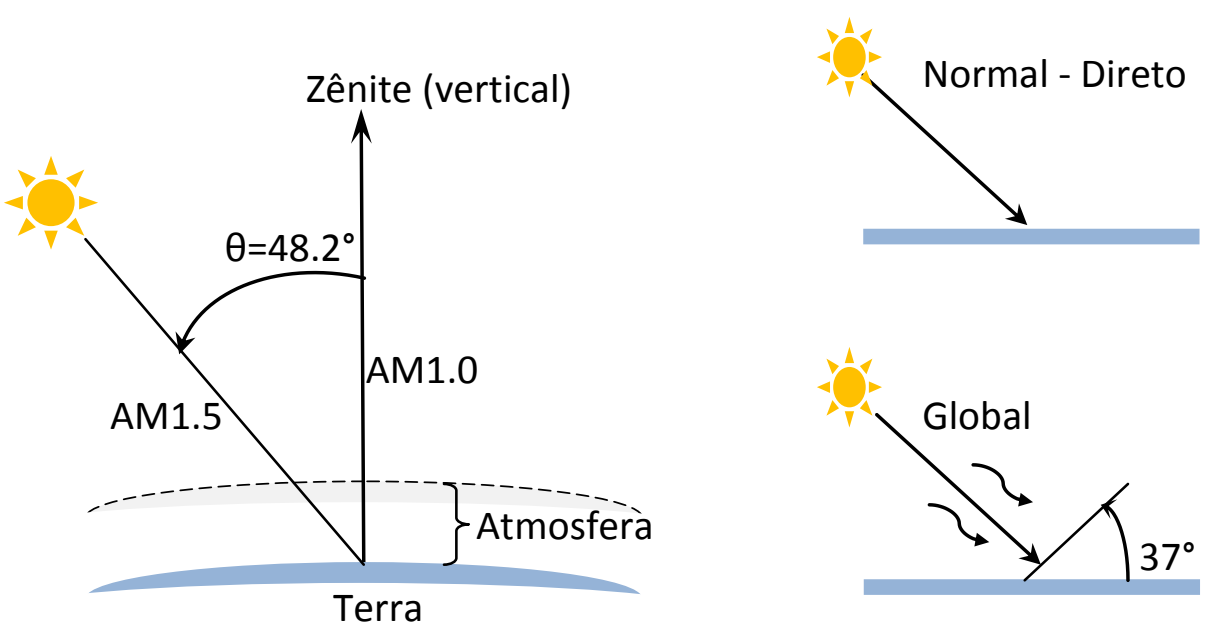

Figura 2.2. Esquemático das condições espectrais para AM1.5. Fonte: Riordan [20]. 


\subsubsection{Efeito Fotovoltaico}

O efeito fotovoltaico foi descoberto por Alexandre-Edmond Becquerel em 1839 que constatou a presença de uma diferença de potencial nos terminais de um semicondutor quando exposto a luz (CRESESB, 2006). Na origem deste fenômeno está o efeito fotoelétrico - que ocorre quando fótons atingem a superfície de um metal com energia suficiente para permitir a liberação dos elétrons.

Conforme a teoria de bandas da mecânica quântica, materiais semicondutores possuem bandas de energia permitidas e proibidas em seu espectro de energia. Dentro da banda permitida, existem as bandas de valência (mais profundas e ocupadas por elétrons) e as bandas de condução, cuja largura é característica de cada semicondutor (FARRET; SIMÕES, 2006). Os elétrons da banda de valência quando excitados por energia térmica ou pela absorção de fótons com quantum de energia superior ao da banda proibida, "saltam" gerando uma lacuna, e passam a ocupar a banda de condução, tornando-se elétrons livres. Fótons com energia inferior ao da banda proibida passam pelo semicondutor sem contribuir para a conversão de energia. No entanto, fótons com energias muito superiores aos da banda proibida não permitem que a energia excedente seja absorvida, sendo dissipada em forma de calor (UNIVERSITAT KASSEL, 2003).

O silício tetravalente é o semicondutor que serve de matéria base para maioria das aplicações envolvendo células fotovoltaicas. A pastilha de silício é formada pela junção de duas camadas dopadas do tipo $n$ e do tipo $p$, permitindo que tenham propriedades elétricas diferentes, isto é, a camada do tipo $\mathrm{n}$ atua como doadora de elétrons, enquanto que a camada do tipo $p$ atua como doadora de lacunas. Assim, quando irradiados pela luz, ocorre à absorção dos fótons e consequente formação do par elétron-lacuna, que uma vez assegurado o equilíbrio entre a geração, recombinação, transporte das portadoras e capacidade de separação da região de depleção, levará ao aumento da concentração de elétrons e lacunas. Desta forma, é produzida uma tensão elétrica entre as camadas, que uma vez conectadas galvanicamente, permite a passagem de corrente elétrica (UNIVERSITAT KASSEL, 2003). 
Explicações mais detalhadas estão fora do escopo deste trabalho, no entanto, podem ser encontradas nos trabalhos de Boer (2010) e Universitat Kassel (2003).

\subsubsection{Tipos de Células Fotovoltaicas}

Quanto à tecnologia utilizada, as células fotovoltaicas são classificadas como de primeira, segunda ou terceira geração (EUROPEAN PHOTOVOLTAIC INDUSTRY ASSOCIATION, 2011).

Na primeira geração estão às células de silício cristalino (c-Si) feitas a partir de fatias finas retiradas de um único cristal ou bloco de silício. Fazem parte deste grupo as células mono e policristalinas de silício (mc-Si e pc-Si, respectivamente). As monocristalinas são entre todas as células fotovoltaicas as mais eficientes, no entanto, requerem um custo maior na produção.

As células da segunda geração baseiam-se na tecnologia de filme fino (thin film), construídas através da deposição de camadas finíssimas de material fotossensível sobre um suporte de baixo custo, tais como vidro, aço inoxidável ou plástico. Dentre as mais comuns estão às células de silício amorfo (a-Si) e de telureto de cádmio (CdTe).

$\mathrm{E}$, mais recentemente, as tecnologias da terceira geração, as quais se incluem: concentradores fotovoltaicos, células termo-fotovoltaicas e células fotovoltaicas orgânicas. Os concentradores fotovoltaicos de silício ou da multijunção de outros semicondutores concentram mediante lentes a irradiação direta da luz solar para as células fotovoltaicas, necessitando de um sistema de rastreamento contínuo em relação ao sol. Por outro lado, as células termo-fotovoltaicas são usadas em sistemas híbridos (termal e elétrico), já as células fotovoltaicas orgânicas, são constituídas por cadeias de polímeros semicondutores de baixo custo, mas ainda com baixa eficiência, inferior a 10\% (LI, Y. et al., 2010; MAYER et al., 2007;) (vide Tabela 2.1). 
Tabela 2.1. Resumo das tecnologias fotovoltaicas comerciais. Fonte: EPIA, 2011 (EUROPEAN PHOTOVOLTAIC INDUSTRY ASSOCIATION, 2011).

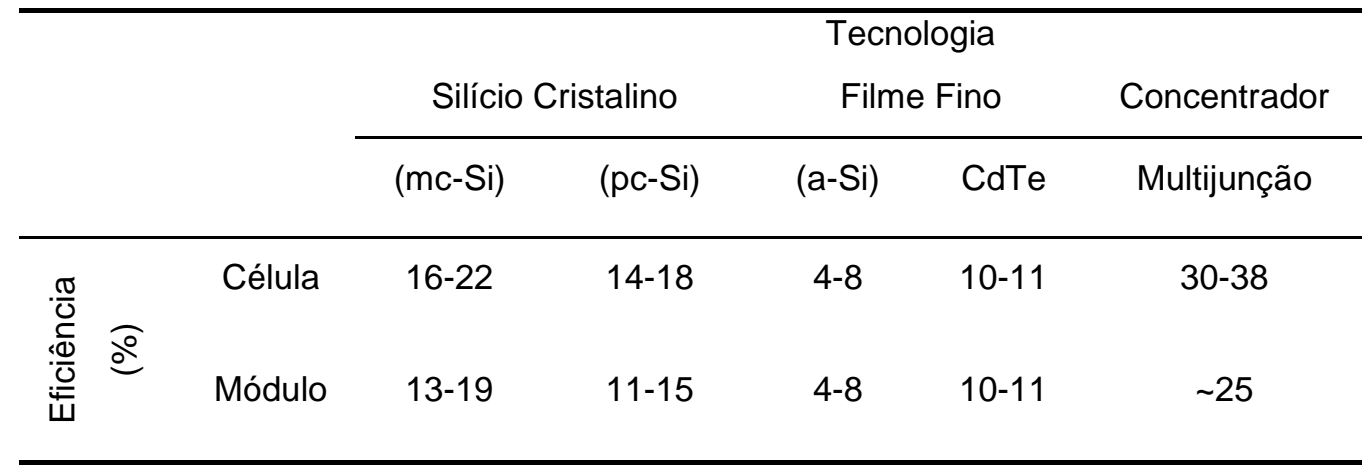

\subsection{Modelo Matemático da Célula Fotovoltaica}

A célula fotovoltaica é basicamente uma junção p-n de um semicondutor normalmente de silício - que quando exposto a luz libera elétrons em torno de um circuito elétrico fechado (RODRIGUEZ; AMARATUNGA, 2007). A taxa de elétrons gerados depende do fluxo de luz incidente e da capacidade de absorção do semicondutor (VILLALVA, 2009).

Para a simulação de sistemas fotovoltaicos, em eletrônica de potência, é necessário definir um modelo circuital da célula fotovoltaica, na qual são consideradas às variações do comportamento elétrico da célula em função dos parâmetros da irradiação e temperatura do ambiente (GOW; MANNING, 1999).

Os modelos da célula fotovoltaica existentes na literatura podem ser divididos em duas categorias: modelos orientados à equação e modelos orientados ao circuito (WANG; HSU, 2011). Os modelos orientados à equação representam a relação corrente - tensão ( $I-V$ ) característica da célula fotovoltaica em uma forma analítica (RAMAPRABHA; MATHUR, 2008). Por outro lado, nos modelos orientados ao circuito, a relação $I-V$ da célula fotovoltaica é representada pelo seu circuito equivalente, para que possa ser simulado mediante softwares de simulação de circuito elétricos (GOW; MANNING, 1999; VILLALVA; GAZOLI; RUPPERT, 2009; WANG; HSU, 2011). As principais vantagens dos modelos orientados ao circuito estão no aproveitamento 
pleno dos modelos dos componentes elétricos e eletrônicos fornecidos pelo programa de simulação e na facilidade de integrar as células fotovoltaicas com os restantes elementos que compõe um sistema fotovoltaico (WANG; HSU, 2011) dessa forma, neste trabalho será abordado o modelo orientado ao circuito.

\subsubsection{Modelo Generalizado e Modelo Simplificado}

O modelo generalizado da célula fotovoltaica (também conhecido por modelo exponencial duplo ou modelo de dois diodos) é derivado da natureza da junção $p-n$ e representa com precisão o comportamento das células fotovoltaicas, sobretudo às do tipo cristalinas de silício (GOW; MANNING, 1999). O modelo é definido por cinco parâmetros: uma fonte de corrente controlada linearmente dependente da luz incidente $\left(I_{P V}\right)$, resistências série e shunt $\left(R_{S}\right.$ e $R_{P}$, respectivamente) e dois diodos ( $D_{1}$ e $D_{2}$ ) que representam o efeito da recombinação das portadoras (ORTIZ-RIVERA; PENG, 2004), Conforme Figura 2.3. Percebe-se que $R_{S}$ afeta significativamente a corrente de curto-circuito da célula ( $I_{S C}$ ) enquanto que $R_{P}$ influência significativamente a tensão de circuito aberto $\left(V_{O C}\right)$.

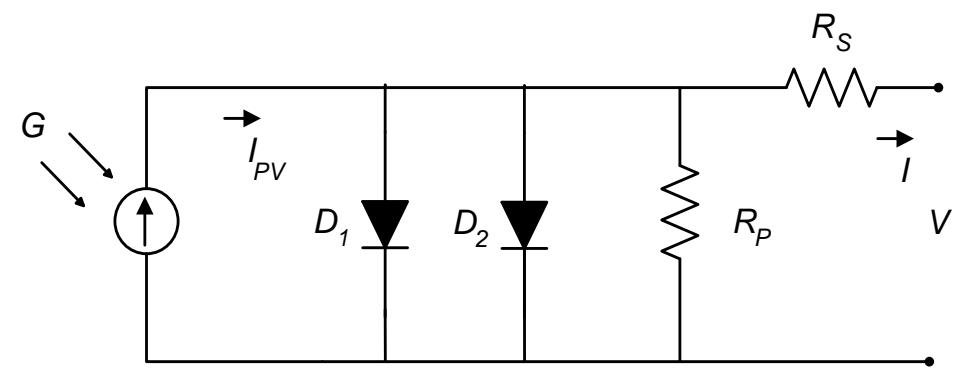

Figura 2.3. Modelo generalizado de uma célula solar.

Os cinco parâmetros do modelo generalizado variam conforme a temperatura e irradiação do ambiente. A relação de dependência, sobretudo em relação à irradiação, não é trivial de se obter, tornando-se necessário um conjunto de testes experimentais (GOW; MANNING, 1999). Assim, para os propósitos deste trabalho é, sem perda de generalidade, preferível utilizar o modelo de um único diodo como mostrado na Figura 
2.4. Este modelo garante o compromisso entre a simplicidade e precisão e já foi usado por vários autores (FEMIA et al., 2005; MASOUM; PADOVAN; MASOUM, 2010; PATEL; AGARWAL, 2008; RAMAPRABHA; MATHUR, 2008; RODRIGUEZ; AMARATUNGA, 2007; VILLALVA, 2010).

Em geral, células fotovoltaicas com características similares são conectadas em série e encapsuladas para formarem módulos e painéis. Se o módulo ou painel está iluminado uniformemente, o modelo resultante é qualitativamente idêntico ao de uma única célula.

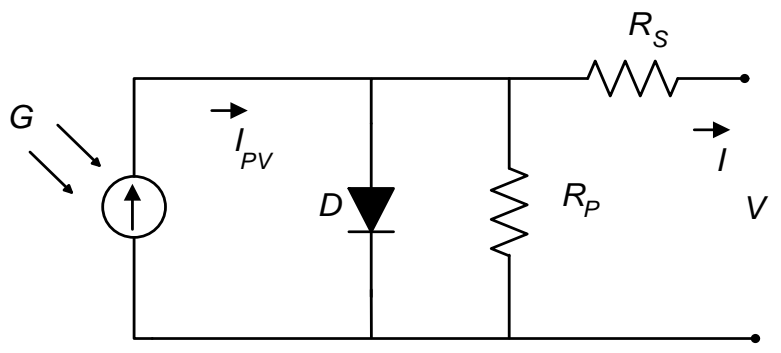

Figura 2.4. Modelo simplificado.

\subsubsection{Módulo Fotovoltaico}

O modelo do módulo usado neste trabalho é apresentado em [4,11] e suas principais vantagens são: (1) todos os parâmetros necessários estão disponíveis nos folhetos de dados do fabricante, (2) é fácil e eficaz para a simulação de dispositivos fotovoltaicos com conversores de potência e (3) garante que a curva $I-V$ e de potência - tensão $(P-V)$ que é ajustada para interpolar três pontos experimentais importantes, a saber, $I_{S C}, P M P$ e $V_{O C}$.

A equação $I-V$ característica do módulo fotovoltaico é não linear e implícita, necessitando de métodos iterativos para solucioná-la, dada por,

$$
I=I_{P V}-I_{O}\left[\exp \left(\frac{V+R_{S} I}{V_{T} a}\right)-1\right]-\frac{V+R_{S} I}{R_{P}}
$$

onde $I_{P V}$ é a corrente induzida pela luz, $I_{O}$ é a corrente de saturação do diodo, $R_{S}$ é a resistência série equivalente do módulo, $R_{P}$ é a resistência equivalente em 
paralelo do módulo, $a$ é o fator de idealidade do diodo, $V_{T}=N_{S} k T / q$ é a tensão térmica do painel com $N_{s}$ células conectadas em série, $k$ é a constante de Boltzmann $\left[1,3806503 \times 10^{-23} \mathrm{~J} / K\right], T(K)$ é a temperatura da junção p-n, e $q$ é a carga elementar do elétron $\left[1,60217646 \times 10^{-19} C\right]$. Se o modulo é composto por $N_{P}$ células conectadas em paralelo, então a corrente induzida e de saturação do módulo fotovoltaico podem ser expressas por: $I_{P V}=I_{P V, C E L L} N_{P}$ e $I_{O}=I_{O, C E L L} N_{P}$ respectivamente. A corrente $I_{P V}$ depende tanto do nível de irradiação $G\left[\mathrm{~W} / \mathrm{m}^{2}\right]$ quanto da temperatura $T$, enquanto que $I_{O}$ depende apenas de $T$ (FEMIA et al., 2005). Maiores detalhes relacionados ao modelo adotado são apresentados por Villalva (2010).

As curvas $I-V, P-V$ e $P-I-V$ são mostradas nas Figuras 2.5a, 2.5b e 2.6, respectivamente. É possível observar-se nas Figuras 2.5 e 2.6, que o principal ponto de interesse - ponto de máxima potência $(P M P)$ - se encontra justamente na região menos linear, exigindo um controle preciso para uma geração eficiente. $O$ próximo item aborda sobre os algoritmos de busca frequentemente adotados.

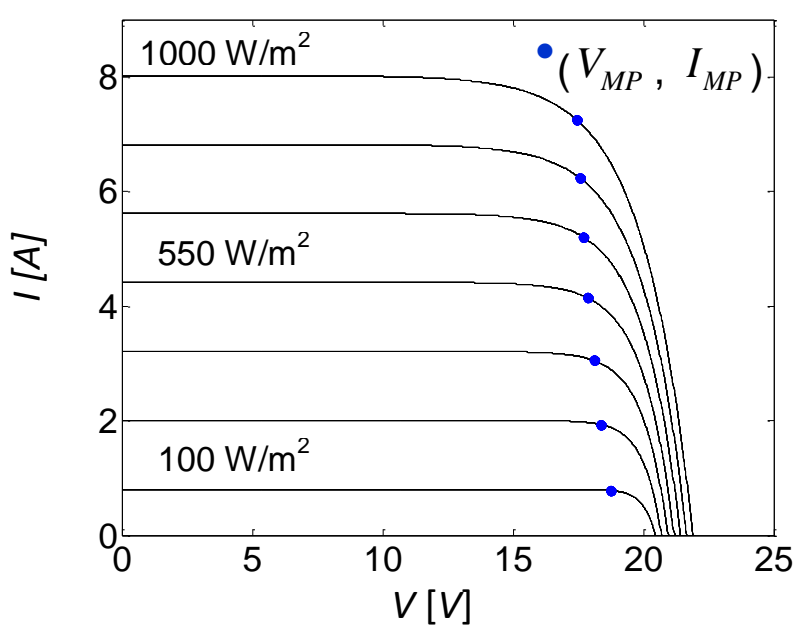

(a)

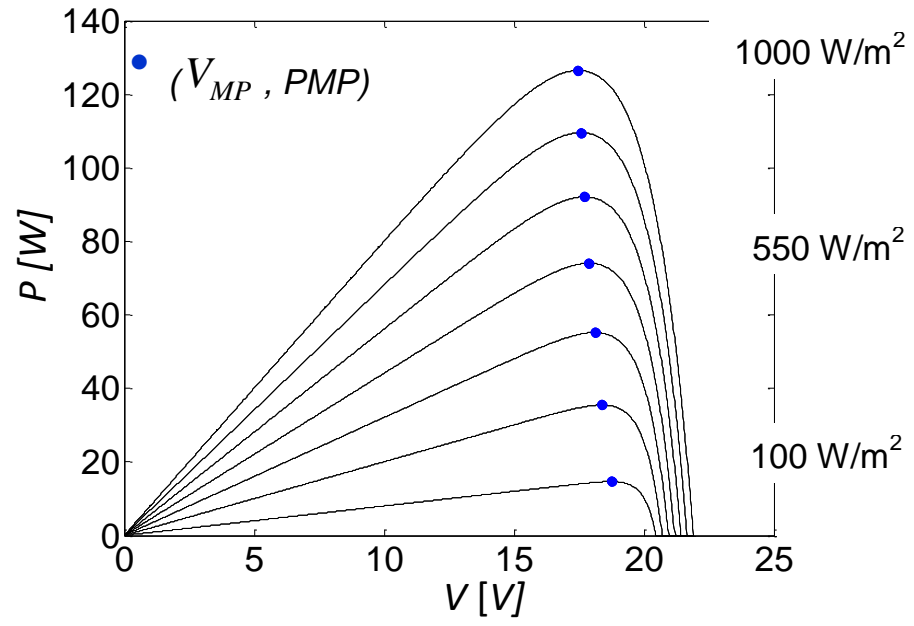

(b)

Figura 2.5. Curvas $I-V$ (a) e $P-V$ (b) de um módulo KC130TM PV, para diferentes níveis de irradiação e os pontos notáveis de $P M P\left(V_{M P}, I_{M P}\right)$ e $\left(V_{M P}, P M P\right)$. 


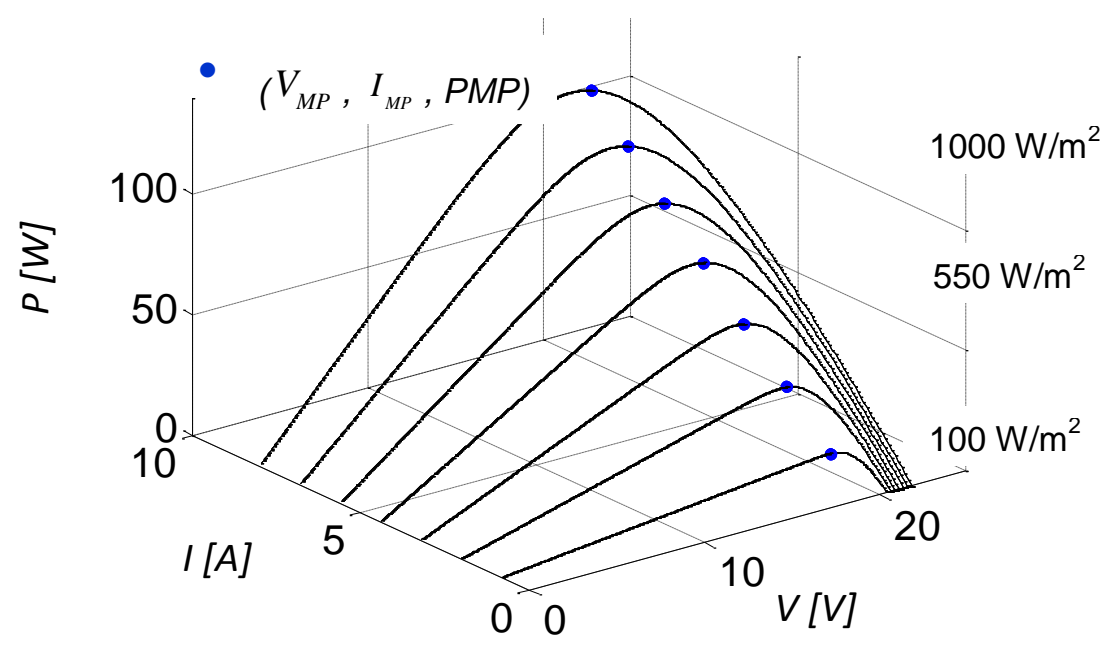

Figura 2.6. $P-I-V$ características do módulo fotovoltaico KC130TM, para diferentes níveis de irradiação e com os pontos notáveis de $P M P\left(V_{M P}, I_{M P}, P M P\right)$.

\subsection{Algoritmos de MPPT}

Algoritmos de MPPT são de extrema importância para a utilização otimizada da energia solar disponível. $\mathrm{O}$ algoritmo de MPPT objetiva determinar o ponto de operação de maior geração de energia elétrica da célula, módulo ou painel fotovoltaico em particular, ou do sistema fotovoltaico em geral, para as variações instantâneas de irradiação e temperatura.

Existem na literatura diversos algoritmos de MPPT já propostos, simulados e até mesmo implementados experimentalmente. Esses algoritmos podem ser classificados em três principais categorias: (1) algoritmos baseados em modelo, (2) algoritmos baseados em treinamento e (3) algoritmos MPPT heurísticos (ELGENDY; ZAHAWI; ATKINSON, 2008; GONZÁLEZ-LLORENTE, 2009).

\subsubsection{Algoritmos de MPPT Baseados em Modelo}

Nesta categoria estão os algoritmos que dependem de um modelo matemático para o cálculo da tensão ou corrente do PMP (ELGENDY; ZAHAWI; ATKINSON, 2008; RODRIGUEZ; AMARATUNGA, 2007); bem como os métodos de aproximação do $P M P$ 
em função das características do painel fotovoltaico (GONZÁLEZ-LLORENTE, 2009). A abordagem pode ser simples como nos métodos de Fração da tensão de circuito aberto $\left(V_{O C}\right)$ e Fração da corrente de curto-circuito ( $\left.I_{S C}\right)$ (VILLALVA, 2010), na qual é determinada, empiricamente, uma constante de proporcionalidade entre o PMP e $V_{O C}$ ou $I_{S C}$; ou mais complexa como no método linear de coordenadas reorientadas (LCRM) (ORTIZ-RIVERA; PENG, 2004).

\subsubsection{Algoritmos de MPPT Baseados em Treinamento}

São métodos rápidos e precisos que requerem o uso de microcontroladores ou processadores digitais de sinais (DSPS) para a implementação do algoritmo. Possuem um custo maior na implementação, em contrapartida dispensam a necessidade de conhecimento detalhado do sistema fotovoltaico ou da sua descrição precisa em termos de modelos matemáticos. Fazem parte deste grupo os algoritmos baseados em inteligência artificial, como: por lógica fuzzy (FEMIA et al., 2005) ou por redes neurais artificiais (SYAFARUDDIN; KARATEPE; HIYAMA, 2008).

\subsubsection{Algoritmos de MPPT Heurísticos}

Estes algoritmos baseiam-se nas medidas de corrente e tensão do painel fotovoltaico para a tomada de decisão de aumento ou diminuição da variável de controle. Possuem a grande vantagem de não necessitarem de um conhecimento prévio das características do painel (ELGENDY; ZAHAWI; ATKINSON, 2008). Os mais simples e largamente usados são o método de Perturbação e Observação e o método de Condutância Incremental. Entretanto, existem outros métodos mais complexos, como a técnica baseada no controle da correlação da ondulação do chaveamento do conversor (RCC, ripple correlation control) (ESRAM et al., 2006; SPIAZZI; BUSO; MATTAVELLI, 2009), ou o método de enxame de partículas proposto por Miyatake et. al. (2007). 


\subsubsection{Perturbação e Observação}

O método de busca por P\&O baseia-se no seguinte procedimento: perturba-se a tensão operante nos terminais do painel num determinado sentido e observa-se se há um aumento ou uma diminuição na potência gerada. Se houver um aumento na potência, deve-se manter a perturbação no mesmo sentido, caso contrário, inverte-se o sentido da perturbação, vide Figura 2.7. Este processo continua periodicamente, até mesmo quando o PMP é alcançado, desta forma, a tensão operante oscila em torno do PMP em regime permanente o que diminui a eficiência do método. A oscilação pode ser minimizada ao reduzindo-se o tamanho do passo. Por outro lado, quanto menor for o passo, mais lento será o algoritmo, comprometendo a eficiência para rápidas mudanças atmosféricas, como acontece em dias nublados (FEMIA et al., 2005). Para solucionar este problema, são utilizados passos de tamanho variável, cujo tamanho diminuí à medida que se aproxima do PMP (ESRAM; CHAPMAN, 2007). Conforme mostrado na Figura 2.7, $V_{R E F}$ é tensão de referência na qual o painel fotovoltaico é forçado a operar. No $P M P, V_{R E F}$ se iguala à tensão de máxima potência $\left(V_{M P}\right)$.

\subsubsection{Condutância Incremental}

Similarmente ao método de $\mathrm{P} \& \mathrm{O}$, o método de condutância incremental (INC) se baseia no principio de que a derivada da curva $P-V$ (Figura 2.5b) é zero no $P M P$, positiva à esquerda do $P M P$ e negativa à direita do $P M P$ :

$\left\{\begin{array}{l}d P / d V=0, \text { no } P M P \\ d P / d V>0, \text { à esquerda do } P M P \\ d P / d V<0, \text { à direita do } P M P\end{array}\right.$

sabendo que

$$
\frac{d P}{d V}=\frac{d(I V)}{d V}=I+V \frac{d I}{d V} \cong I+V \frac{\Delta I}{\Delta V}
$$




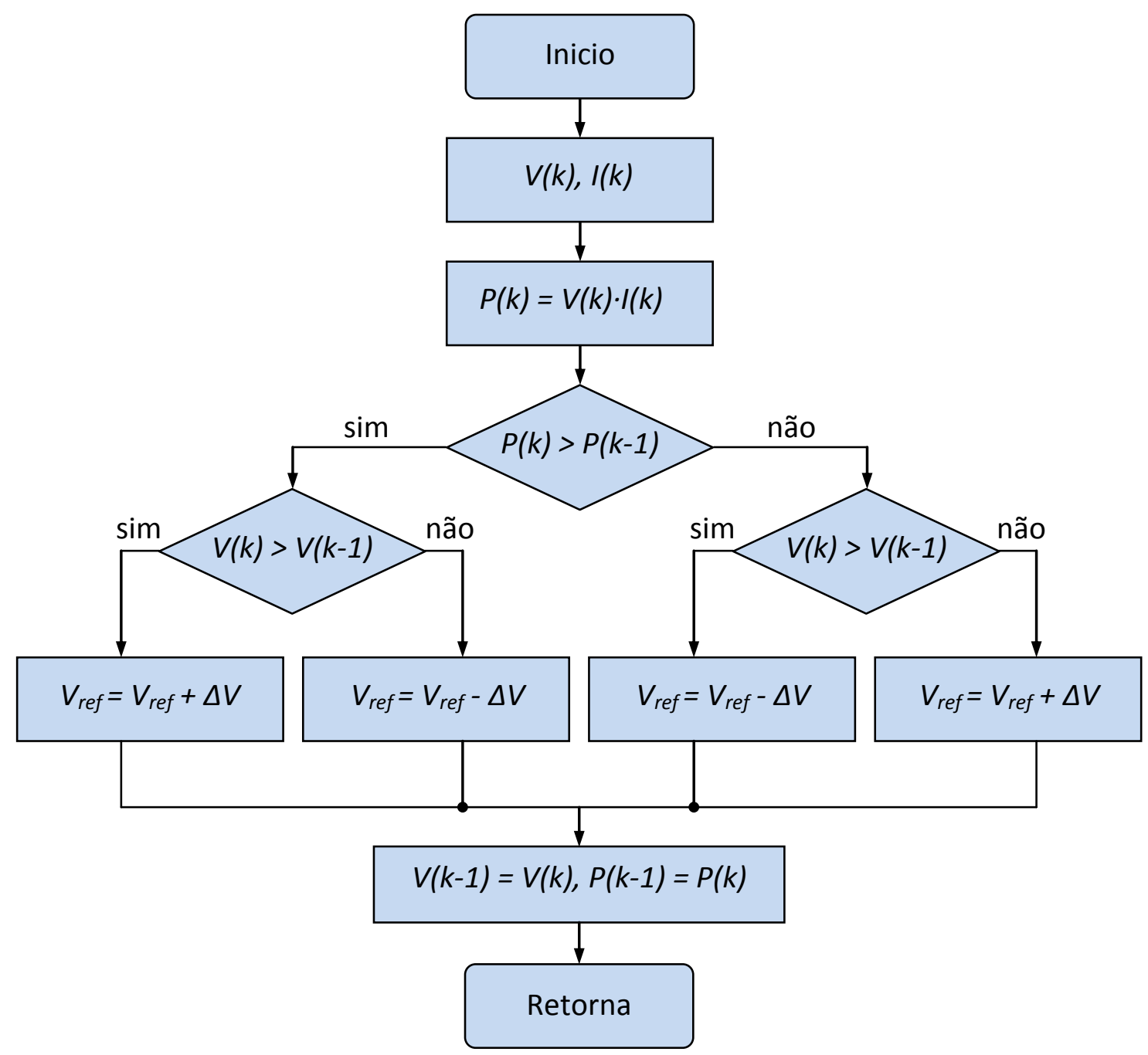

Figura 2.7. Perturbação e observação: algoritmo de busca do ponto de máxima potência.

(4) pode ser reescrita como

$$
\left\{\begin{array}{l}
\Delta I / \Delta V=-I / V, \text { no } P M P \\
\Delta I / \Delta V>-I / V, \text { à esquerda do } P M P \\
\Delta I / \Delta V<-I / V, \text { à direita do } P M P
\end{array}\right.
$$

assim, a condutância instantânea $I / V$ é comparada à condutância incremental $\Delta I / \Delta V$. Uma vez alcançado o $P M P$, o ponto de operação do painel fotovoltaico é mantido até que ocorra uma variação em $\Delta I$ indicando uma mudança nas condições 
atmosféricas, então a tensão de referência é decrementada ou incrementada para a busca do novo PMP (ESRAM; CHAPMAN, 2007).

\subsection{Conversor $\mathrm{CC}-\mathrm{CC}$}

A potência fornecida pelo painel fotovoltaico depende das condições ambientais (irradiação e temperatura) e da carga efetiva nele conectada. Assim, a impossibilidade de arbitrariamente escolher as condições ambientais, remete todo controle na variação da carga dinâmica vista pelo painel. Isto é realizado por intermédio de conversores CCCC ou CC-CA conforme a aplicação de interesse.

Existem na literatura diversas topologias de conversores de potência CC-CC, as mais comumente usadas são às do tipo SISO (única entrada e única saída) de segunda ordem: Buck, Boost e Buck-Boost. São as mais simples, baratas e apresentam resultados satisfatórios para as diversas aplicações. Além de servirem de base para topologias mais complexas.

No presente trabalho foi escolhido o conversor do tipo boost. Este conversor, por ser elevador de tensão é uma boa opção para aplicações voltadas à conexão com a rede de distribuição (VILLALVA, 2010), uma vez que quanto maior a tensão no barramento $\mathrm{CC}$ do inversor que conecta o sistema à rede, menor será a relação do número de espiras do transformador responsável pela isolação galvânica, desde que assegurado o nível de potência, sendo assim, amplamente adotado por diversos autores (CHAOUACHI; KAMEL; NAGASAKA, 2010; COELHO; CONCER; MARTINS, 2009; FEMIA, 2005; GONZÁLEZ-LLORENTE, 2009; MIYATAKE et al.,2007; SPIAZZI; BUSO; MATTAVELLI, 2009). Entretanto, esta topologia exige maiores cuidados no que se refere ao controle chaveado por modulação da largura de pulso (PWM) como mencionado por Middlebrook (1988) - devido à existência de um zero no semi-plano direito e a indutância efetiva ser dependente da razão cíclica - como também pela limitação da região de atuação do MPPT para baixas irradiações, como observado por Coelho, Concer e Martins (2009). 


\subsection{Trabalhos Anteriores}

Nos trabalhos sobre o desenvolvimento, simulação e implementação de algoritmos de MPPT em sistemas fotovoltaicos uma condição relevante tem sido ignorada. Os algoritmos são implementados sem um controle independente e robusto da tensão ou da corrente de entrada dos painéis fotovoltaicos. Ou seja, o MPPT atua diretamente na razão cíclica do conversor, deixando o controle em malha aberta sobre a tensão terminal do painel conforme mencionado por Villalva (2010). Esta condição limita a eficiência do MPPT, independentemente da técnica adotada. Por outro lado, técnicas de controle moderno, como por lógica fuzzy, geram melhorias significativas quando comparadas aos compensadores lineares. Desta forma, o neste trabalho é apresentado uma análise com resultados de simulação e experimentais corroborando com essa abordagem. Na Tabela 2.2 são apresentadas de forma resumida as principais características dos trabalhos anteriores encontrados na literatura em relação ao proposto neste trabalho. 


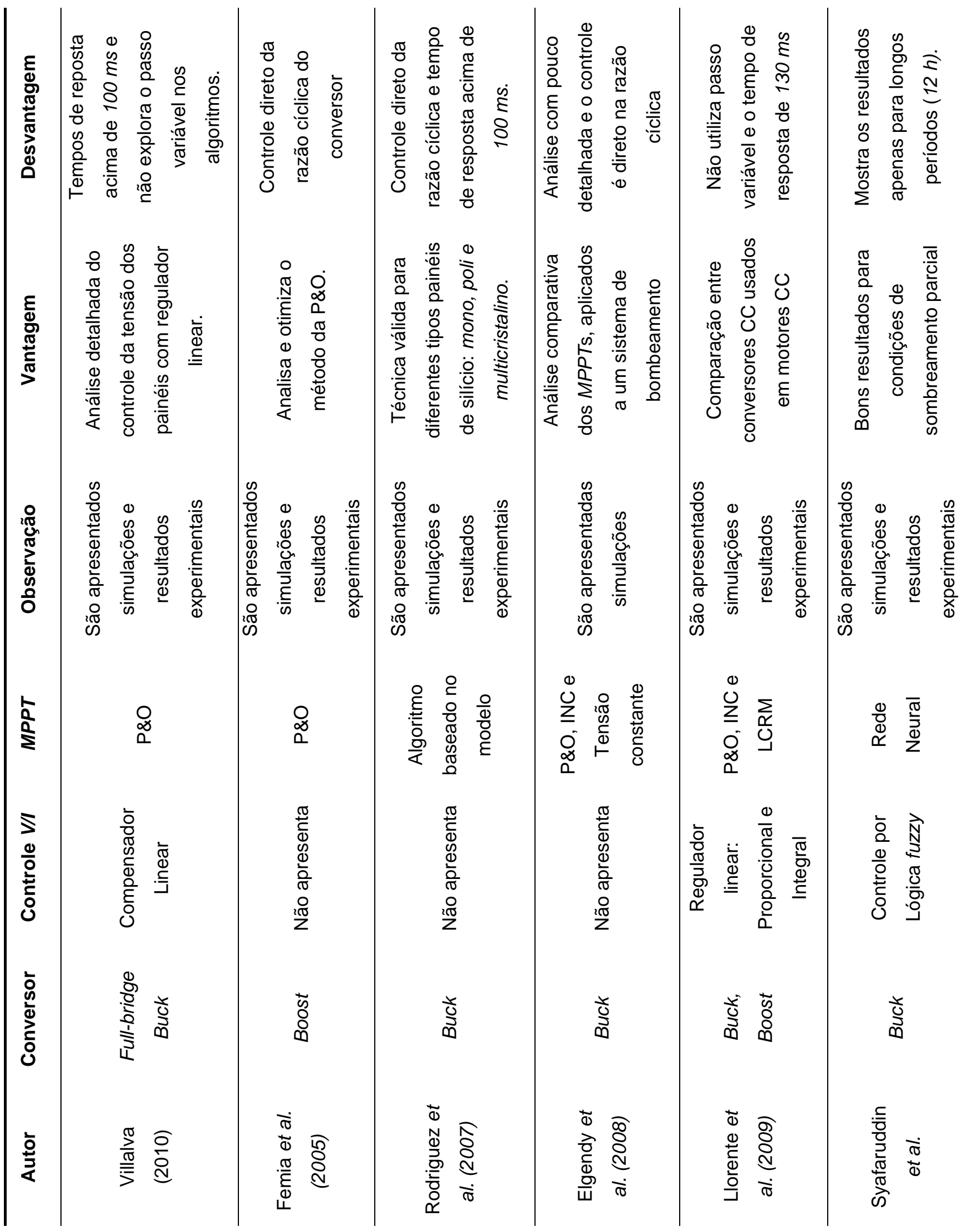




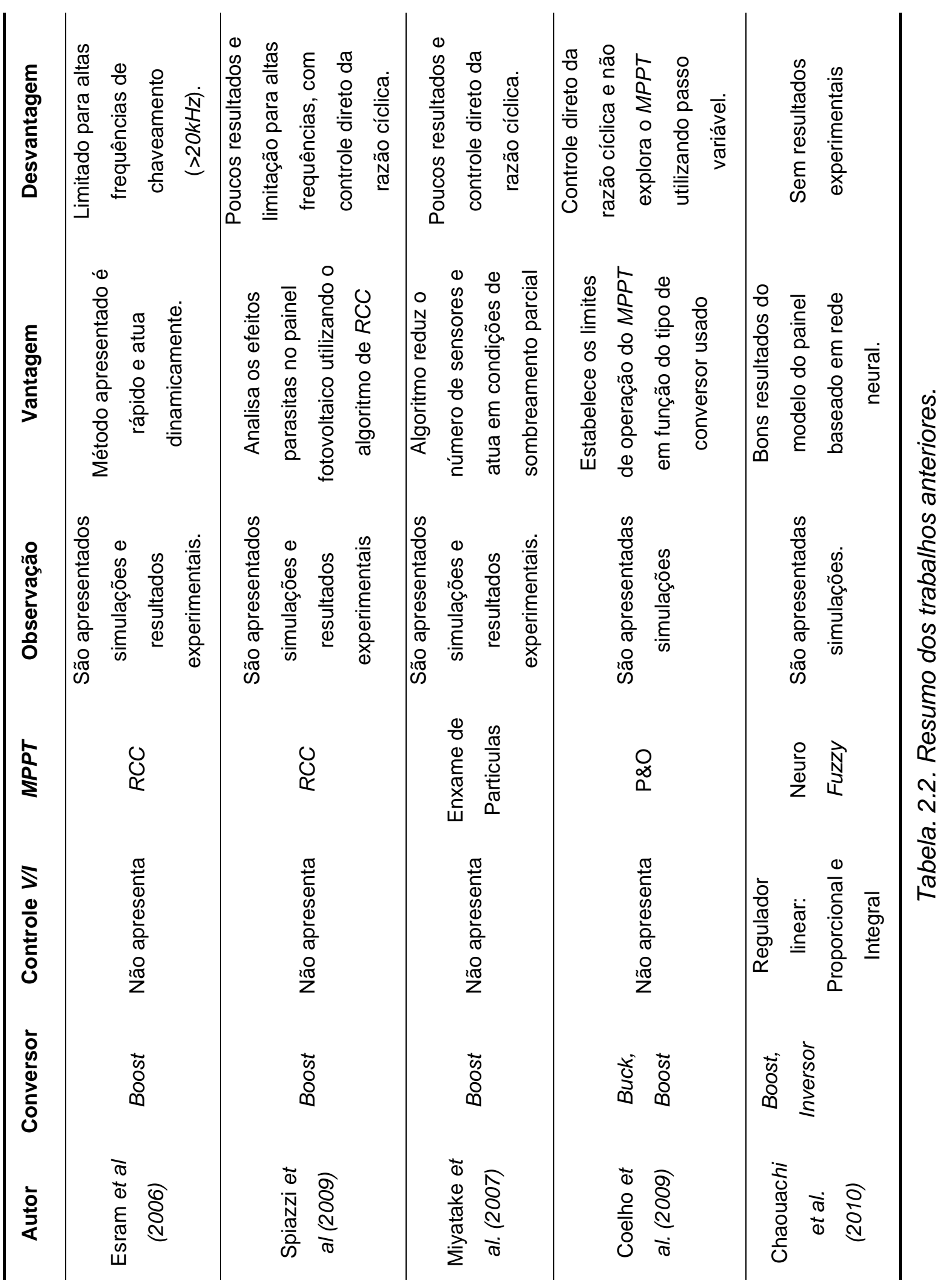




\subsection{Considerações Finais}

Neste capitulo foram apresentados os princípios gerais envolvendo um sistema fotovoltaico. Definiu-se o modelo físico a ser empregue nos próximos Capítulos e mostraram-se as categorias dos algoritmos de busca em função da técnica aplicada. Por fim, foram expostos os critérios tidos como base na escolha do conversor, e a contextualização do trabalho atual em relação aos trabalhos anteriores encontrados na literatura. 


\section{Modelagem do Sistema Fotovoltaico}

\subsection{Introdução}

O sistema fotovoltaico apresentado nesta dissertação é constituído por painéis fotovoltaicos que alimentam um conversor elevador de tensão conectado a uma carga resistiva e um subsistema de controle cuja referência de tensão é estabelecida pelo MPPT, conforme mostrado no diagrama em blocos da Figura 3.1. Além disso, neste capítulo é apresentada a análise matemática do sistema fotovoltaico, na qual são abordadas as desvantagens do controle direto do MPPT sobre a razão cíclica do conversor e a vantagem da utilização de reguladores lineares e/ou não lineares para controlar a tensão terminal dos painéis (em malha fechada) de forma a alcançar um melhor desempenho do algoritmo de busca do PMP. Posteriormente, são descritos os critérios considerados na escolha da variável de controle e apresentadas às características e os parâmetros dos módulos fotovoltaicos utilizados. Na sequência, são analisadas as funções de transferência da planta linearizada em regime permanente bem como, uma análise de pequenos sinais. Finalmente, é discutida a influência dos elementos parasitas - capacitivos e indutivos - do painel fotovoltaico no comportamento da função transferência da planta (painel fotovoltaico + conversor eletrônico). 


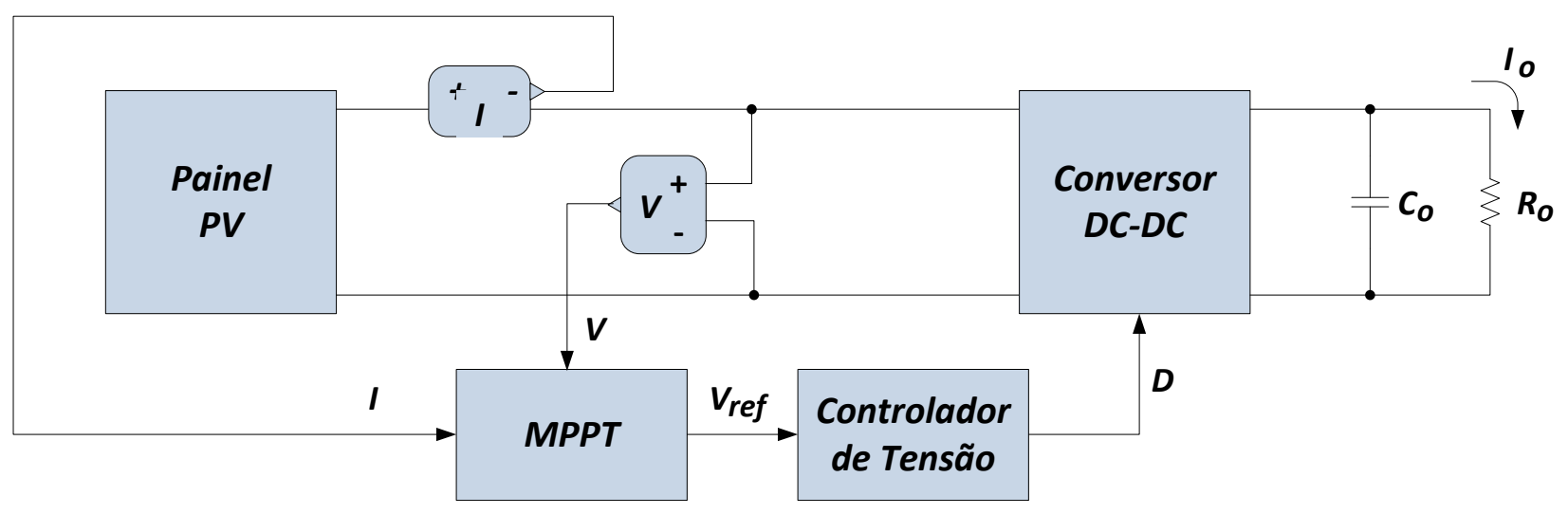

Figura 3.1. Diagrama do sistema fotovoltaico em estudo.

\subsection{Desvantagens do Controle Direto}

O acionamento direto das chaves do conversor CC-CC pelo MPPT é frequentemente encontrado na literatura, conforme apresentado anteriormente na Tabela 2.2. Os algoritmos de MPPT funcionam dinamicamente, isto é, definem continuamente o ponto de operação em função da resposta dinâmica das variáveis monitoradas em um determinado intervalo de tempo.

Assim, rápidas e frequentes variações nas variáveis monitoradas pelo algoritmo resultam em mudanças bruscas do ponto de operação, afetando diretamente a eficiência do MPPT e independentemente do tipo de algoritmo utilizado quer seja baseado em modelo, em treinamento ou heurístico. Isto ocorre por que a tarefa do MPPT é de definir o ponto de operação de referência do sistema, no caso o $P M P$, mas não garante que o sistema opere nesta mesma condição. Por exemplo, o algoritmo da Fração da Tensão de Circuito Aberto ( $V_{O C}$ ) (VILLALVA, 2010) calcula o PMP mediante uma constante de proporcionalidade $(k)$ determinada empiricamente, que relaciona a tensão do PMP com a tensão de circuito aberto do painel fotovoltaico. Assim, uma vez determinado $k$, é necessário que o conversor eletrônico seja desligado, periodicamente, para obtenção do valor de $V_{O C}$. Entretanto, quando os painéis ficam expostos a rápidas alterações atmosféricas, como acontece em dias parcialmente nublados, a tensão de circuito aberto varia com maior frequência, fazendo-se 
necessário diminuir o período entre as amostras consecutivas, para que se determine a $V_{O C}$ mais rapidamente. Isto resulta em uma maior perda de energia, causada por duas situações: devido ao desligamento repetido do conversor (VILLALVA, 2010) e, por outro lado, devido ao tempo a ser esperado até que o sistema estabilize para cada amostragem.

Já os algoritmos que utilizam redes neurais (SYAFARUDDIN; KARATEPE; HIYAMA, 2008) e que controlam a razão cíclica do conversor, quando sujeitos a rápidas mudanças atmosféricas variam rapidamente a razão cíclica, ou seja, situação semelhante à malha aberta, na qual não existe nem controle do sobressinal ou do tempo de estabilização. Por fim, nos algoritmos heurísticos como o P\&O que geram perturbações na forma de passos, em torno do $P M P$, o uso do controle direto da razão cíclica do conversor implica em maoires dificuldades para o algoritmo em encontrar o $P M P$, devido à sua incapacidade em distinguir entre as perturbações causadas pelas mudanças atmosféricas - de irradiação ou de temperatura - das perturbações provocadas pelo passo do próprio algoritmo, conforme foi mencionado por Femia et al. (2005).

O sistema de controle combinando o MPPT para estabelecer a referência do $P M P$ e um regulador que atua sobre a corrente ou tensão terminal do painel força o sistema fotovoltaico a operar de forma mais efetiva na busca do PMP sob rápidas mudanças atmosféricas, uma vez que o controle em malha fechada visa melhorar a resposta transitória do sistema fotovoltaico como um todo e impedir que as variações bruscas sejam refletidas imediatamente na variável de saída, melhorando dessa forma o comportamento geral do sistema.

\subsection{Variável de Controle: Tensão}

A não linearidade da variável de controle influi diretamente na resposta dinâmica do controlador utilizado. Assim, as curvas normalizadas $P-V$ e $P-I$ do painel na Figura 3.2, demonstram que à esquerda do $P M P$ as inclinações de $P-V$ e $P-I$ possuem derivadas positivas e aproximadamente iguais, entretanto, à direita do 
$P M P$ a inclinação de $P-I$ decresce mais acentuadamente significando que, nesta região, a corrente possui magnitude maior do que a corrente de $I_{M P}$ e que o comportamento dinâmico do painel é não linear tornando a busca pelo PMP mais difícil conforme é mencionado em (XIAO et al., 2007).

Além disso, de acordo com as curvas $I-V$ (Figuras 3.3 e 3.4) percebe-se que os fatores ambientais (irradiação solar e temperatura na célula) influenciam distintamente no deslocamento do $P M P$, isto é: diferentes irradiações causam um deslocamento do PMP predominantemente na direção vertical - no sentido da corrente; enquanto que diferentes temperaturas na célula produzem um deslocamento na direção horizontal - no sentido da tensão.

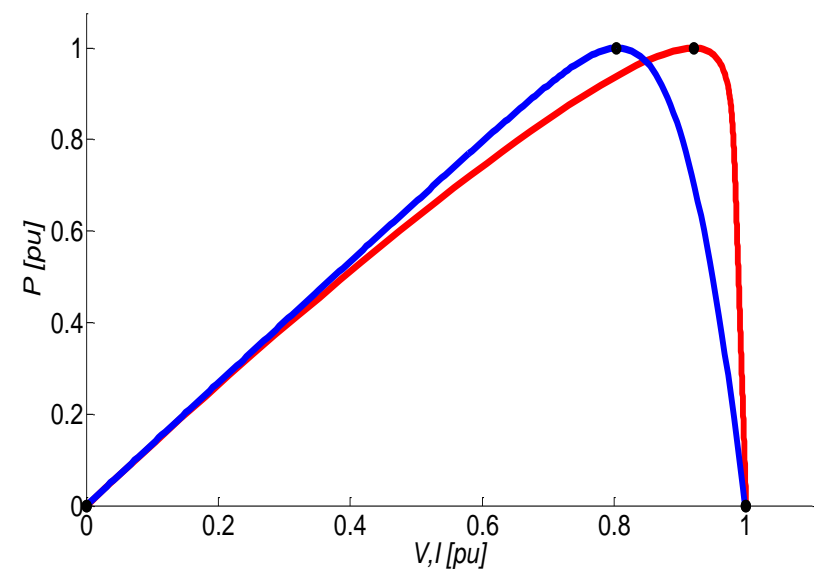

- $P-V$

- $P-1$

- $P M P$

Figura 3.2. Curvas normalizadas de $P-V$ e $P-I$.

$\mathrm{Na}$ prática, variações bruscas e de grande amplitude da irradiação solar ocorrem com maior frequência em dias parcialmente nublados, ou devido à reflexão, refração e obstrução da luz incidente por objetos ao redor dos painéis. Entretanto, variações na temperatura da célula ocorrem mais lentamente e em intervalos definidos. Dessa forma, é recomendável adotar como variável de controle a tensão nos painéis por exigir uma menor resposta dinâmica do controlador quando comparado ao controle da corrente dos (XIAO et al., 2007). 


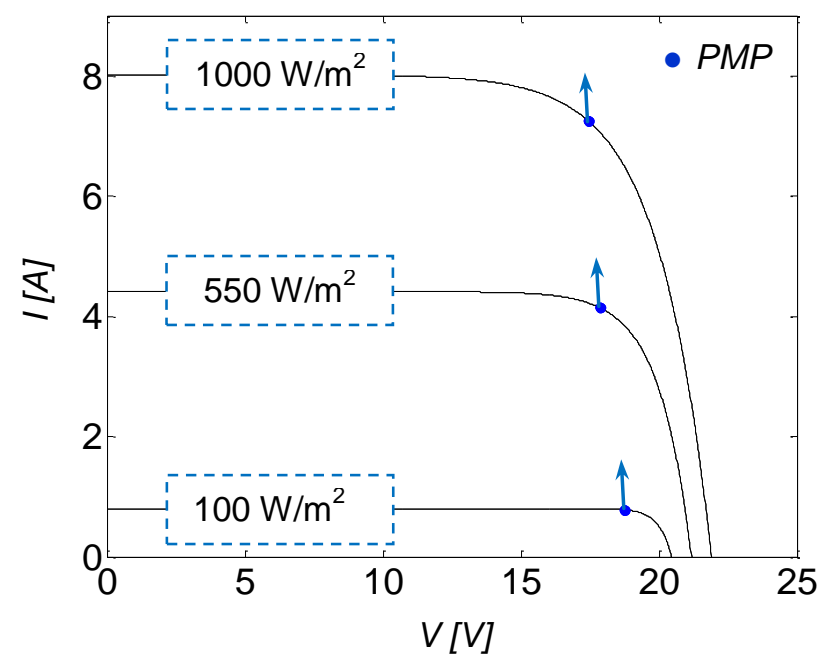

Figura 3.3. Curvas I- V simuladas para diferentes irradiações a $25^{\circ} \mathrm{C}$.

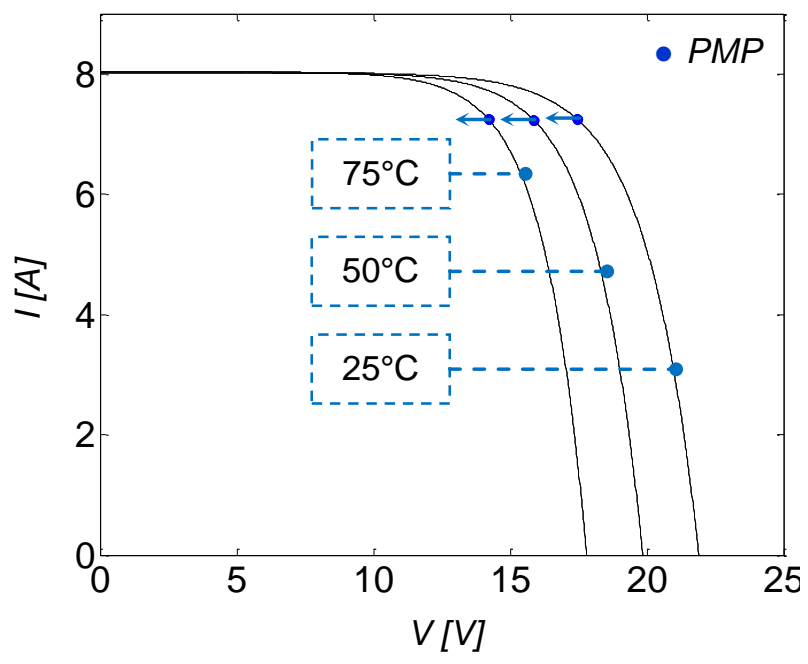

Figura 3.4. Curvas I-V simuladas para diferentes temperaturas a $1000 \mathrm{~W} / \mathrm{m}^{2}$.

\subsection{Especificação do Sistema Fotovoltaico}

O conjunto de painéis fotovoltaicos utilizados neste trabalho é constituído por dois módulos KC130TM conectados em série. As características elétricas e os parâmetros dos módulos KC130TM, do conversor elevador de tensão e do modelo do painel fotovoltaico adotado são apresentados nas Tabelas 3.1, 3.2 e 3.3, respectivamente.

\subsection{Modelagem Matemática}

O sistema fotovoltaico é não linear e variante no tempo (KADRI; GAUBERT; CHAMPENOIS, 2011) devido às características elétricas dos painéis fotovoltaicos (vide Figura 3.2) que associado ao efeito do chaveamento (decorrente da operação dos conversores eletrônicos) resulta em equações diferenciais complexas e fora do escopo desta dissertação. No entanto, o sistema não linear pode ser aproximado por equações lineares em determinados intervalos de tempo (XIAO et al., 2007). O processo de linearização estabelece que para um determinado ponto de operação sujeito a 
pequenas perturbações existe um modelo linear de pequenos sinais entre a entrada e saída que difere ligeiramente do modelo não linear (CHEN, 1999).

Tabela 3.1. Especificações elétricas do módulo KC130TM em STC ${ }^{6}$.

\begin{tabular}{llll}
\hline Símbolo & Parâmetro & Valor & Unidade \\
\hline$P_{M A X}$ & Potência Máxima & 260,1 & {$[\mathrm{~W}]$} \\
$V_{M P}$ & Tensão em $P_{M A X}$ & 35,2 & {$[\mathrm{~V}]$} \\
$I_{M P}$ & Corrente em $P_{M A X}$ & 7,39 & {$[\mathrm{~A}]$} \\
$V_{O C}$ & Tensão de Circuito Aberto & 43,8 & {$[\mathrm{~V}]$} \\
$I_{S C}$ & Corrente de Curto Circuito & 8,02 & {$[\mathrm{~A}]$} \\
$C_{V}$ & Coeficiente de Temperatura de $V_{O C}$ & $-8,21 \times 10^{-2}$ & {$\left[\mathrm{~V} /{ }^{\circ} \mathrm{C}\right]$} \\
$C_{l}$ & Coeficiente de Temperatura de $I_{S C}$ & $3,18 \times 10^{-3}$ & {$\left[\mathrm{~A} /{ }^{\circ} \mathrm{C}\right]$} \\
& Tensão Máxima do Sistema & 600 & {$[\mathrm{~V}]$} \\
\hline
\end{tabular}

Tabela 3.2. Parâmetros do conversor elevador de tensão.

\begin{tabular}{llll}
\hline Símbolo & Parâmetro & Valor & Unidade \\
\hline$C$ & Capacitor na entrada do boost & 1 & {$[\mathrm{mF}]$} \\
$r_{C}$ & Resistência série do capacitor & 0,5 & {$[\Omega]$} \\
$L$ & Indutor & 5,0 & {$[\mathrm{mH}]$} \\
$r_{L}$ & Resistência série do indutor & 0,3 & {$[\Omega]$} \\
$D$ & Razão cíclica nominal & 0,76 & \\
$r_{O N}$ & Resistência da chave ligada & 0,05 & {$[\Omega]$} \\
$R_{D}$ & Resistência série do diodo & 0,02 & {$[\Omega]$} \\
$V_{D}$ & Tensão direta do diodo & 0,6 & {$[\mathrm{~V}]$} \\
$C_{O}$ & Capacitor de saída & 1,4 & {$[\mathrm{mF}]$} \\
$R_{O}$ & Carga nominal & 87 & {$[\Omega]$} \\
$V_{O}$ & Tensão nominal na saída & 150 & {$[\mathrm{~V}]$} \\
\hline
\end{tabular}

${ }^{6}$ STANDARD TEST CONDITIONS: AM1.5, $25{ }^{\circ} \mathrm{C}$ e $1000 \mathrm{~W} / \mathrm{m}^{2}$. 
Tabela 3.3. Parâmetros ${ }^{7}$ do modelo ajustado do conjunto fotovoltaico formado por dois módulos KC130TM conectados série em STC.

\begin{tabular}{llll}
\hline Símbolo & Parâmetro & Valor & Unidade \\
\hline$I_{P V}$ & Corrente Gerada pela Luz & 8,0378 & {$[A]$} \\
$I_{O}$ & Corrente de Saturação do Diodo & 3,598 & {$[\mathrm{nA}]$} \\
$a$ & Fator de Idealidade do Diodo & 1,1 & \\
$R_{P}$ & Resistência Shunt Equivalente & 176,272 & {$[\Omega]$} \\
$R_{S}$ & Resistência Série Equivalente & 0,180 & {$[\Omega]$} \\
\hline
\end{tabular}

\subsubsection{Linearização do Painel Fotovoltaico}

A equação característica $i-v$ representa o modelo matemático dos painéis fotovoltaicos utilizados neste trabalho, conforme reescrita abaixo:

$$
i=I_{P V}-I_{O}\left[\exp \left(\frac{v+R_{S} i}{V_{T} a}\right)-1\right]-\frac{v+R_{S} i}{R_{P}}
$$

a linearização é feita em torno do ponto de interesse, que neste caso corresponde ao PMP (vide Figura 3.3).

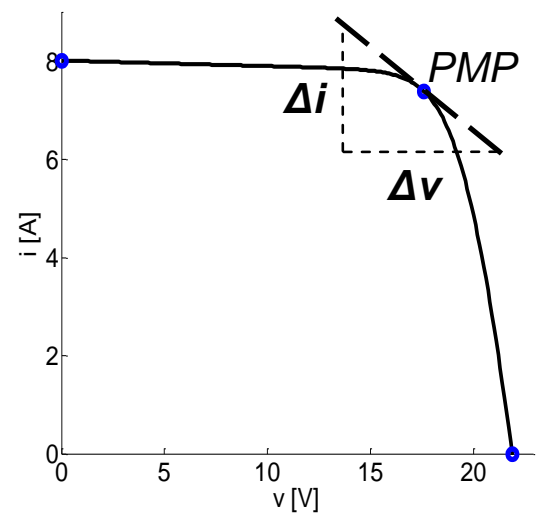

Figura 3.3. Linearização da curva $i-v$ nas proximidades do PMP do módulo solar KC130TM.

O modelo linear, determinado pela reta tangente à curva $i-v$ no ponto da

\footnotetext{
${ }^{7}$ Obtidos pelo algoritmo proposto [4].
} 
linearização $P M P\left(V_{M P}, I_{M P}\right)$ é dado por Villalva, de Siqueira e Ruppert (2010):

$$
i=g\left(v-V_{M P}\right)+I_{M P}
$$

tal que

$$
g=\frac{d i}{d v}=\frac{1}{r_{P V}} \approx \frac{\Delta i}{\Delta v}
$$

onde $r_{p v}$ é a resistência dinâmica da célula que depende da irradiação e temperatura da célula e portanto, possui comportamento variante no tempo (XIAO et al., 2007). Mediante a equação (7), determina-se o circuito linear equivalente na vizinhança de PMP (VILLALVA; de SIQUEIRA; RUPPERT, 2010), como mostrado na Figura 3.4, onde $R_{E Q}=-1 / g$ e $V_{E Q}=V_{M P}-I_{M P} / g$.

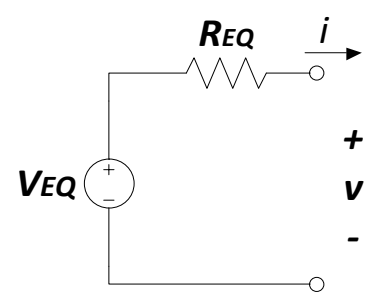

Figura 3.4. Circuito linear equivalente no ponto de máxima potência.

\subsubsection{Linearização do Sistema Fotovoltaico}

Na Figura 3.5 é apresentado o sistema fotovoltaico estudado neste trabalho. Assume-se que o capacitor $C_{o}$ é grande o suficiente para garantir que a tensão na saída seja constante. Desta forma, o modelo do sistema é obtido pelo método da modelagem de pequenos sinais e de acordo com o modo de operação do conversor por modulação de largura de pulso (PWM) (ERICKSON; MAKSIMOVIC, 2001). A análise matemática a ser apresentada nos próximos itens tem como principal objetivo a obtenção do modelo circuital de pequenos sinais do sistema fotovoltaico + conversor elevador de tensão bem como, a função de transferência de pequenos sinais $\tilde{v}(s) / \tilde{d}(s)$, onde $\tilde{v}$ e $\tilde{d}$ são, respectivamente, pequenas perturbações na tensão do painel fotovoltaico $v$ e na razão cíclica $d$. 
Para uma representação mais precisa do sistema consideraram-se os seguintes efeitos no modelo físico do conversor elevador de tensão: resistência série do capacitor de entrada $\left(r_{C}\right)$, resistência série do indutor $\left(r_{L}\right)$, resistência da chave ligada $\left(r_{O N}\right)$, resistência série do diodo $\left(R_{D}\right)$ e a tensão direta do diodo $\left(V_{D}\right)$, conforme representado na Figura 3.6, onde $i$ é a corrente de entrada do conversor elevador de tensão, $T_{S}$ é o período do chaveamento, $L$ é o valor da indutância, $C$ é o valor da capacitância de entrada do conversor e $R_{O}$ é a resistência da mínima carga a ser suprida pelo painel fotovoltaico.

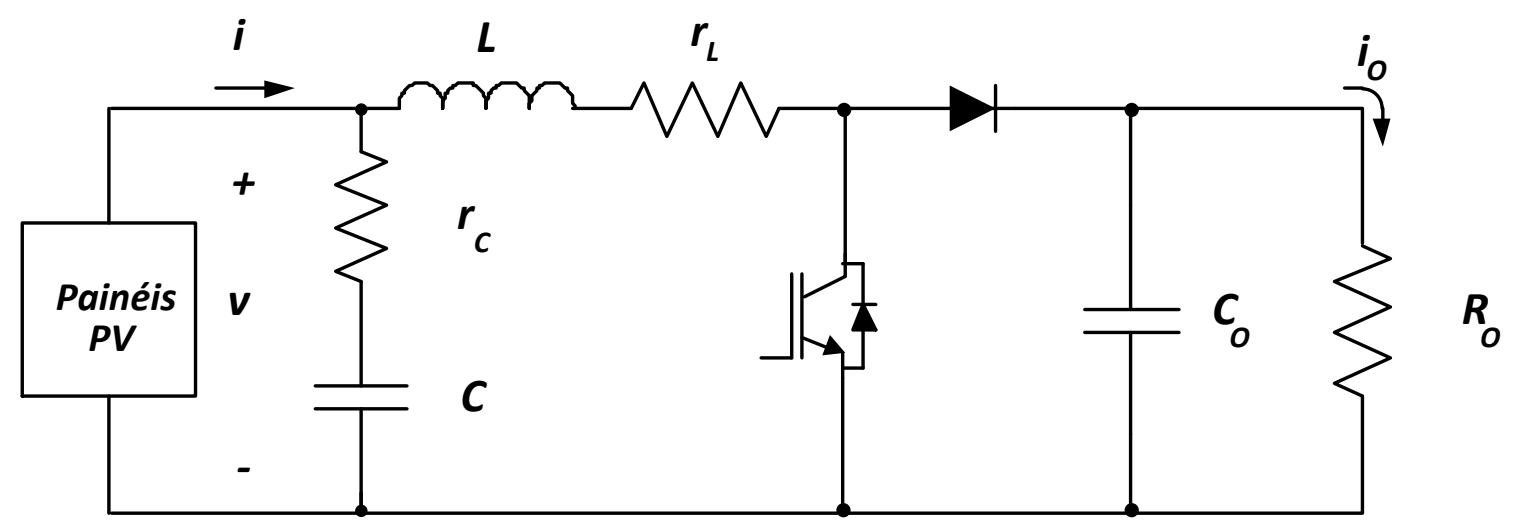

Figura 3.5. Diagrama esquemático do conversor elevador de tensão.

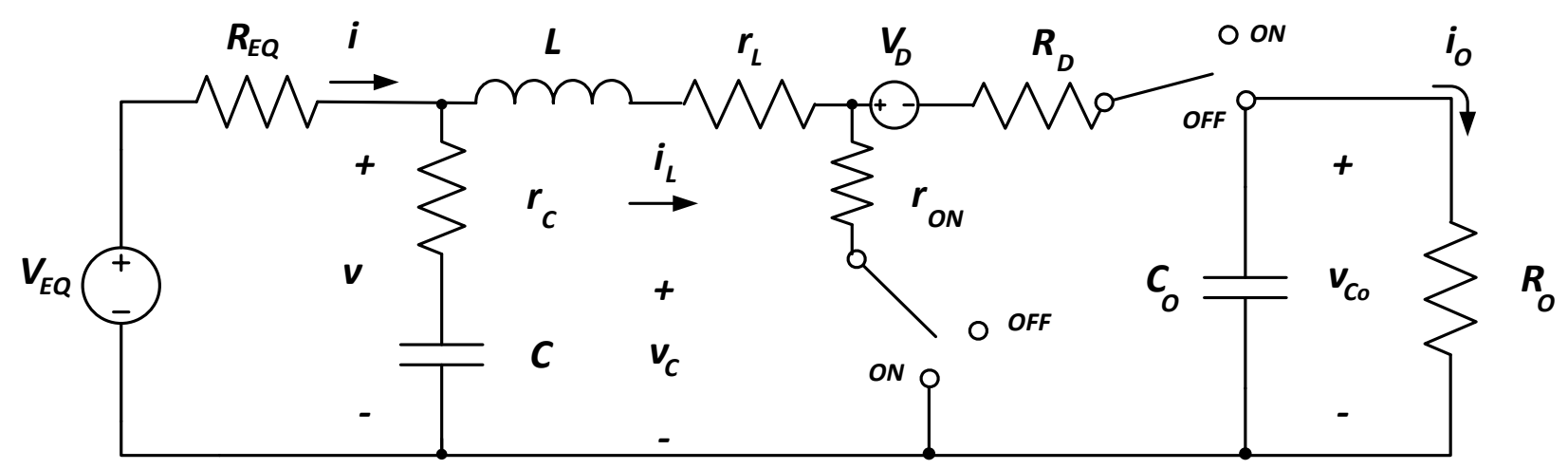

Figura 3.6. Circuito geral do sistema fotovoltaico incluindo os efeitos parasitas dos componentes.

Com o conversor operando no modo de condução contínua, há apenas dois estados possíveis para as variáveis do sistema: estado com chave ligada (ON) e estado com chave desligada (OFF). 
Aplicando-se as leis de Kirchhoff das correntes e das tensões para ambas às situações têm-se:

$$
\begin{aligned}
& \left.\begin{array}{l}
L \frac{d i_{L}}{d t}=v-i_{L}\left(r_{L}+r_{O N}\right) \\
C \frac{d v_{C}}{d t}=\frac{V_{E Q}-v}{R_{E Q}}-i_{L} \\
C_{O} \frac{d v_{C_{o}}}{d t}=-i_{O}
\end{array}\right\} \times d \quad \text { (9), para chave ligada e } \\
& \left.\begin{array}{l}
L \frac{d i_{L}}{d t}=v-i_{L}\left(r_{L}+R_{D}\right)-V_{D}-v_{C_{o}} \\
C \frac{d v_{C}}{d t}=\frac{V_{E Q}-v}{R_{E Q}}-i_{L} \\
C_{o} \frac{d v_{C_{o}}}{d t}=i_{L}-i_{O}
\end{array}\right\} \times(1-d)
\end{aligned}
$$

Considerando a Figura 3.6 percebe-se que:

$$
v=r_{C} C \frac{d v_{C}}{d t}+v_{C}
$$

(11). Mediante a relação

da corrente do capacitor de entrada em (9) e (10) e utilizando (11), o resultado obtido é:

$$
v=\left(\frac{r_{C}}{r_{C}+R_{E Q}}\right) V_{E Q}+\left(\frac{R_{E Q}}{r_{C}+R_{E Q}}\right) v_{C}-\left(r_{C} \| R_{E Q}\right) i_{L}
$$

\subsubsection{Obtenção da Função de Transferência de Pequenos Sinais por Equação de Espaço de Estados}

Considerando a notação matricial das equações por espaço de estados, na qual as variáveis de estado, as entradas e a saída são definidas como: 
$x(t)=\left[\begin{array}{l}i_{L} \\ v_{C} \\ v_{C_{o}}\end{array}\right], u(t)=\left[\begin{array}{l}V_{e q} \\ V_{D} \\ i_{O}\end{array}\right]$, e $y(t)=[v]$, resultando em dois sistemas: $\dot{x}=A_{1} x+B_{1} u$, $y=C_{1} x+E_{1} u$ durante o intervalo $d T_{S}$ e $\dot{x}=A_{2} x+B_{2} u, y=C_{2} x+E_{2} u$ durante o intervalo $(1-d) T_{S}$

Com o objetivo de se obter a média das equações dos estados no ponto de interesse, é feita a ponderação no tempo dos dois sistemas:

$$
\begin{aligned}
& \dot{x}=\left[A_{1} d+A_{2}(1-d)\right] x+\left[B_{1} d+B_{2}(1-d)\right] u \\
& y=\left[C_{1} d+C_{2}(1-d)\right] x+\left[E_{1} d+E_{2}(1-d)\right] u
\end{aligned}
$$

assumindo que as entradas $u$ e $d$ podem ser decompostas em um valor médio CC e uma pequena componente CA, é obtido como resultado:

$$
\begin{aligned}
& u=U+\tilde{u} \\
& d=D+\tilde{d} \\
& x=X+\tilde{x} \\
& y=Y+\tilde{y}
\end{aligned}
$$

desprezando-se os termos CA de $2^{\underline{a}}$ ordem e considerando as identidades $A=A_{1} D+A_{2}(1-D), B=B_{1} D+B_{2}(1-D), C=C_{1} D+C_{2}(1-D)$, e $E=E_{1} D+E_{2}(1-D)$, obtém-se:

$$
\begin{aligned}
& \left(\begin{array}{ccc}
L & 0 & 0 \\
0 & C & 0 \\
0 & 0 & C_{O}
\end{array}\right) \frac{d \tilde{x}}{d t}=A \tilde{x}+B \tilde{u}+\left[\left(A_{1}-A_{2}\right) X+\left(B_{1}-B_{2}\right) U\right] \tilde{d} \\
& \tilde{y}=C \tilde{x}+E \tilde{u}+\left[\left(C_{1}-C_{2}\right) X+\left(E_{1}-E_{2}\right) U\right] \tilde{d}
\end{aligned}
$$

tal que as equações de estado e da saída em regime permanente são dadas por $X=-A^{-1} B U$ e por $Y=\left(-C A^{-1} B+E\right) U$. Assim a função de transferência é determinada aplicando-se a transformada de Laplace em (15) e considerando as entradas separadamente:

$$
\tilde{y}(s)=\tilde{v}(s)=\left.G_{v d}\right|_{\tilde{i}_{O}=0} \tilde{d}(s)+\left.G_{v i}\right|_{\tilde{d}(s)=0} \tilde{i}_{O}(s)
$$




\subsubsection{Modelo Circuital CA de Pequenos Sinais}

A técnica que representa o conversor + painéis fotovoltaicos das equações por espaço de estados permite determinar de maneira compacta e simples a função de transferência da planta linearizada do circuito. No entanto, para resultados literais, este procedimento gera expressões de alta entropia (MIDDLEBROOK, 1991) nas quais é difícil de determinar isoladamente os efeitos dos diferentes elementos do sistema. Assim, para uma abordagem orientada ao projeto é importante que se tenha um modelo circuital CA de pequenos sinais que forneça expressões de baixa entropia cujas relações entre as entradas e a saída sejam facilmente compreendidas e o efeito de elementos adicionais sejam analisados sem a necessidade de se recorrer a equações matemáticas complexas.

As equações do indutor $L$ em (9) e (10) são somadas pelo principio do balanceamento da tensão sobre o indutor e utilizando a decomposição dos sinais em CC e CA de (11), tem-se:

$$
\begin{aligned}
& 0=V-I_{L}\left(r_{L}+r_{O N} D+R_{D} D^{\prime}\right)-V_{D} D^{\prime}-V_{C_{O}} D^{\prime} \\
& L \frac{d \tilde{i}_{L}}{d t}=\tilde{v}-\tilde{i}_{L}\left(r_{L}+r_{O N} D+R_{D^{\prime}} D^{\prime}\right)+\tilde{d}\left(V_{D}+V_{C_{O}}-I_{L}\left(r_{O N}-R_{D}\right)\right)-\tilde{v}_{C_{O}} D
\end{aligned}
$$

sendo $D^{\prime}=1-D$, cujo modelo CA é mostrado na Figura 3.7.

Pelo principio do balanceamento de carga do capacitor e fazendo o mesmo procedimento anterior, são obtidas, para o capacitor da entrada $C$ e para o capacitor da saída $C_{O}$, as relações apresentadas em (18) e (19) respectivamente.

$$
\begin{aligned}
& 0=\frac{V_{E Q}-V}{R_{E Q}}-I_{L} \\
& C \frac{d \tilde{v}_{C}}{d t}=-\frac{\tilde{v}}{R_{E Q}}-\tilde{i}_{L} \\
& 0=-I_{O}+I_{L} D^{\prime} \\
& C_{O} \frac{d \tilde{v}_{C_{o}}}{d t}=-\tilde{i}_{O}-\tilde{d} I_{L}
\end{aligned}
$$

Baseando-se nas Figuras 3.7, 3.8 e 3.9, é possível construir o modelo CA 
completo de pequenos sinais conforme é mostrado na Figura 3.10, onde $R_{\alpha}$ e $V_{\alpha}$ podem ser definido como: $R_{\alpha}=r_{L}+r_{O N} D+R_{D} D^{\prime}$ e $V_{\alpha}=V_{D}+V_{C_{O}}-I_{L}\left(r_{O N}-R_{D}\right)$. Assim, mediante esse modelo, é possível serem observadas duas fontes independentes $\tilde{d}$ e $\tilde{i}_{o}$ e a saída $\tilde{v}$. Desse modo, a função de transferência pode ser determinada tal como em (16) utilizando o principio da superposição.

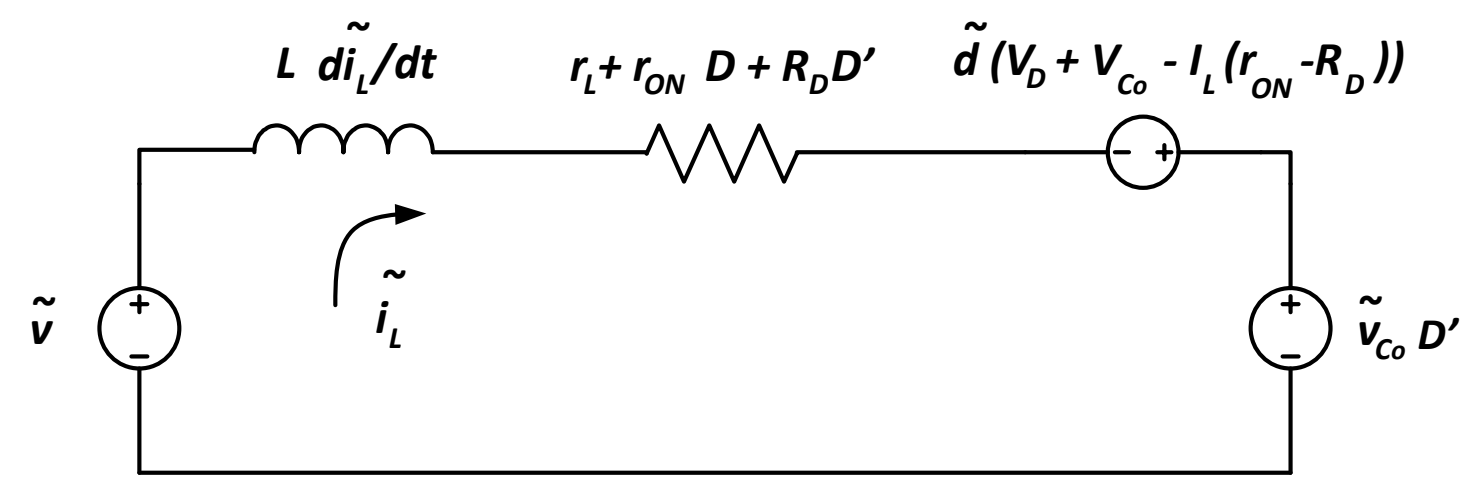

Figura 3.7. Circuito de pequenos sinais equivalente para a malha do indutor.

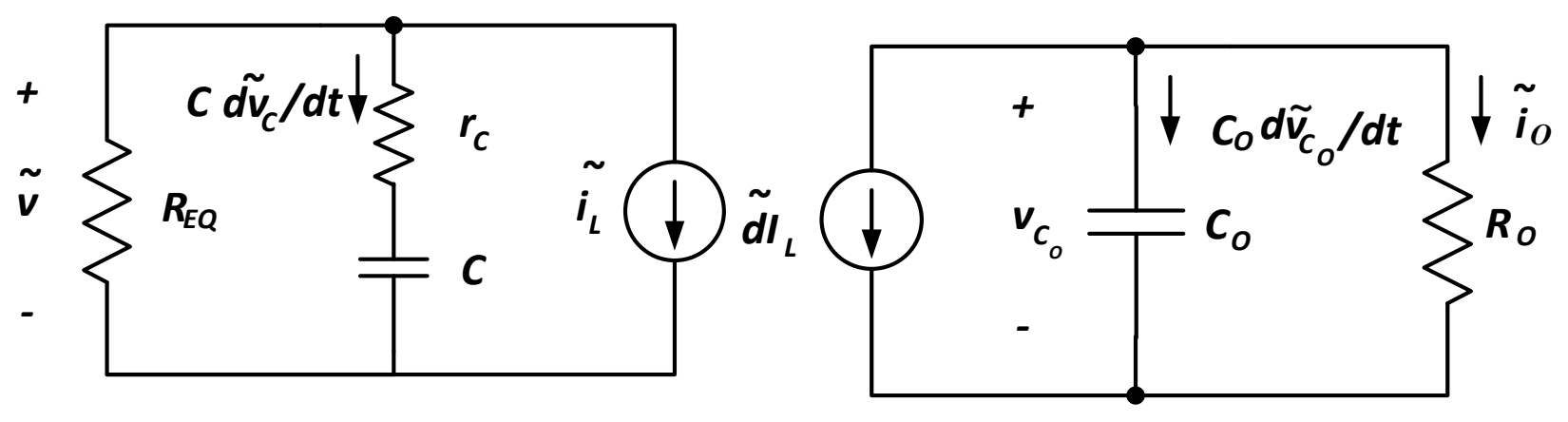

Figura 3.8. Circuito de pequenos sinais equivalente para o nó do capacitor de entrada.

Figura 3.9. Circuito de pequenos sinais equivalente para o nó do capacitor de saída. 


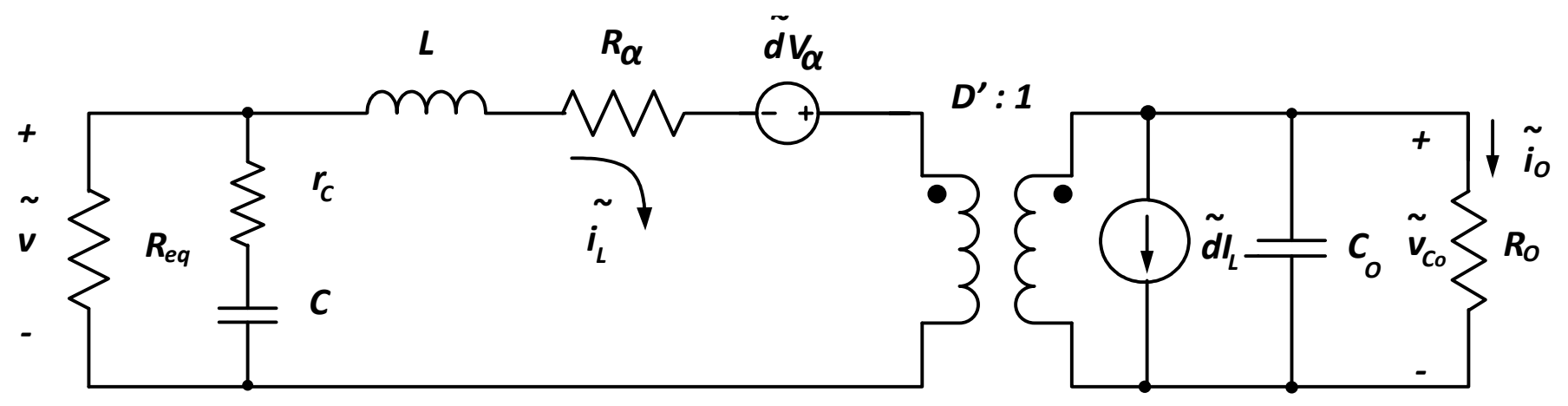

Figura 3.10. Circuito linear equivalente de pequenos sinais do sistema fotovoltaico.

Este modelo contém as duas fontes independentes $\left(\tilde{d}\right.$ e $\left.\tilde{i}_{o}\right)$ e a saída $\tilde{v}$. A determinação da função de transferência é feita utilizando-se os princípios de superposição e das relações de divisor de corrente e divisor de tensão. Assim, a função de transferência da $\tilde{d}(s)$ para tensão de entrada dos painéis $\tilde{v}(s)$ é dada por:

$$
G_{v d}(s)=-\left(V_{\alpha}+I_{L} D^{\prime}\left(R_{O} \| \frac{1}{s C_{O}}\right)\right)\left(\frac{\left(r_{C}+\frac{1}{s C}\right) \| R_{E Q}}{\left(r_{C}+\frac{1}{s C}\right) \| R_{E Q}+R_{\alpha}+s L+\left(R_{O} \| \frac{1}{s C_{O}}\right) D^{\prime 2}}\right)
$$

ou seja,

$$
\begin{aligned}
& G_{v d}(s)=-R_{e q}\left(\frac{s^{2} C C_{O} R_{O} r_{C} V_{\alpha}+s\left(V_{\alpha}\left(C r_{C}+C_{O} R_{O}\right)+I_{L} R_{O} D^{\prime} C r_{C}\right)+V+I_{L} R_{O} D^{\prime}}{s^{3} \tau_{3}+s^{2} \tau_{2}+s \tau_{1}+R_{O} D^{\prime 2}+R_{\alpha}+R_{E Q}}\right) \\
& \tau_{3}=L C C_{O} R_{O}\left(R_{E Q}+r_{C}\right) \\
& \tau_{2}=C_{O} R_{O}\left(C R_{E Q} r_{C}+C R_{\alpha}\left(R_{E Q}+r_{C}\right)+L\right)+L C\left(R_{E Q}+r_{C}\right) \\
& \tau_{1}=C R_{E Q} r_{C}+C_{O} R_{O}\left(R+R_{E Q}\right)+\left(C R_{\alpha}+C R_{O} D^{\prime 2}\right)\left(R_{E Q}+r_{C}\right)+L
\end{aligned}
$$

A função de transferência entre a corrente na carga $\tilde{i}_{o}(s)$ e a tensão $\tilde{v}(s)$ é dada por:

$$
G_{v i}(s)=-\frac{R_{E Q}}{D^{\prime 2}}\left(\frac{s\left(C r_{C}+1\right)}{s^{3} L C \frac{C_{O}}{D^{\prime 2}}\left(R_{E Q}+r_{C}\right)+s^{2} \frac{C_{O}}{D^{\prime 2}}\left(L+C R_{\alpha}\left(R_{E Q}+r_{C}\right)\right)+s C\left(R_{E Q}+r_{C}\right)+1}\right)
$$

Entretanto, o sinal negativo encontrado em $G_{v d}(s)$ e $G_{v i}(s)$ é devido à relação 
contrária entre $\tilde{d}$ e $\tilde{v}$ e $\tilde{i}_{O}$, ou seja, perturbações positivas $\tilde{d}$ na razão cíclica $D$ geram, respectivamente, perturbações negativas sobre $\tilde{v}$ e $\tilde{i}_{O}$, na tensão de entrada e na corrente de saída.

Com os parâmetros do sistema fotovoltaico das Tabelas 3.1, 3.2 e 3.3, e com o painel linearizado no $P M P\left(R_{E Q}=4,58 \Omega\right.$ e $\left.V_{E Q}=69,07 \mathrm{~V}\right)$, obtêm-se as respostas em frequência das funções de transferência $G_{v d}(s)$ e $G_{v i}(s)$ apresentados nas Figuras 3.11 e 3.12 .

A resposta em frequência da Figura 3.11 mostra que a curva é monotônica, isto é, existe apenas uma frequência de corte, permitindo utilizar o conceito de margem de fase e margem de ganho para definir a estabilidade do sistema.

Embora não apresentadas neste trabalho, duas outras configurações $\left(G_{1 v d}(s) \mathrm{e}\right.$ $G_{2 v d}(s)$ ) foram testadas com o objetivo de comparar o modelo atual $\left(G_{v d}(s)\right)$ com outros modelos mais simplificados. No primeiro caso, desconsideraram-se as variações na corrente da saída do conversor elevador de tensão $\left(\tilde{i}_{o}=0\right)$ e no segundo caso, considera-se uma fonte de tensão constante na saída do conversor $\left(C_{o}=\infty\right)$.

A resposta ao degrau unitário das respectivas funções de transferência é apresentada na Figura 3.13. Observa-se que os modelos mais simplificados têm o sobressinal e o tempo de estabilização menor, no entanto estas mesmas simplificações, podem levar a resultados mais distantes da prática, na qual a carga é variável e capacitores são responsáveis por fixar a tensão na saída. Desta forma, optou-se neste trabalho em utilizar o modelo $G_{v d}(s)$ mais próximo da realidade prática. 


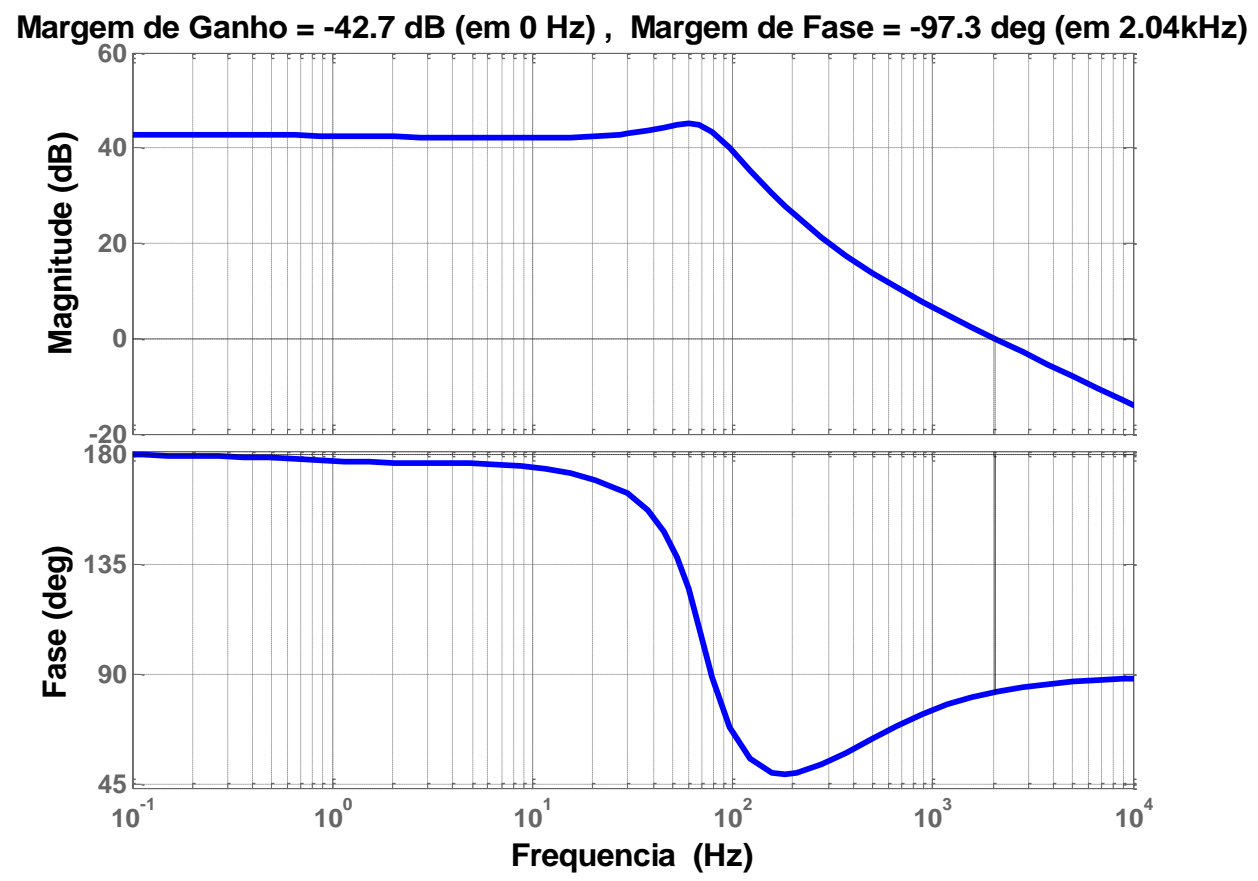

Figura 3.11. Diagrama de Bode da função de transferência $G_{v d}(s)$.

Margem de Ganho $=-25.6 \mathrm{~dB}(\mathrm{em} 0 \mathrm{~Hz})$, Margem de Fase $=-118 \mathrm{deg}(\mathrm{em} 44.4 \mathrm{~Hz})$

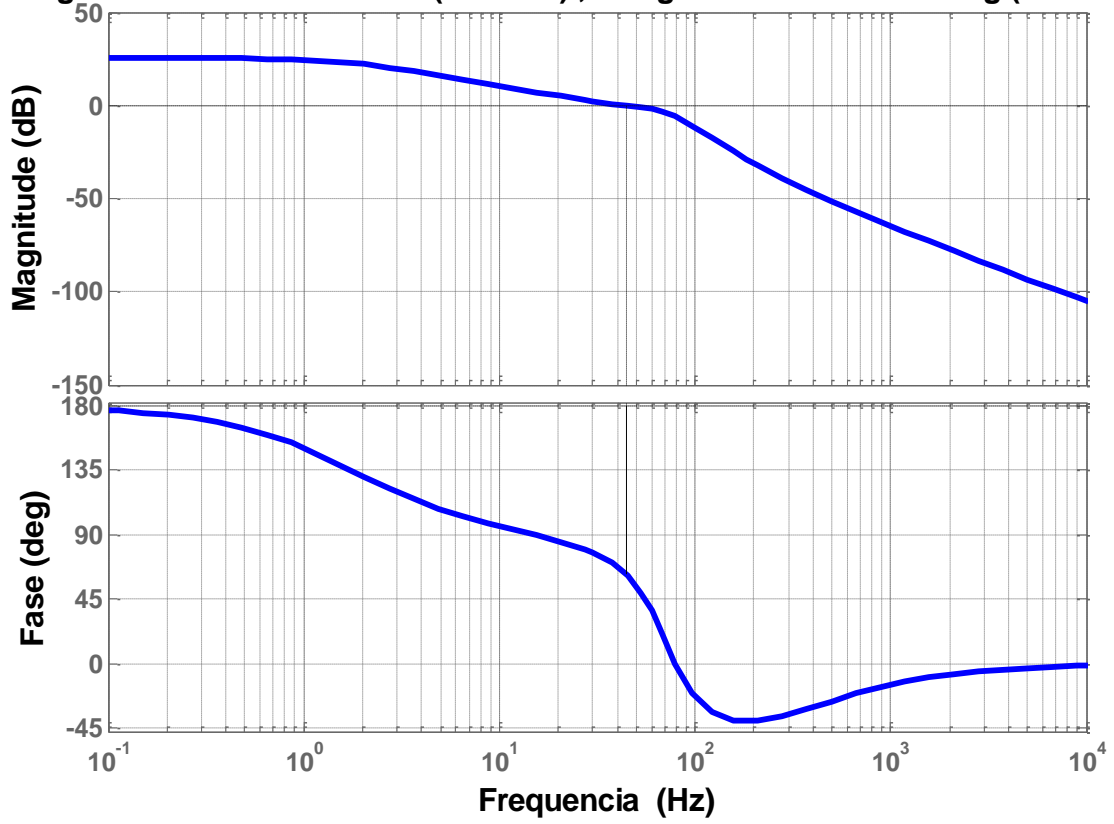

Figura 3.12. Diagrama de Bode da função de transferência $G_{v i}(s)$. 


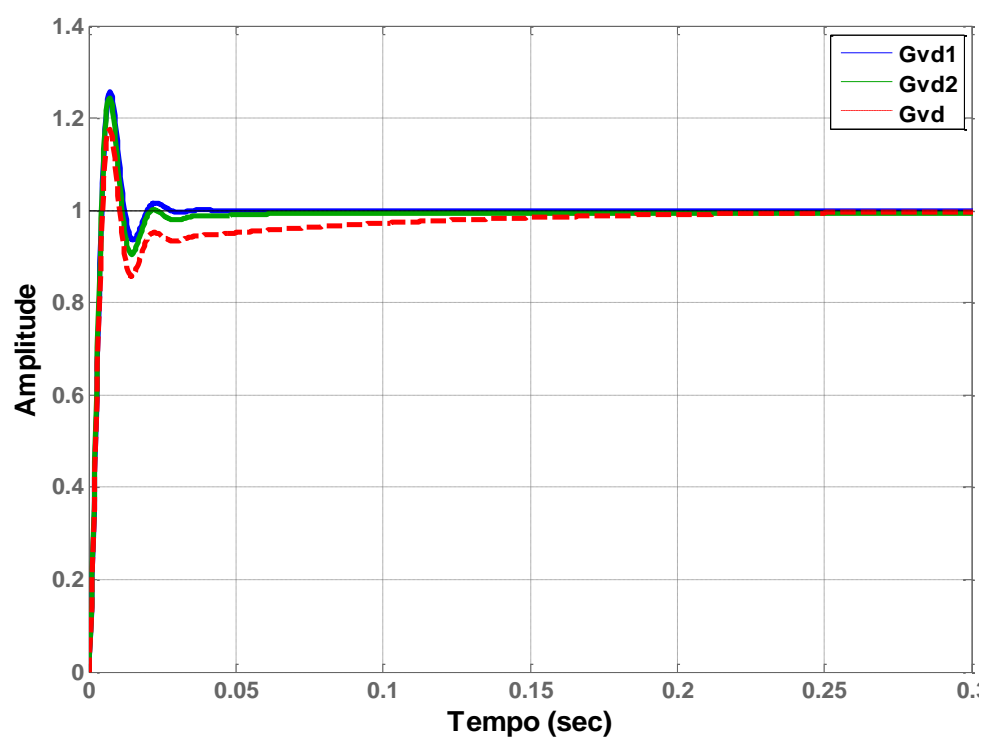

Figura 3.13. Resposta ao degrau unitário do modelo considerando tensão na saída constante (em azul), modelo considerando carga constante (em verde) e o modelo utilizado (em vermelho).

\subsection{Efeito de Elementos Parasitas: Capacitivo e Indutivo}

O painel fotovoltaico possui elementos parasitas, ou seja, uma capacitância shunt não linear associada à junção $p$-n dos diodos e uma indutância série associada às conexões das células (SPIAZZI; BUSO; MATTAVELLI, 2009). Estes elementos parasitas podem ser ignorados quando o conversor opera em frequências relativamente baixas $(\leq 20 \mathrm{kHz})$ porém, tais afirmações não podem ser desprezadas quando os conversores são submetidos a frequências superiores a $20 \mathrm{kHz}$. Resultados experimentais na literatura reportam estes efeitos em conversores CC-CC operando em frequências acima de $20 \mathrm{kHz}$ (SPIAZZI; BUSO; MATTAVELLI, 2009). Além disso, algoritmos que se baseiam no ripple dos elementos - tal como o RCC (ESRAM et al., 2006) - são bastante afetados pelos efeitos combinados da capacitância e da indutância parasitas conforme investigado por Spiazzi, Buso e Mattavelli (2009).

Nesta seção, é analisado o efeito destes elementos na função de transferência de controle para saída $G_{v d}(s)$, determinada anteriormente, utilizando-se do Teorema do Elemento Extra de Middlebrook. O Teorema do Elemento Extra de Middlebrook é apresentado em Erickson e Maksimovic (2001) e Middlebrook, Vorpérian e Lindal 
(1998) é uma ferramenta bastante útil que permite determinar a função de transferência modificada pela adição de elementos extras ao circuito linear inicial.

Verifica-se, também, em (MIDDLEBROOK; VORPÉRIAN; LINDAL, 1998) que a função de transferência modificada pode ser expressa como:

$$
G_{v d}(s)=\left(\left.G_{v d}(s)\right|_{\substack{Z_{O(s)=0}(s)=0 \\ i_{O}}}\right)\left(\frac{\left.1+\frac{Z_{O}(s)}{Z_{N}(s)}\right)}{\left(1+\frac{Z_{O}(s)}{Z_{D}(s)}\right)}\right.
$$

onde $\left(\left.G_{v d}(s)\right|_{\substack{Z_{O}(s)=0 \\ i_{o}(s)=0}}\right)$ é a função de transferência inicial sem o elemento extra $Z_{O}(s), Z_{D}(s)$ é a impedância no ponto da conexão do elemento extra na condição $\tilde{d}=0, Z_{N}(s)$ é a impedância no ponto da conexão do elemento extra na condição que $\tilde{v}=0$ e $Z_{O}(s)$ é a impedância do elemento extra. Alternativamente, $Z_{N}(s)$ também pode ser determinado em termos do modelo do circuito canônico (ERICKSON; MAKSIMOVIC, 2001) apresentado na Figura 3.14.

$$
Z_{N}(s)=-\frac{e(s)}{j(s)}
$$

Na qual mediante a Figura 3.10, resulta para presente caso $e(s)=V_{\alpha} / D^{\prime}$ e $j(s)=I_{L}$. Conforme mencionado anteriormente, fazendo-se $\tilde{d}=0$ obtém-se:

$$
Z_{D}(s)=\left(r_{C}+\frac{1}{s C}\right) \|\left(\left(R_{\alpha}+s L\right)+\left(R_{O} \| \frac{1}{s C_{O}}\right) D^{\prime 2}\right)
$$

Por outro lado:

$$
Z_{O}(s)=R_{E Q} \| \frac{1}{s C_{P V}}+s L_{P V}
$$




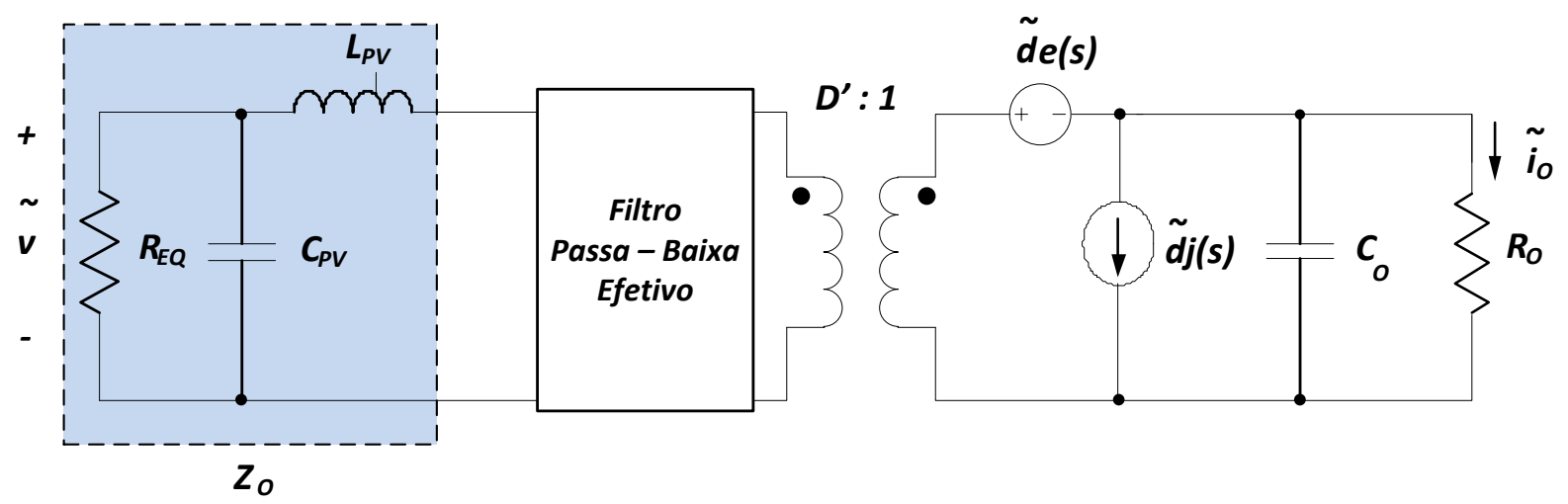

Figura 3.14. Modelo canônico do circuito do conversor elevador de tensão estudado considerando-se os efeitos parasitas do painel fotovoltaico.

Após a determinação de todos os elementos do termo $\frac{\left(1+\frac{Z_{O}(s)}{Z_{N}(s)}\right)}{\left(1+\frac{Z_{O}(s)}{Z_{D}(s)}\right)}$ em (23) (fator de correção) e para que os efeitos parasitas não afetem a função de transferência do controle para saída é necessário que o fator de correção tenha magnitude próxima da unidade, isto é:

$$
\begin{aligned}
& \left\|Z_{O}(s)\right\|<\left\|Z_{N}(s)\right\|, \quad \text { e } \\
& \left\|Z_{O}(s)\right\|<<\left\|Z_{D}(s)\right\|
\end{aligned}
$$

As respostas em frequência de $\left\|Z_{N}(s)\right\|$ e $\left\|Z_{D}(s)\right\|$ são apresentadas na Figura 3.15. O módulo de $\left\|Z_{N}(s)\right\|$ é constante para todas as frequências, por sua vez, $\left\|Z_{D}(s)\right\|$ apresenta um ganho baixo $(-10 d B)$, sendo deste modo o fator limitante na análise. Nota-se que os maiores valores de $\left\|Z_{D}(s)\right\|$ ocorrem em torno de 90-100 Hz, assim caso o conversor opere em altas frequências há a necessidade de aumentar $\left\|Z_{D}(s)\right\|$, o que pode ser feito diminuindo-se a razão cíclica $D$ ou ainda, aumentando a indutância $L$ e capacitância de entrada $C$ do conversor. 

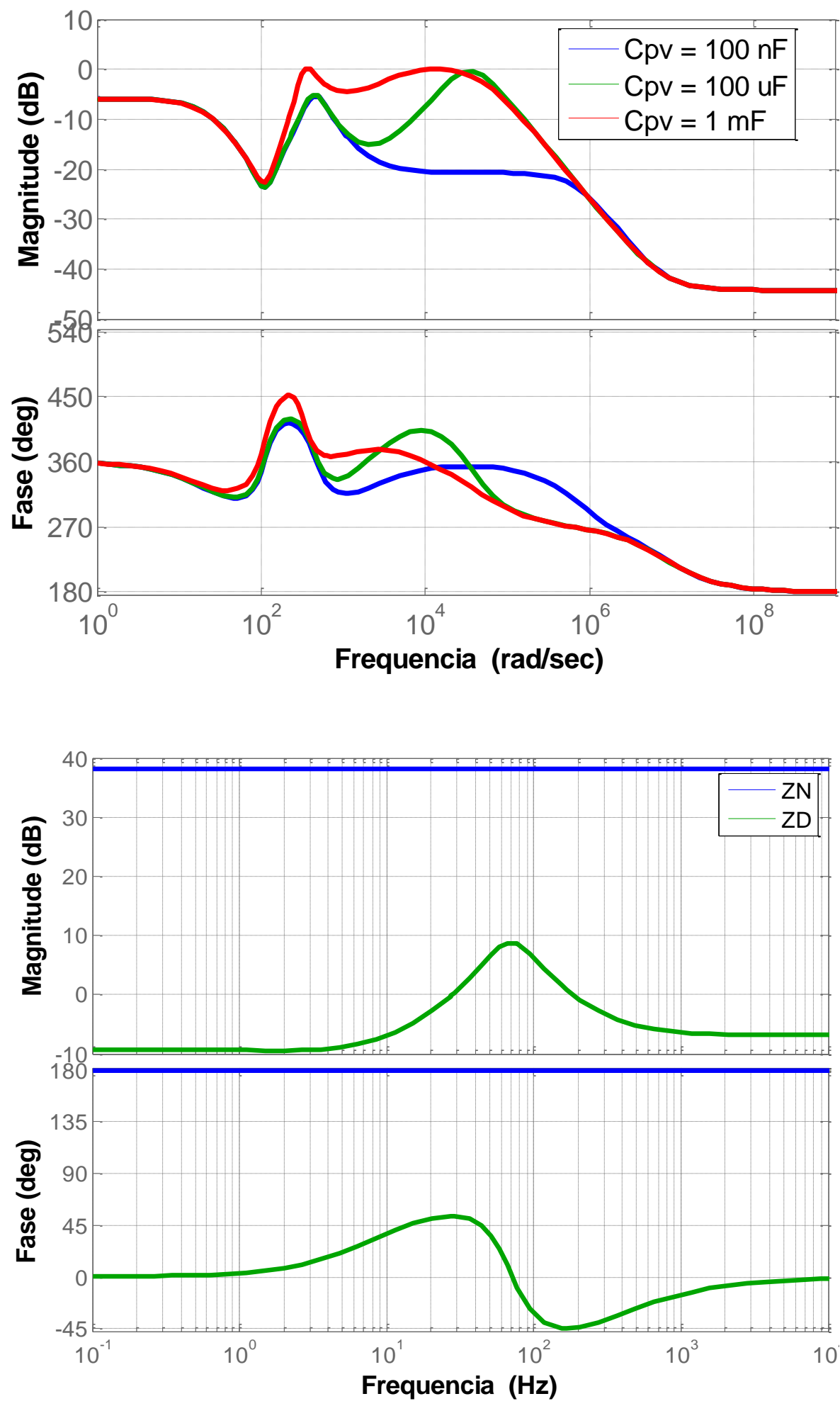

Figura 3.15. Diagrama de Bode de $\left\|Z_{N}(s)\right\|$ e $\left\|Z_{D}(s)\right\|$. 
Spiazzi, Buso e Mattavelli (2009), comentam sobre a medição da capacitância e indutância parasitas. Valores típicos estão na faixa das centenas $\mathrm{nF}$ para a capacitância parasita e dezenas de $\mu \mathrm{H}$ para a indutância parasita.

Estudos mais detalhados estão fora do escopo deste trabalho, uma vez que o sistema proposto opera em frequências de chaveamento menores do que $20 \mathrm{kHz}$, no entanto, outras análises poderiam ser consideradas, tais como à adição de filtros passa - baixa nos terminais da fonte de alimentação do conversor, ou ainda, à conexão de outros sistemas ao barramento CC na saída do conversor, valendo-se do mesmo Teorema do Elemento Extra de Middlebrook para determinar os fatores de correção a serem acrescentados à função de transferência inicial.

\subsection{Considerações Finais}

Neste capítulo foi apresentada a metodologia utilizada na modelagem matemática do sistema proposto. Considerações sobre a importância e necessidade de controlar a tensão nos terminais dos painéis fotovoltaicos foram abordadas.

A modelagem matemática baseou-se na linearização de todo o sistema fotovoltaico para o ponto de operação correspondente ao PMP. Duas abordagens foram apresentadas para a obtenção da função de transferência: uma utilizando equações no espaço de estados e a outra orientada ao projeto utilizando o modelo circuital de pequenos sinais.

Por fim, utilizou-se o Teorema do Elemento Extra de Middlebrook para determinar os critérios que permitam compensar o efeito de elementos parasitas na função de transferência determinada inicialmente. 



\section{Controle do Sistema Fotovoltaico}

\subsection{Introdução}

Neste capitulo é desenvolvido o projeto do controlador em malha fechada da tensão nos terminais do painel fotovoltaico que alimenta o conversor CC-CC (Figura $4.1)$.

Inicialmente, é testado um controlador linear do tipo proporcional e integral - PI. Além disso, é feita a análise em malha fechada utilizando-se os conceitos de margem de fase, margem de ganho, estabilidade e rejeição ao ruído, bem como são apresentados e discutidos os resultados das simulações do controlador $P /$ para regimes transitórios e permanentes são apresentados e discutidos. Posteriormente, é desenvolvido um controlador fuzzy $P D$, que atua paralelamente ao controlador $P l$, fazendo um ajuste fino. Por fim, são comparados os resultados das simulações do controlador proposto são apresentados e comparados em relação ao controlador $P I$. 


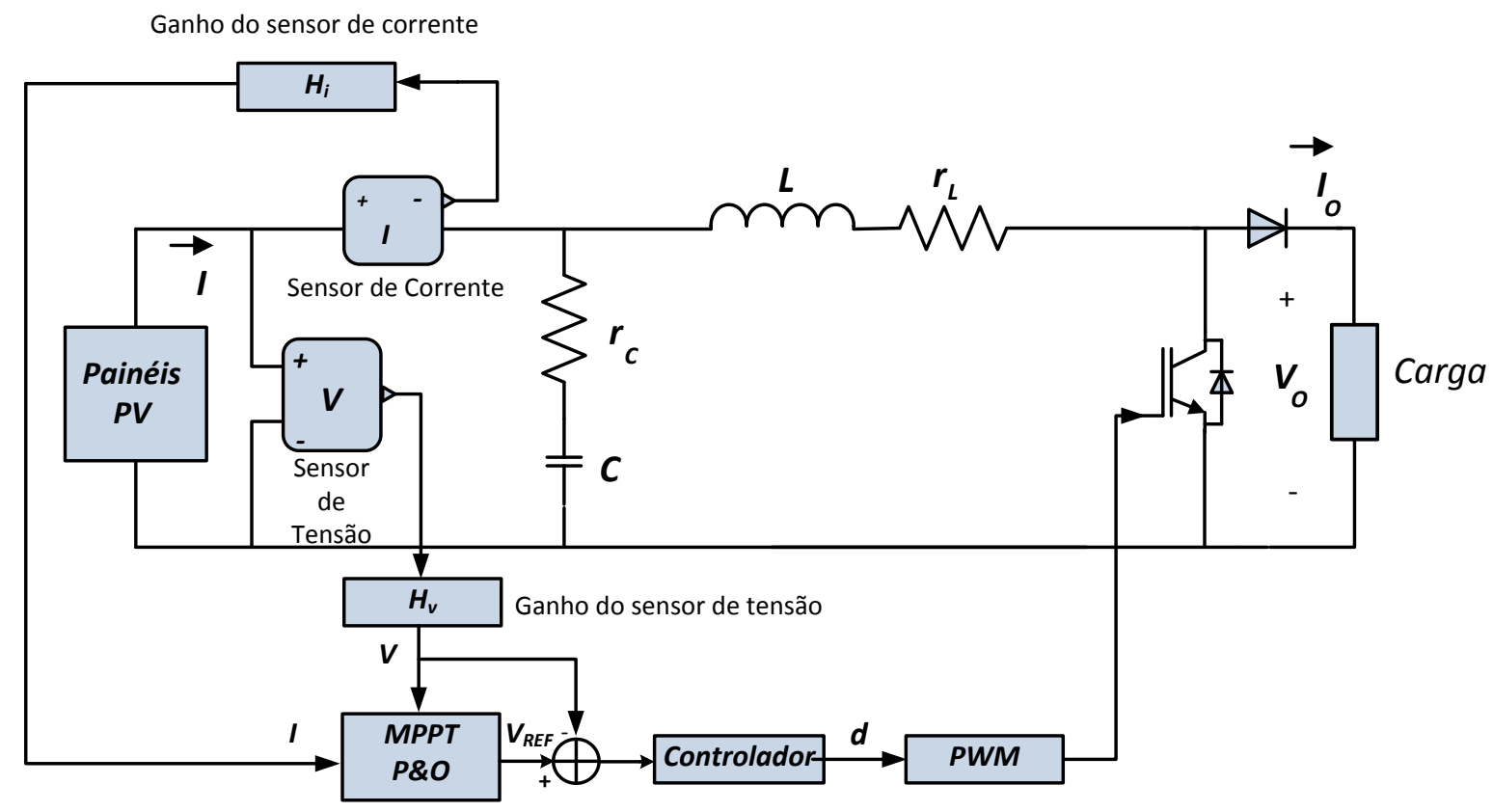

Figura 4.1. Conversor elevador de tensão com controle da tensão de entrada.

\subsection{Controle}

Conforme mencionado por Xiao et. al. (2007), o comportamento não linear e variante no tempo dos painéis fotovoltaicos e do conversor chaveado dificultam o projeto do controlador de tensão. No entanto, a função de transferência obtida no capitulo anterior permite o desenvolvimento de controladores lineares na região dos pontos próximos ao PMP. A lei de controle aplicada nesta dissertação baseia-se na realimentação negativa da saída e atua na razão cíclica da modulação PWM, conforme mostrado no diagrama em blocos da Figura 4.2.

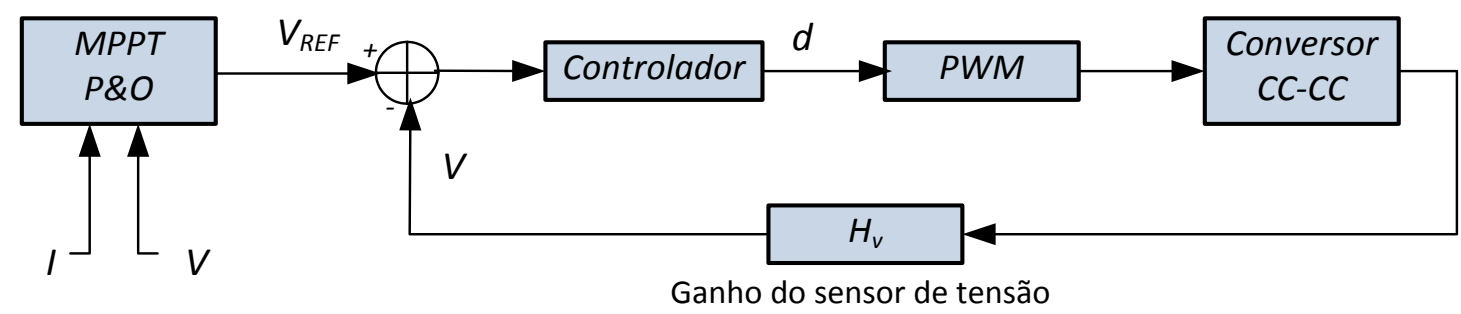

Figura 4.2. Diagrama em blocos do conversor CC-CC controlado e com referência gerada pelo algoritmo MPPT. 
Tendo como critério o aumento da largura de banda e da margem de fase da planta $G_{v d}(s)$, determinaram-se, via software, os ganhos proporcional e integral do controlador linear utilizando o Sisotool $\left(\right.$ MatLab ${ }^{\mathrm{TM}}$ Toolbox) mostrados na Tabela 4.1. Entretanto, qualquer outro método da teoria de sistemas lineares pode ser utilizado para determinar os ganhos do controlador. Os diagramas de Bode em malha fechada são apresentados nas Figuras 4.3 e 4.4, ambos com ganho de realimentação $H_{V}=1 / 70$.

Tabela 4.1. Ganho proporcional e integral do controlador linear.

\begin{tabular}{llll}
\hline Símbolo & Parâmetro & Valor & Unidade \\
\hline & Largura de banda & 1000 & {$[\mathrm{~Hz}]$} \\
$M F$ & Margem de fase & 80 & {$\left[{ }^{\circ}\right]$} \\
$K_{p}$ & Ganho Proporcional & -29 & \\
$K_{i}$ & Ganho Integral & -3200 & \\
\hline
\end{tabular}

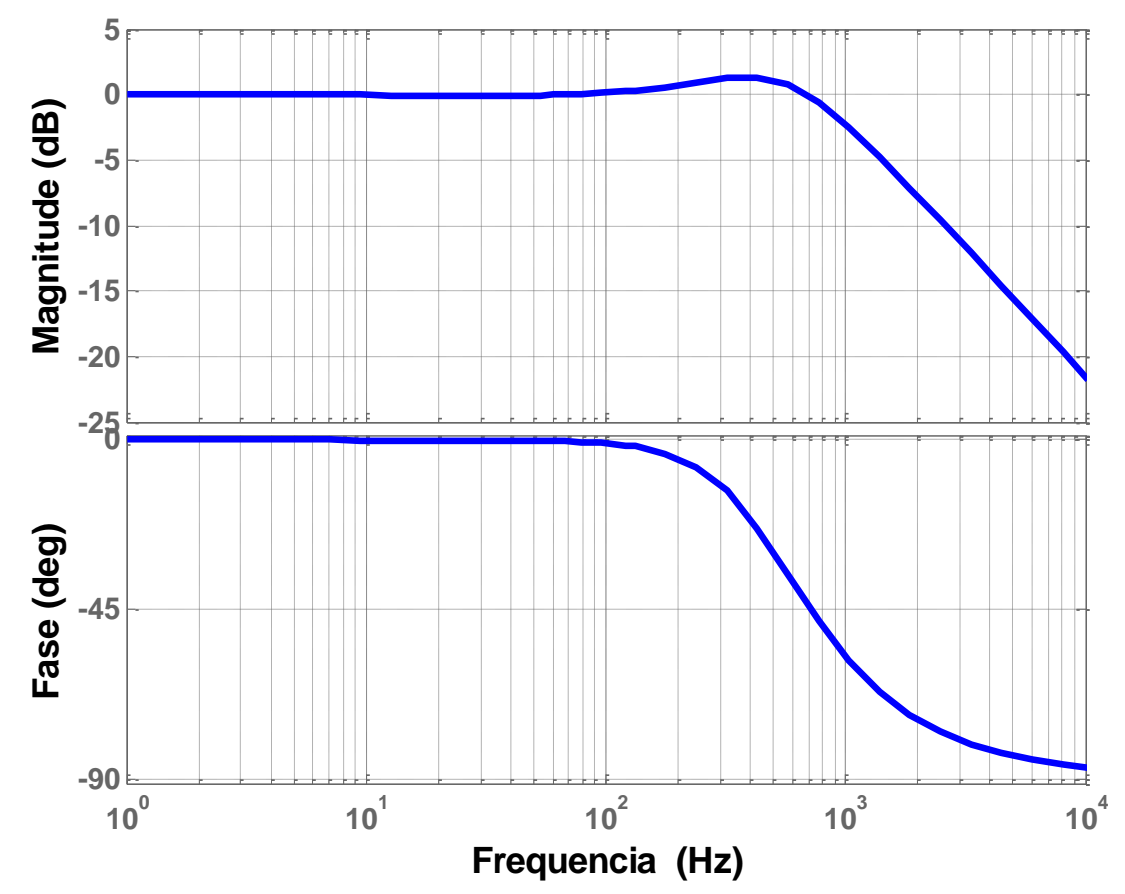

Figura 4.3. Resposta em frequência em malha fechada com realimentação unitária usando o controlador PI. 


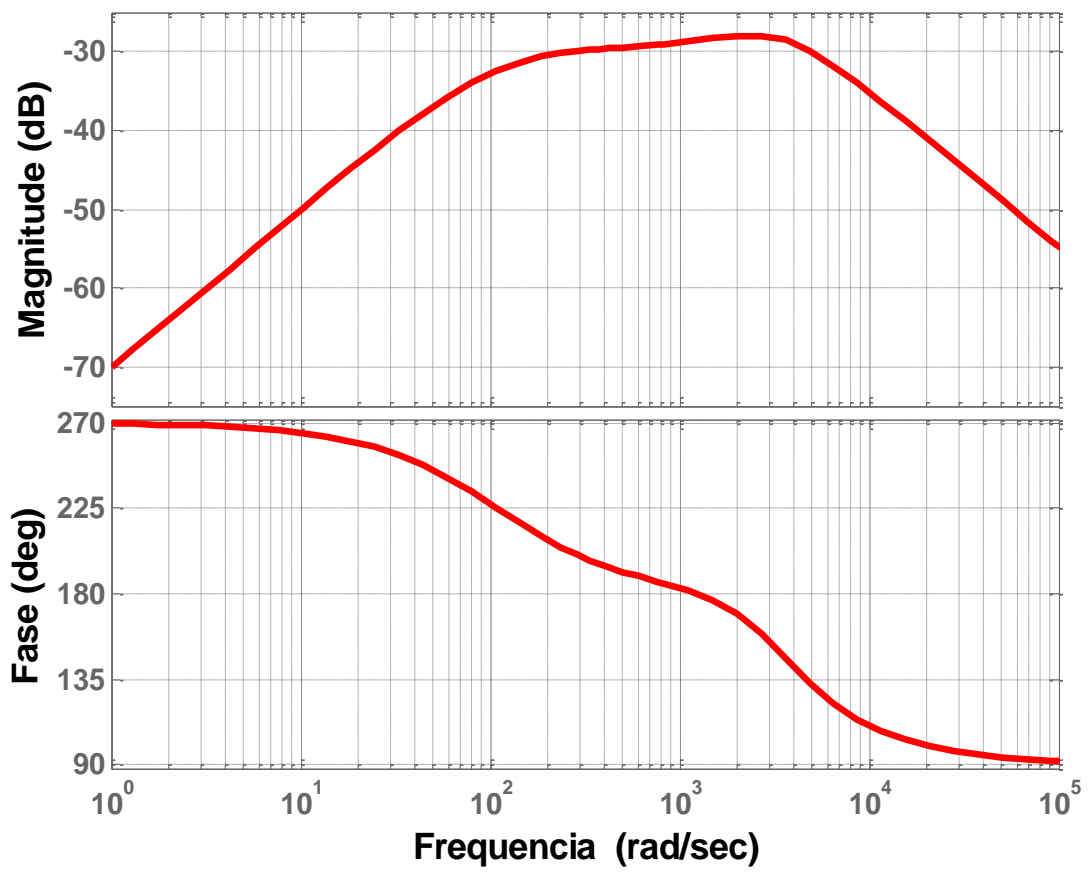

Figura 4.4. Resposta em frequência em malha fechada com realimentação unitária da rejeição a uma perturbação indesejável na entrada da planta.

A Figura 4.4 mostra a robustez do sistema para rejeitar perturbações constantes na entrada da planta - saída do controlador. Comparando a Figura 4.3, com a planta $G_{v d}(s)$ da, Figura 3.11, percebe-se que o controlador $P I$ em malha fechada, aumentou significativamente a margem de fase.

A resposta ao degrau é obtida pela simulação do sistema fotovoltaico da Figura 4.1 utilizando o Simulink (MatLab ${ }^{\mathrm{TM}}$ software), cujo resultado é apresentado na Figura 4.5. 


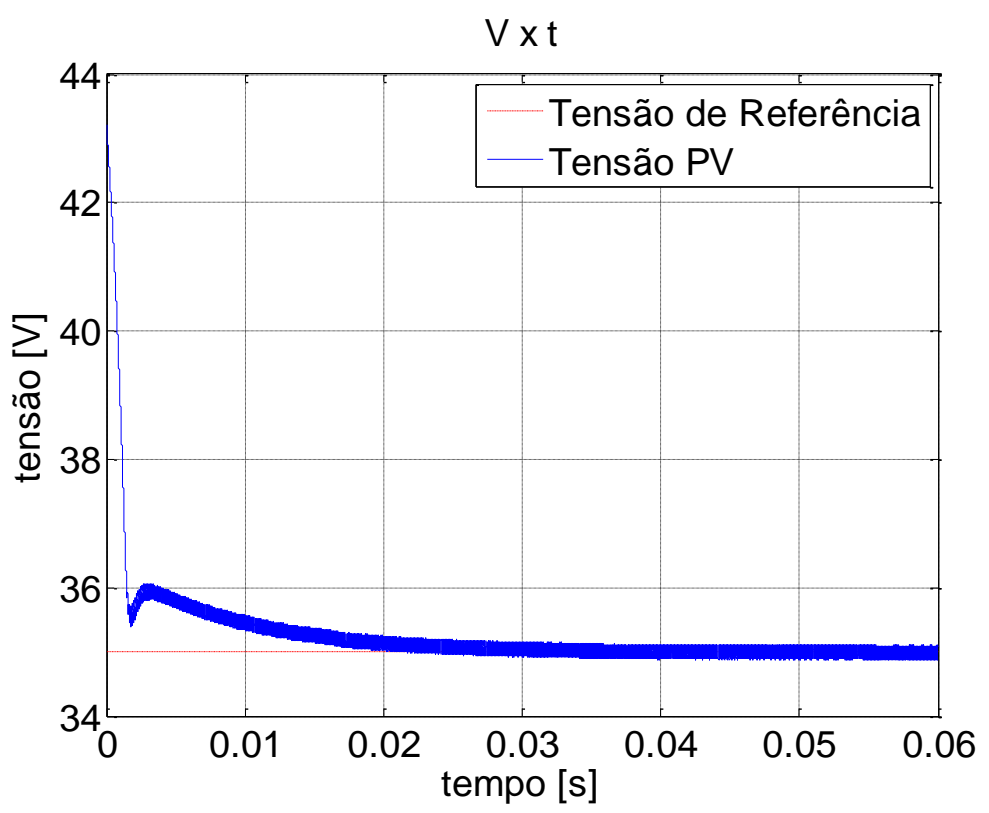

Figura 4.5. Resposta no domínio do tempo da tensão do painel foto voltaico usando o controlador PI para uma referência constante $V_{R E F}=35 \mathrm{~V}$ (linha pontilhada). $T s=1 \mu \mathrm{s}$, ripple $=2 \%$.

Embora o controlador linear $\mathrm{Pl}$ apresente ripple de $2 \%$ e sem erro de regime permanente, a resposta no transitório de aproximadamente 0,03 s não é tão satisfatória quanto deveria. O tempo que o sistema leva para estabilizar ("settling time") e o sobressinal ("overshoof") podem ao final do dia corresponder a uma parcela significativa de energia desperdiçada. E levando em consideração que o ponto de referência em um sistema fotovoltaico varia conforme as condições atmosféricas e as tomadas de decisões do algoritmo de busca, torna-se deste modo necessária à otimização da resposta transitória do controlador linear.

Os próximos itens deste capítulo focam no projeto de um controlador fuzzy cujo objetivo é o de atuar em conjunto com o controlador $\mathrm{Pl}$ para reduzir o tempo de resposta do sistema.

\subsubsection{Controlador Fuzzy PD + PI}

Existem na literatura diversas aplicações fotovoltaicas em que técnicas de controle por lógica fuzzy (FLC) são utilizadas (ALAJMI, 2011; CECATI; CIANETTA; SIANO, 2010; CHIU; OUYANG, 2011; LI, J.; WANG, 2009). O FLC não requer 
conhecimento detalhado do processo a ser controlado nem a sua descrição precisa em termos do modelo matemático, além disso, quando projetado corretamente, supera os controladores mais complexos porque adapta as suas saídas para o estado atual do sistema, mesmo sem o uso de observadores (CECATI; CIANETTA; SIANO, 2010). A sua natureza heurística associada à simplicidade e eficácia em sistemas lineares como não lineares têm motivado o uso em larga escala nos processos industriais (LI, J.; WANG, 2009).

Na Figura 4.6 é mostrado o diagrama geral de um estimador/controlador fuzzy. $\mathrm{Na}$ "Base de Dados" são definidos os tipos de funções de pertinência e o número de pontos discretizados a serem usados. As variáveis de entrada do processo de inferência são fuzzificadas na "Interface de Fuzzificação" e medidas por meio de sensores. Com base em um conjunto de regras linguísticas definidas na "Base de Conhecimento" é gerada uma resposta que após passar pela "Interface de Defuzzificação" resulta em uma ação de controle no atuador da planta. Maiores informações sobre o FLC podem ser encontrados em (ROSS, 2010).

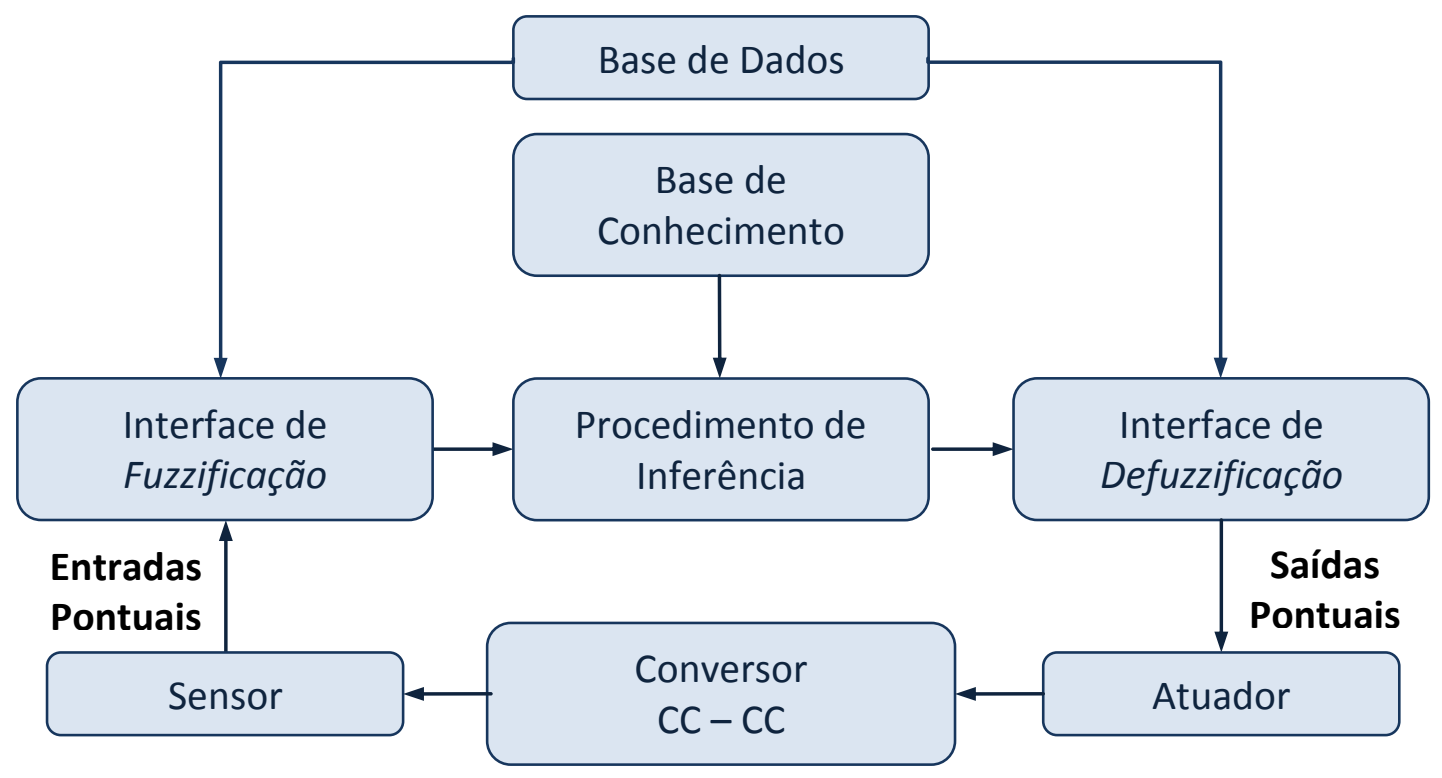

Figura 4.6. Diagrama em blocos de um estimador/controlador fuzzy.

As variáveis de entrada do $F L C$ são definidas como (25):

1) O erro $e(k)$, i.e., diferença entre a tensão de referência fornecida pelo 
$M P P T V_{R E F}$ pela tensão no painel fotovoltaico $V$.

2) A variação do erro $\Delta e(k)$, i.e., diferença entre o erro no instante atual $e(k)$ pelo erro no instante anterior $e(k-1)$.

$$
\begin{aligned}
& e(k)=V_{R E F}-V \\
& \Delta e(k)=e(k)-e(k-1)
\end{aligned}
$$

Sendo que $k$ denota os valores medidos no começo do $k^{\text {th }}$ ciclo de chaveamento.

As variáveis de entrada são normalizadas no intervalo de discurso $[-1,1]$, utilizando fatores de escala apropriados $\left(n_{e}\right.$ para $e(k)$ e $n_{\Delta e}$ para $\left.\Delta e(k)\right)$. Os valores dos fatores de normalização dependem do tipo de conversor utilizado. A saída do controlador fuzzy PD é uma variação inferida no ciclo de trabalho $\delta d(k)$ no $k^{\text {th }}$ tempo de amostragem com um fator de ganho $\eta$ conforme mostrado na Figura 4.7.

As funções de pertinência têm forma triangular e trapezoidal, por requererem poucos parâmetros e dessa forma necessitam de menos espaço em memória (DI PIAZZA et al., 2008). Os conjuntos fuzzy das variáveis de entrada e saída são iguais e simétricos, subdividindo-se em: PO (positivo), NE (negativo), ZE (zero), vide Figura 4.8.

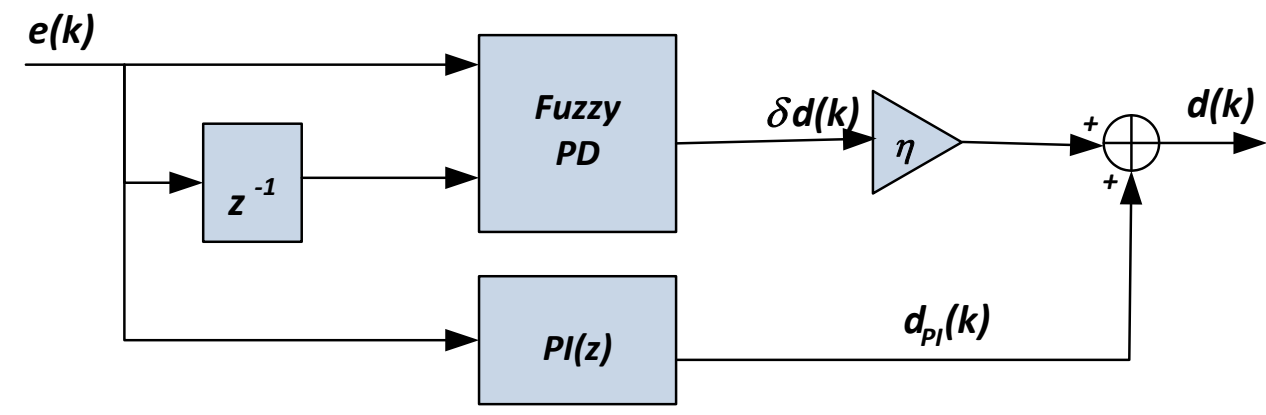

Figura 4.7. Esquemático do controlador Fuzzy PD+PI do conversor CC - CC. 


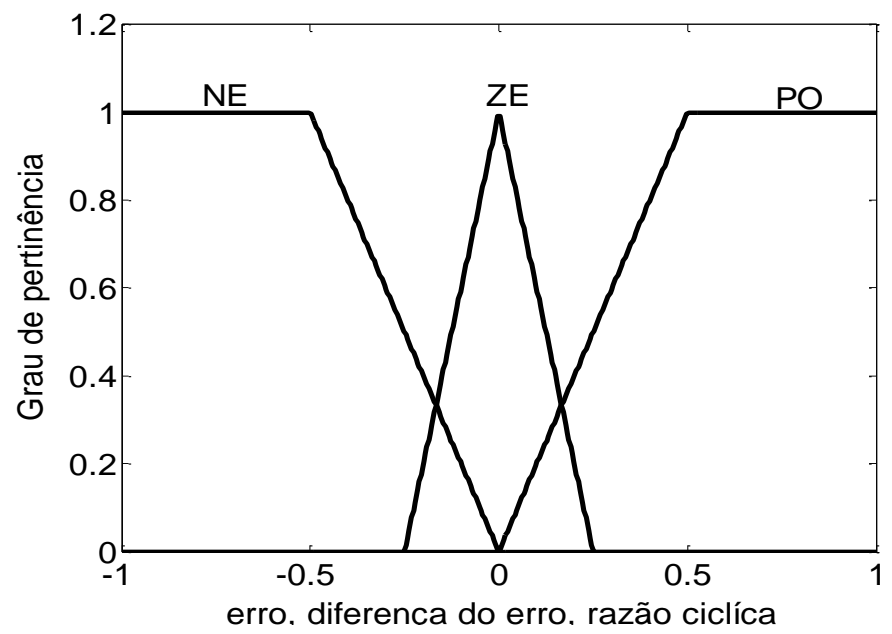

Figura 4.8. Funções de pertinência das variáveis de entrada e saída.

A construção da base de regras que relaciona a entrada fuzzy com a saída fuzzy depende do conhecimento sobre a dinâmica do sistema. As regras de controle proposto são apresentadas na Tabela 4.2.

Após a fuzzificação dos valores do par de entradas $(e(k), \Delta e(k))$, toma lugar o procedimento de inferência, resultando na região fuzzy de saída, que está relacionada com a saída do processo $\delta d(k)$. Basicamente, o procedimento de inferência consiste em:

1. encontrar todas as regras ativadas,

2. determinar a saída fuzzy para cada uma delas, aplicando a regra generalizada do tipo modus-pones (i.e. se $e(k) e<$ variável linguística $>$ e $\Delta e(k)$ é < variável linguística> então $\delta d(k)$ é < variável linguística>) e por fim;

3. agregar todas as regras fuzzy de saída.

Para a operação booleana "e" de cada regra ativada foi utilizado o operador produto e para a operação de inferência foi utilizado o operador minimum. Por sua vez, a agregação de todas as regiões fuzzy de saída foi implementada utilizando-se o operador maximum.

Finalmente, no processo de defuzzificação, para que se tenha um valor crisp na 
saída foi usado o método do centróide:

$$
\delta d=\frac{\sum_{k=1}^{N} \mu\left(V_{k}\right) * V_{k}}{\sum_{k=1}^{N} \mu\left(V_{k}\right)}
$$

onde $\mu$ é o grau de pertinência, $N$ é o número de pontos discretizados e $V_{k}$ é o elemento crisp do universo de discurso. A Figura 4.9 mostra a superfície de controle resultante.

No domínio discreto, o ciclo de trabalho no $k^{\text {th }}$ tempo de amostragem definido pelo controlador fuzzy $P D+P I$ é dado:

$$
d(k)=d_{P I}(k)+\eta \delta d(k)
$$

\begin{tabular}{|c|c|c|c|c|}
\hline \multirow{2}{*}{\multicolumn{2}{|c|}{$\delta d$}} & \multicolumn{3}{|c|}{$\bar{e}$} \\
\hline & & $\mathrm{NE}$ & ZE & $\mathrm{PO}$ \\
\hline \multirow{3}{*}{$\Delta e$} & $\mathrm{NE}$ & $\mathrm{PO}$ & ZE & $\mathrm{NE}$ \\
\hline & ZE & $\mathrm{PO}$ & ZE & $\mathrm{NE}$ \\
\hline & $\mathrm{PO}$ & $\mathrm{PO}$ & ZE & $\mathrm{NE}$ \\
\hline
\end{tabular}

Tabela 4.2 . Base de regras do sistema fuzzy.

Na Figura 4.10 é apresentada a resposta no tempo do controlador fuzzy $P D+P I$ - Observa-se que há uma melhora significativa da resposta transitória, levando o sistema a estabilizar muito rapidamente quando comparado ao controlador linear $P I$, entretanto ocorre um aumento do ripple e do erro em regime.

$\mathrm{Na}$ Figura 4.11 é mostrada a resposta utilizando apenas o controlador fuzzy. Como esperado, a ausência do integrador leva ao erro em regime permanente. 


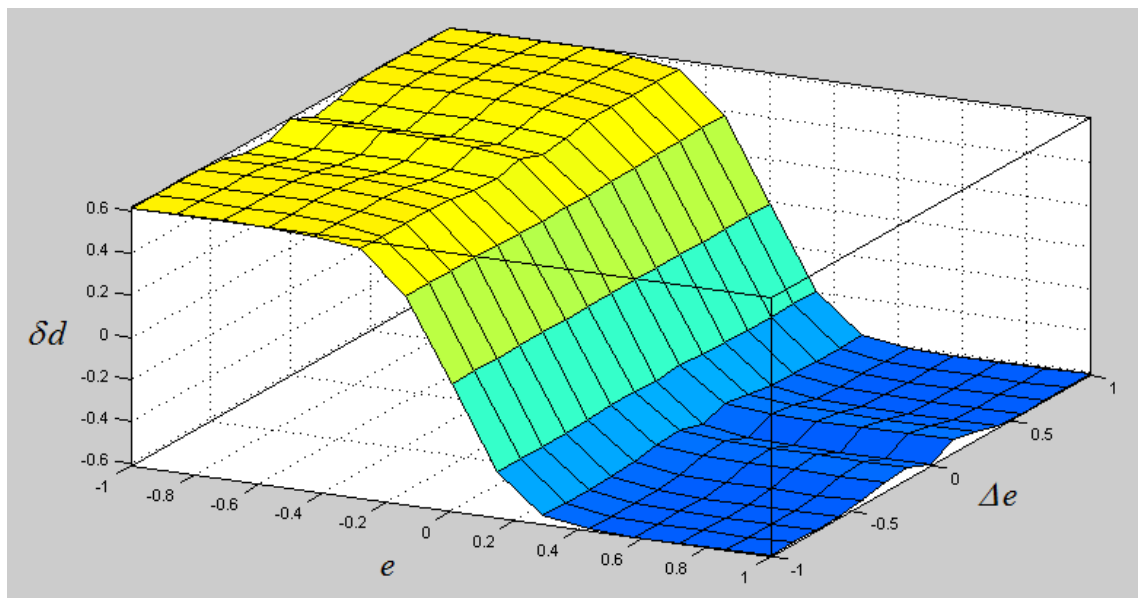

Figura 4.9. Superfície de controle do sistema fuzzy.

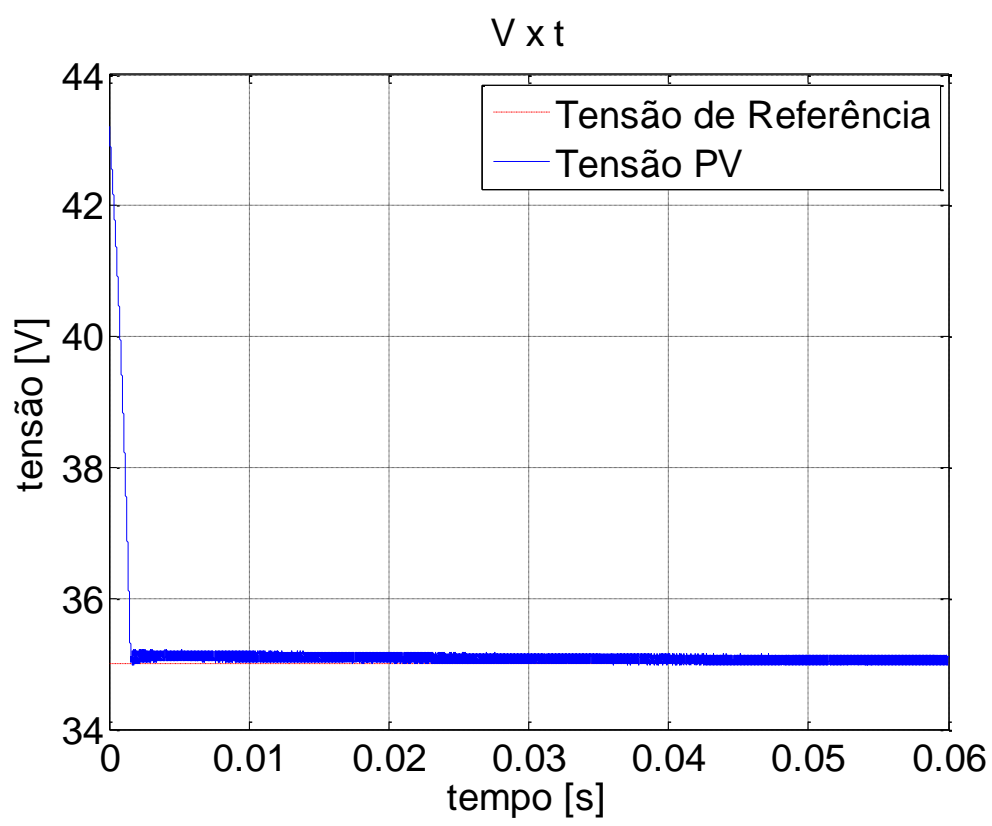

Figura 4.10. Resposta no domínio do tempo da tensão do painel fotovoltaico (linha contínua) usando o controlador Fuzzy $P D+P I$ para uma referência de $V_{R E F}=35 \mathrm{~V}$ (linha pontilhada). Ts=1 $\mu s$, ripple $=0,23 \mathrm{~V}$. 


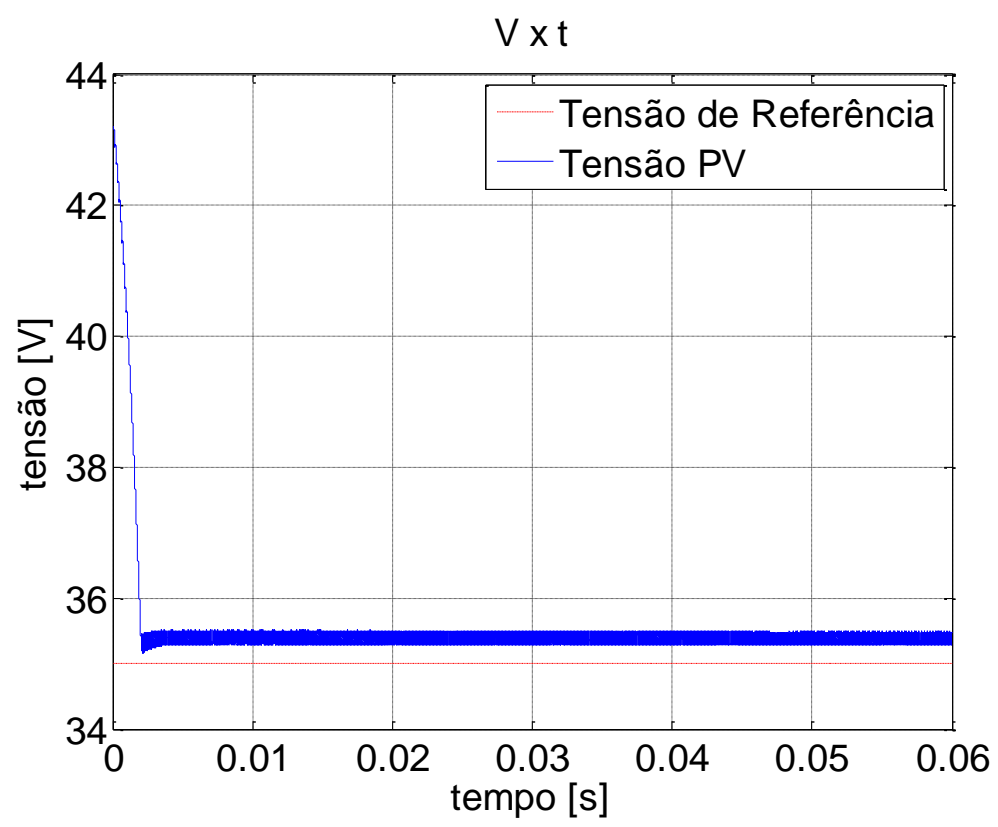

Figura 4.11. Resposta no domínio do tempo da tensão do painel fotovoltaico (linha contínua) usando apenas o controlador fuzzy $P D$ para uma referência de $V_{R E F}=35 V$ (linha pontilhada). $T s=1 \mu s$, ripple $=0,23 \mathrm{~V}$.

\subsection{Considerações Finais}

O tempo de estabilização e o sobressinal em malha fechada podem desempenhar um papel importante no rendimento em sistemas fotovoltaicos, uma vez que a tensão de referência varia constantemente em função do MPPT e das condições ambientais.

Neste capitulo, foi definido um controlador linear PI e efetuadas análises de estabilidade do sistema em malha fechada. Além disso, projetou-se um controlador não linear fuzzy PD com o papel de atuar paralelamente ao controlador Pl. Descreveu-se detalhadamente o controlador fuzzy e apresentaram-se às respostas no tempo que demonstram uma melhora significativa em termos de sobressinal e tempo de estabilização.

Contudo, a resposta transitória e a resposta em regime do sistema estão atreladas entre si, de modo que se por um lado ocorreu uma diminuição do sobressinal 
e o do tempo de estabilização, em contrapartida o ripple e o erro em regime foram ligeiramente afetados. 


\section{Bancada Experimental e Análise de Resultados}

\subsection{Introdução}

Para validar o sistema de controle apresentado no Capítulo 4, foi construída uma bancada experimental composta por um conversor elevador de tensão alimentado por painéis fotovoltaicos, com potência nominal de $260 \mathrm{~W}$, e conectado a um banco de resistências. Como forma de verificar o desempenho do sistema empregado nessa dissertação, serão apresentados e comparados resultados experimentais com simulações do painel fotovoltaico + conversor CC-CC. Além disso, são descritos detalhes relevantes referentes à montagem em bancada.

\subsection{Descrição da Bancada Experimental}

Nesta seção são descritos de forma geral os principais elementos utilizados na bancada de ensaios mostrada na Figura 5.1.

\section{FONTE FOTOVOLTAICA}

Duas fontes foram utilizadas na bancada experimental: (1) painéis fotovoltaicos KC130TM fabricados pela Kyocera (vide Figura 5.2) e (2) módulo simulador de matriz solar E4360A Modular Solar Array Simulator mainframe (SAS) fabricado pela Agilent Technologies (vide Figura 5.3).

O SAS tem capacidade máxima de $1200 W$ e gera curvas I - $V$ mediante a definição de três pontos: tensão de circuito aberto, corrente de curto circuito e o ponto de máxima potência. Além disso, o SAS permite que curvas I - $V$ sejam geradas mediante uma tabela de pontos definida pelo usuário. 


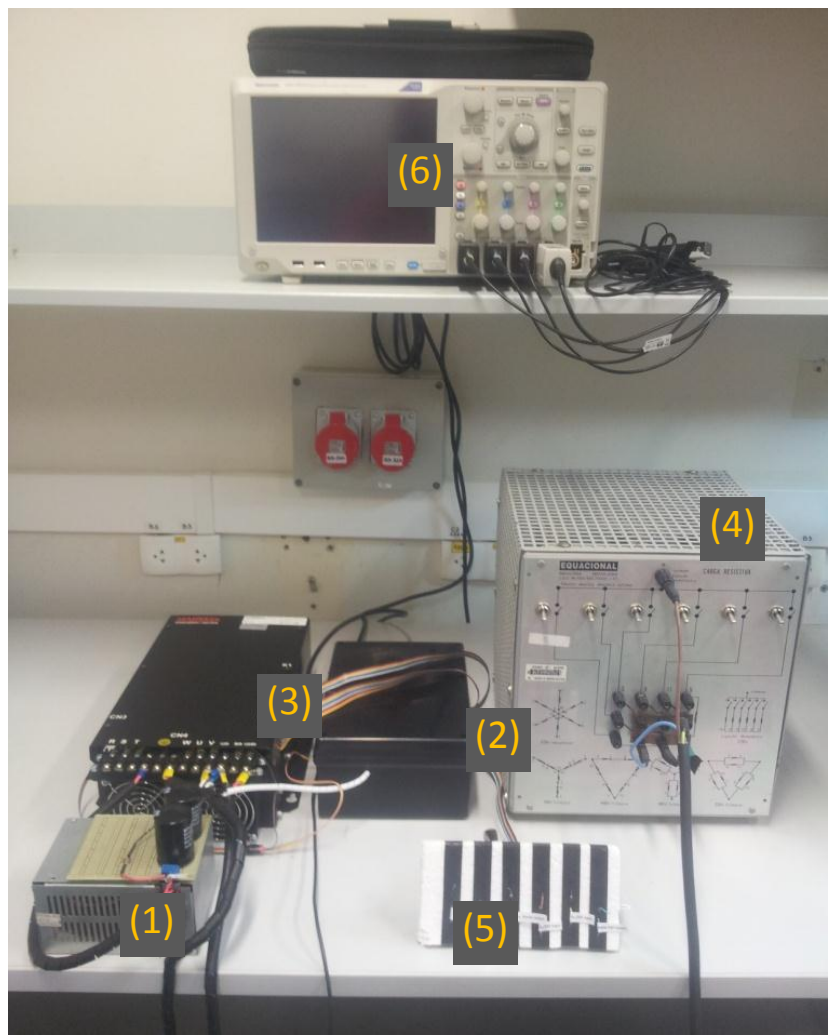

Figura 5.1. Visão geral da bancada experimental: (1) Indutor e capacitor na entrada do conversor. (2) Módulo responsável pelo condicionamento dos sinais analógicos, processamento digital e drivers do chave. (3) Inversor trifásico de IGBT's. (4) Carga resistiva. (5) Sinais disponíveis para medição. (6) Osciloscópio.

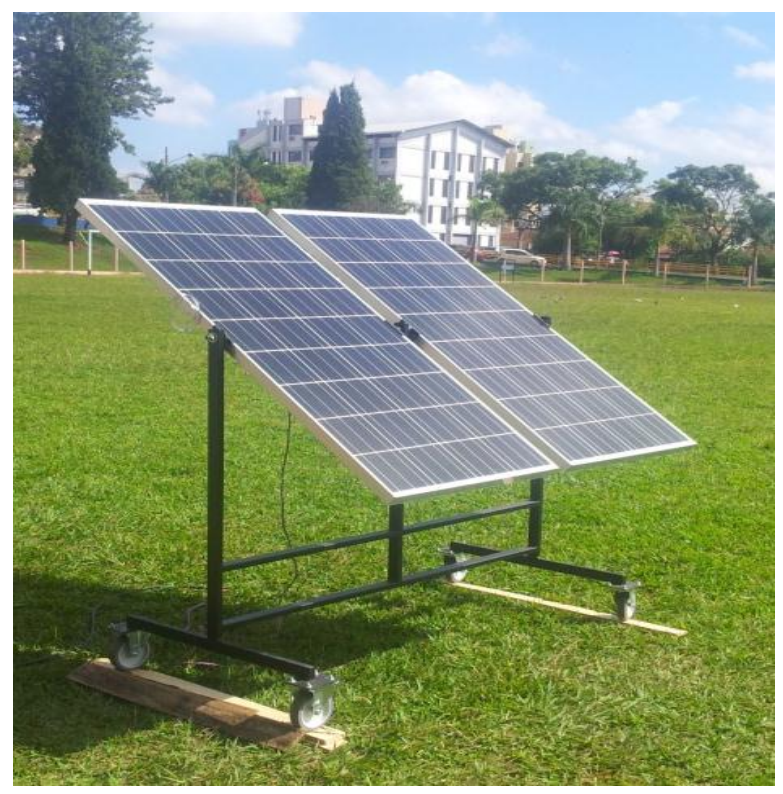

Figura 5.2. Painéis fotovoltaicos instalados em suporte móvel. 


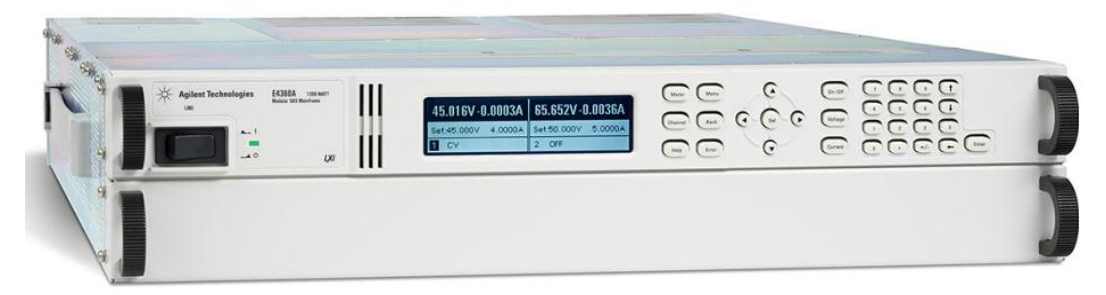

Figura 5.3. Módulo simulador de matriz solar. Fonte: figura extraída do www.home.agilent.com.

O módulo fotovoltaico KC130TM é do tipo policristalino de silício, fabricado pela Kyocera, possui 36 células conectadas em série e divididas em dois grupos. Em paralelo com cada grupo estão conectados diodos de passagem (bypass). Nos testes realizados, são utilizados dois módulos KC130TM conectados em série e instalados em um suporte metálico móvel, tendo cada painel movimento independente com um grau de liberdade, conforme mostrado na Figura 5.2. As especificações elétricas do conjunto fotovoltaico foram apresentadas nas Tabelas 3.1 e 3.3.

\section{(1) ELEMENTOS PASSIVOS}

Nos terminais dos painéis fotovoltaicos foi utilizada uma associação de capacitores eletrolíticos com capacitância equivalente $C=980 \mu F$ e ESR (equivalent series resistance) $r_{C}=145 \mathrm{~m} \Omega$ (calculado mediante os dados do folheto do fabricante) e são responsáveis por filtrar as ondulações na tensão da entrada do conversor. O filtro passa - baixa na saída do conversor é composto pelo indutor de ferrite colocado no interior de uma estrutura metálica isolada para redução de interferências eletromagnéticas, de indutância $L=5 \mathrm{mH}$ com resistência série medida de $r_{L}=0,4 \Omega$ e pelo o banco de capacitores eletrolíticos na saída que possui uma capacitância equivalente de $C_{o}=1360 \mu \mathrm{F}$ incorporada ao barramento CC do módulo de IGBT SKS 21F B6U+E1CIF+B6Cl 12V12 fabricado pela SEMIKRON. 
(2) CONDICIONAMENTO, PROCESSAMENTO DE SINAIS E ACIONAMENTO DAS CHAVES

Para a aquisição do sinal analógico de corrente na entrada do conversor é usado o sensor de efeito hall que está incorporado ao módulo de IGBT's da Semikron, enquanto que o sinal analógico de tensão na entrada do conversor é obtido por meio de um divisor resistivo com resistência equivalente de $11 \mathrm{k} \Omega$ e tolerância de $2 \%$. Ambos os sinais são transferidos para placa de sensores de condicionamento de sinais (com saída em tensão compreendida entre 0 e $3 V$ ), mostrada em (2.1) na Figura 5.4. Posteriormente, os sinais condicionados são lidos pelo conversor analógico - digital (A/D) do sistema de processamento, vide (2.2) na Figura 5.4. As funções de filtragem digital (média móvel), algoritmos de busca do PMP (P\&O e InC) e do sistema de controle da tensão terminal do painel (controlador fuzzy PD $+\mathrm{PI}$ ) foram implementados em kit experimental Delfino TMS320F28335 fabricado pela Texas Instruments. O sinal digital de PWM gerado, internamente no $D S P$, é sincronizado com o módulo $A / D$ operando a uma frequência de $10 \mathrm{kHz}$. O sinal modulado do $D S P$ é fornecido a uma placa de acionamento, vide (2.3) da Figura 5.4, responsável pela interface que equaliza os níveis de tensão da saída do modulador ( 0 a $3 V$ ) com os níveis de tensão de acionamento dos drivers ( 0 a $15 \mathrm{~V}$ ) e também pela alimentação do sensor hall de corrente.

As placas de condicionamento de sinais analógicos, de processamento de sinais digitais e de acionamento das chaves foram acopladas em um único módulo, facilitando o uso em campo, como mostrado na Figura 5.5.

\section{(3) CHAVES}

A configuração SPDT (Single Pole Double Throw) do conversor CC foi feita usando um dos braços do módulo IGBT da SEMIKRON, com capacidade de condução de $21 \mathrm{~A}$ e tensão reversa do diodo de $1200 \mathrm{~V}$ (dados do folheto do fabricante), vide Figura 5.6. 


\section{(4) CARGA}

A carga utilizada nos testes é estática e puramente resistiva, possui chaves seletoras que permitem diferentes associações do banco de resistências, com capacidade máxima de $400 \mathrm{~W}$ (vide Figura 5.6).

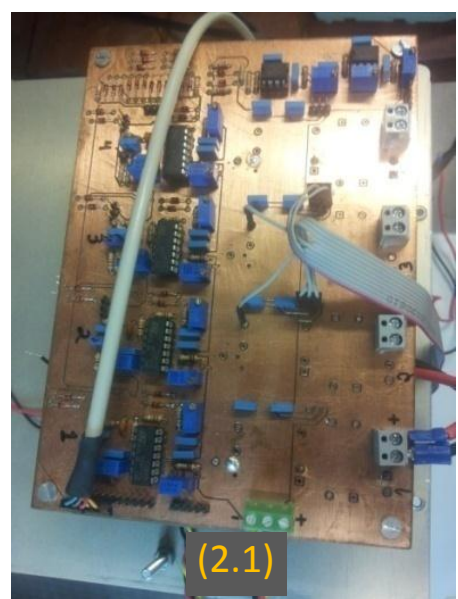

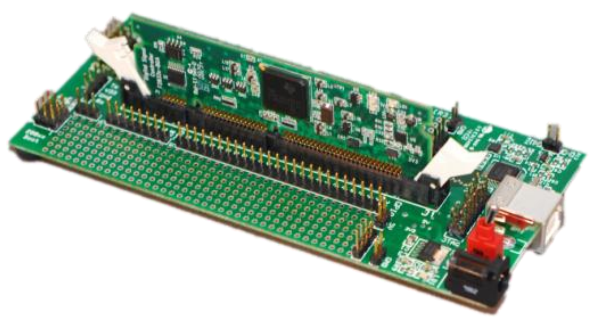

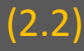

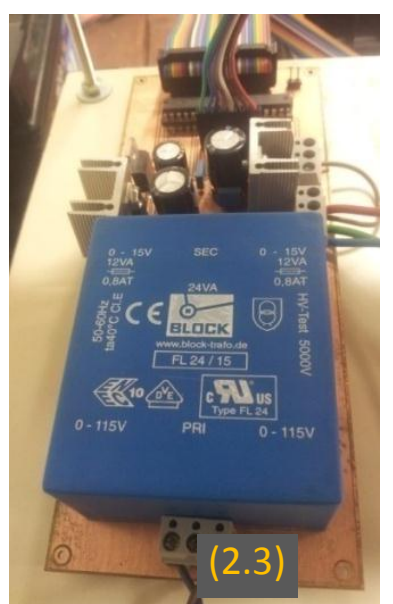

Figura 5.4. (2.1) placa de sensores e condicionamento de sinais analógicos; (2.2) placa de processamento digital; (2.3) placa de acionamento dos drivers e alimentação do sensor hall.
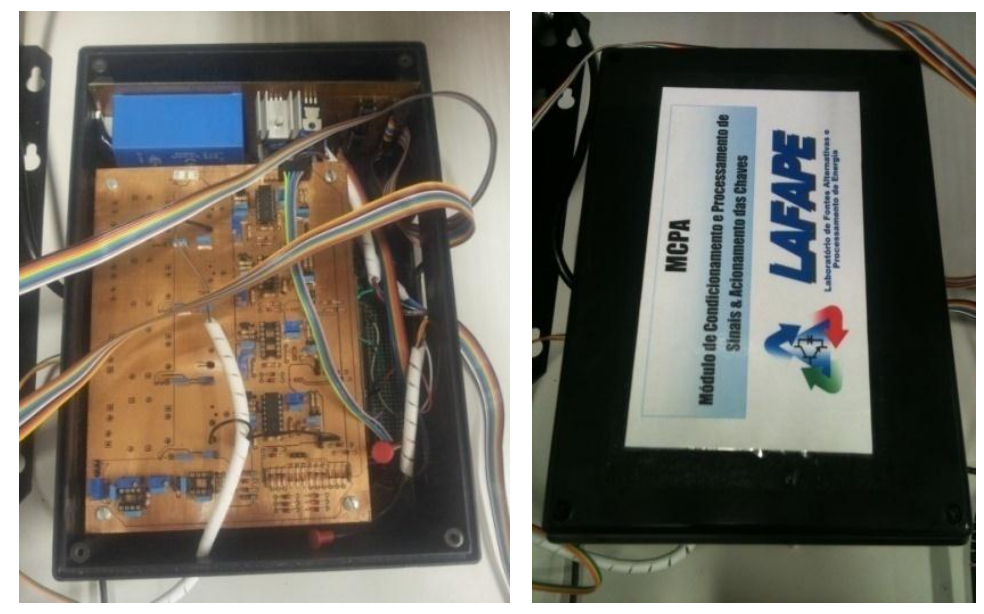

Figura 5.5. Módulo contendo as placas de condicionamento, processamento, acionamento e saídas para medições. 


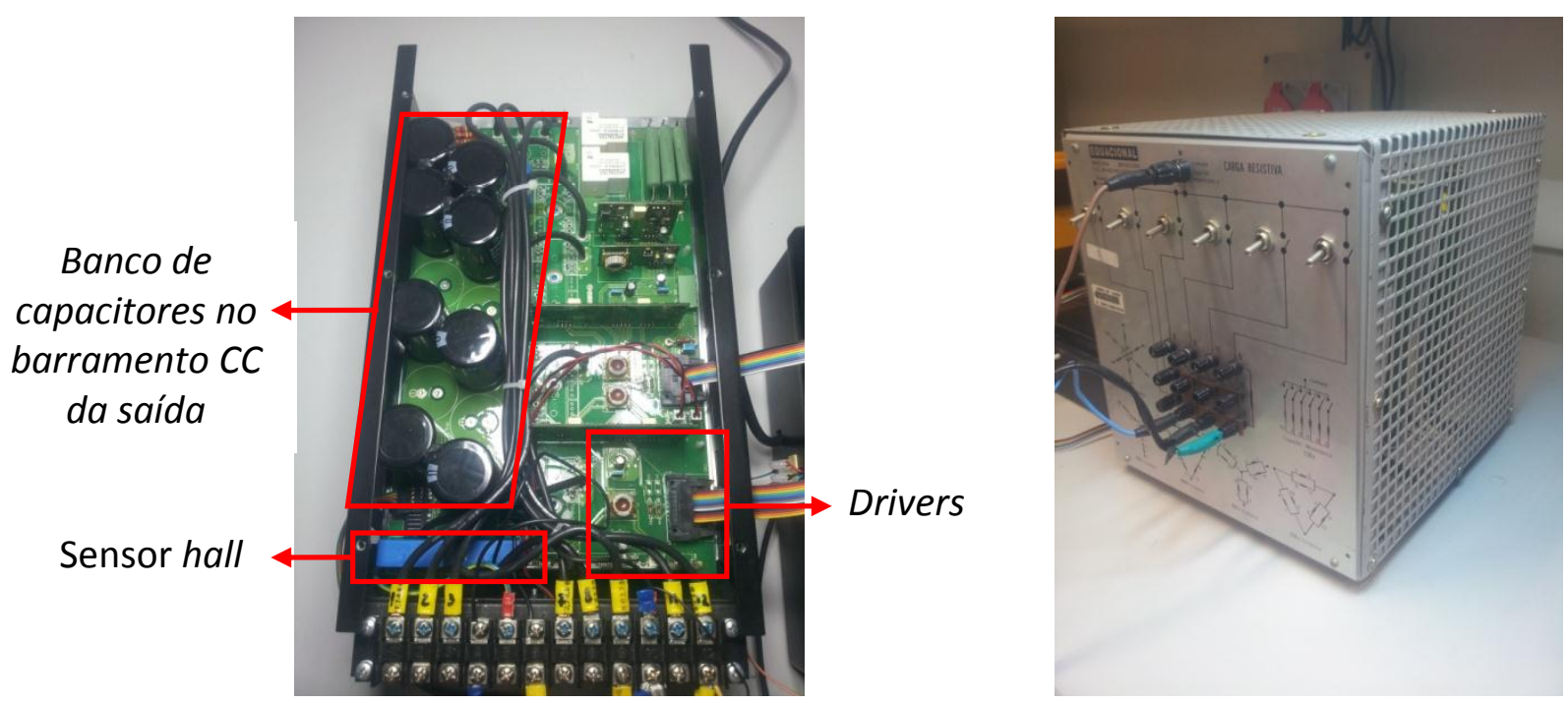

Figura 5.6. Inversor trifásico de IGBT's e carga estática resistiva.

\subsubsection{Considerações Importantes}

Nesta seção são abordados alguns dos critérios considerados para a implementação do sistema de controle da tensão terminal dos painéis fotovoltaicos.

\section{REGIÃO DE OPERAÇÃO}

O ponto de operação do sistema fotovoltaico proposto é definido pela intersecção da curva de carga pela curva da fonte geradora em uma determinada condição de irradiação e temperatura. Coelho, Concer e Martins (2009) analisam as regiões de operação do MPPT em função da carga e da razão cíclica. Assim, baseando-se neste mesmo estudo e conhecidas à carga nominal $\left(R_{o}=87 \Omega\right)$ e a razão cíclica $(D=0,76)$, determinou-se a região de operação do $M P P T$, que corresponde aos pontos compreendidos entre $\left[\arctan \left(1 / R_{O}\right), 90^{\circ}\right]$, i.e., $\left[0,66^{\circ}, 90^{\circ}\right]$. O limite inferior $\left[0,66^{\circ}\right]$ possui um valor desprezível, de modo que o MPPT operará em toda a região da curva, como se observa na f $90^{\circ} 5.7$. 


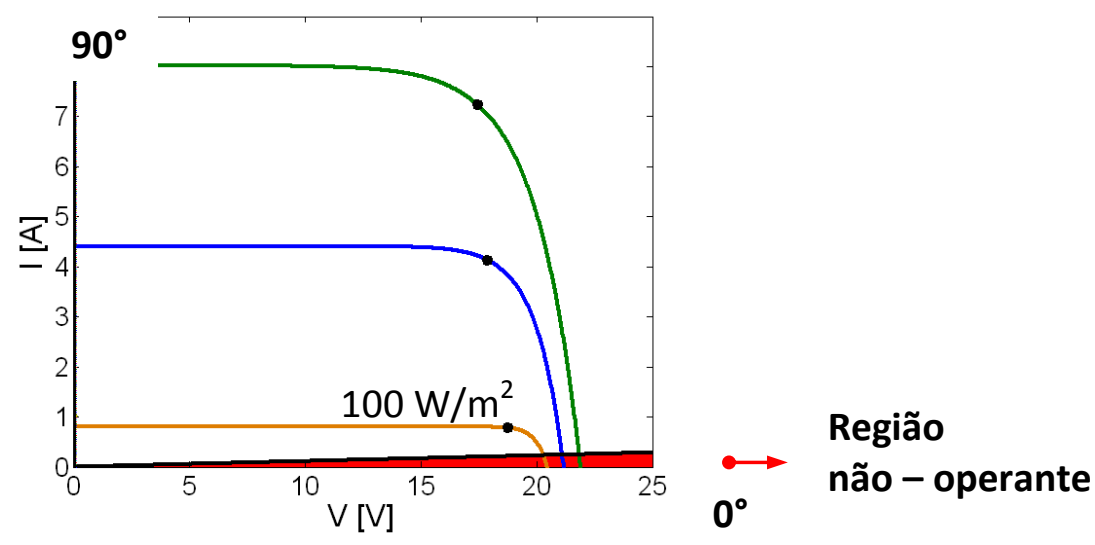

Figura 5.7. Região de operação do MPPT.

\section{SISTEMA FUZZY EMBARCADO EM DSP}

$O$ desenvolvimento de reguladores lineares em um $D S P$, tal como o controlador proporcional integral apresentado anteriormente, é simples e requer pouco espaço de memória. Por outro lado, cuidados adicionais devem ser tomados ao se desenvolver um sistema fuzzy que opere com reduzidos tempos de execução, pouca quantidade de memória e uma alta resolução.

Ao adotar funções de pertinência lineares (triangular ou trapezoidal), o uso de variáveis do tipo inteira (int) e de conjuntos fuzzy simétricos e normalizados, permitem que sejam feitas simplificações na execução do programa ou código. Esses critérios foram considerados na fuzzificação das variáveis de entrada e no processo de inferência. Por outro lado, para a obtenção da resposta fuzzy final, gerada no processo de defuzzificação, pelo método do centro de área (centróide) apresentado na equação (26), desenvolveu-se uma técnica que busca o compromisso entre alta resolução e baixo tempo de execução, porém com pequeno aumento do custo computacional.

De forma sucinta, a técnica utilizada propõe a identificação e parametrização da agregação das regiões fuzzy de saída, resultante do processo de inferência, em termos de figuras geométricas mais simples (triângulos, retângulos e trapézios), cujas fórmulas de centros de área são bem conhecidas. Deste modo, determina-se o centro da área total, combinando os centróides de cada figura geométrica ("F1", "F2" e "F3" na Figura 5.8).

Este procedimento permitiu obter a resposta exata do centro de área total, sem o uso de laços de repetição (do tipo "for", "while" e "do while") que consomem 
considerável tempo de execução do código e memória. Além disso, não se empregou o método tradicional que indexa uma tabela de todos os pontos discretos possíveis de entrada e saída, uma vez que, neste procedimento é necessária uma elevada disponibilidade de memória (SUETAKE, 2008).

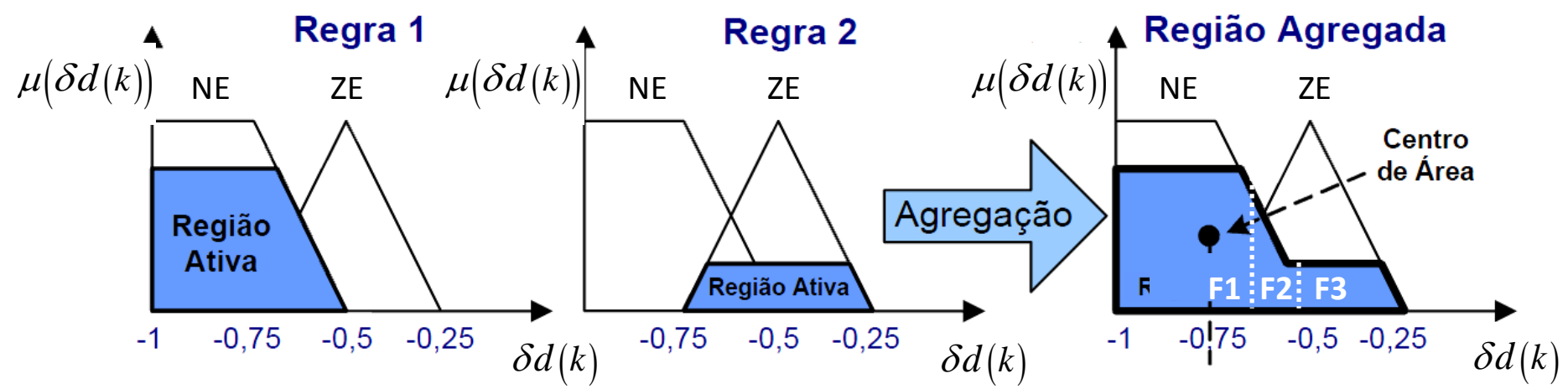

Figura 5.8. Agregação e defuzzificação. Fonte: Suetake (SUETAKE, 2008). $\delta d$

$\delta d$

\subsection{Simulações}

As simulações do sistema proposto foram realizadas utilizando o software Simulink do MATLAB ${ }^{\mathrm{TM}}$, porém, nas simulações, foi considerado apenas o algoritmo de $\mathrm{P} \& O$.

\subsubsection{Determinação das Condições Iniciais e do Tempo de Amostragem do MPPT}

Neste item são abordados os critérios usados para estabelecer as condições iniciais dos elementos passivos e sobre o tempo mínimo entre as amostragens realizadas pelo MPPT.

\section{CONDIÇÃO INICIAL DOS ELEMENTOS PASSIVOS}

Diferentemente das condições ideais, na prática, o ganho de tensão no conversor elevador de tensão diminui à medida que a razão cíclica (região na qual o ciclo de trabalho é superior a $80 \%$ ) se aproxima da unidade, em geral, o ganho máximo está na ordem de cinco a seis vezes a tensão de entrada (MOHAN; UNDELAND; ROBBINS, 1995). Conseqüentemente, apesar do controlador fuzzy PD + PI ter sido 
projetado para operar em diferentes tensões na vizinhança do $P M P$, se a referência estiver muito distante do $P M P$, maior será o sobressinal e o tempo de estabilização. Assim sendo, é necessário estimar a tensão inicial dos capacitores na entrada e saída do conversor e a corrente inicial do indutor, aproximando a simulação das condições práticas.

Para isso, admite-se que o conversor esteja inicialmente desligado, desta forma após um longo período de tempo (maior do que seis vezes da constante de tempo) o capacitor se carrega com a tensão do circuito aberto do painel $\left(V_{o c}\right)$ e a corrente no indutor se reduz a zero. Admite-se que o capacitor na saída esteja desconectado da carga e, portanto, inicia com a tensão de circuito aberto $(150 \mathrm{~V})$.

\section{ESCOLHA DO INTERVALO DO TEMPO DE AMOSTRAGEM DO MPPT}

O intervalo de tempo da amostragem $T_{\alpha}$ utilizada pelo MPPT deve ser maior que um tempo mínimo garantindo que o sistema fotovoltaico tenha estabilizado e reduzindo o número de oscilações em torno do $P M P$ em regime permanente. Em (FEMIA et al., 2005) é demonstrado que o tempo mínimo é aproximadamente de:

$$
T_{\varepsilon} \cong-\frac{\sqrt{L C}}{\xi} \ln (\varepsilon)
$$

onde $\xi$ é o fator de amortecimento. Normalmente $\varepsilon=0,1$ é considerado um valor razoável para assumir que o transiente esteja finalizado (FEMIA et al., 2005). Por outra, o fator de amortecimento é dado por:

$$
\xi=\frac{1}{2} \frac{I_{m p}}{V_{m p}} \sqrt{\frac{L}{C}}+\left(\frac{r_{C}+r_{L}}{2}\right) \sqrt{\frac{C}{L}}
$$

Usando as Tabelas 3.1 e 3.2 resulta em $\xi=0,3130$ e $T_{0,1}=16,5 \mathrm{~ms}$, portanto $T_{\alpha} \geq T_{0,1}$. Nas simulações e nos experimentos utilizou-se $T_{\alpha}=17 \mathrm{~ms}$. 


\subsubsection{Dinâmica do Sistema}

Iniciando com o capacitor na entrada carregado com a tensão de circuito aberto do painel fotovoltaico $\left(V_{o c}\right)$ e sem corrente residual no indutor, o algoritmo $\mathrm{P} \& \mathrm{O}$ inicialmente perturba (aumentando) a tensão de referência do controlador fuzzy PD + PI e "observa" que a potência drenada do painel diminui, significando que a referência se afastou do $P M P$, desta forma o algoritmo começa a decrescer a referência até atingir o $P M P$. Neste momento, o sistema entra em regime permanente e oscila em torno do PMP conforme é mostrado na Figura 5.9 quando é utilizado passo fixo ou com passo variável como é mostrado na Figura 5.10. Como pode ser visto, o controlador tem um bom desempenho, com sobressinal igual a zero e tempo de estabilização menor que 17 ms, levando o sistema rapidamente ao regime permanente (FEMIA et al., 2005) e aumentando a eficiência na geração.
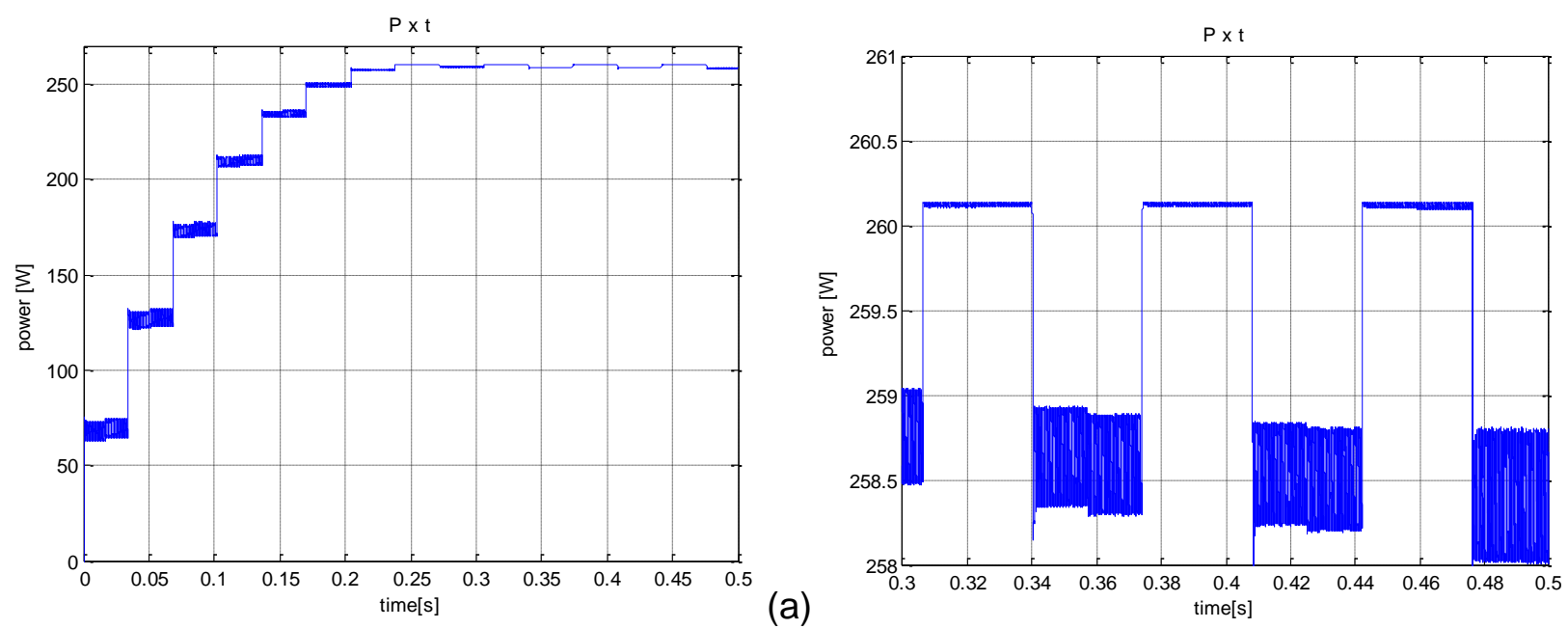

(a) 

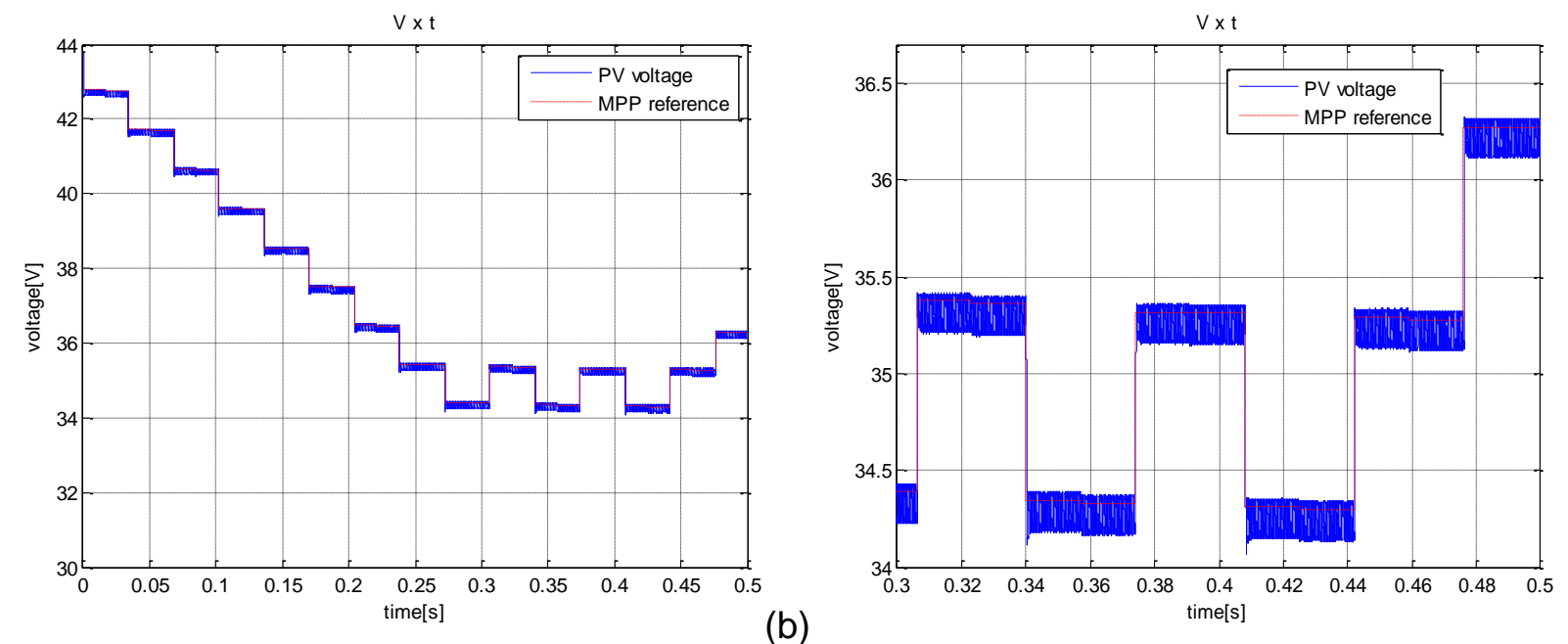

Figura 5.9. Simulações no domínio do tempo para $G=1000 \mathrm{~W} / \mathrm{m}^{2}$ e $T=298,15 \mathrm{~K}$, com passo fixo $=[1,0] \mathrm{V}, T_{\alpha}=17 \mathrm{~ms}$. (a) Curva de potência (b) Curva de tensão.
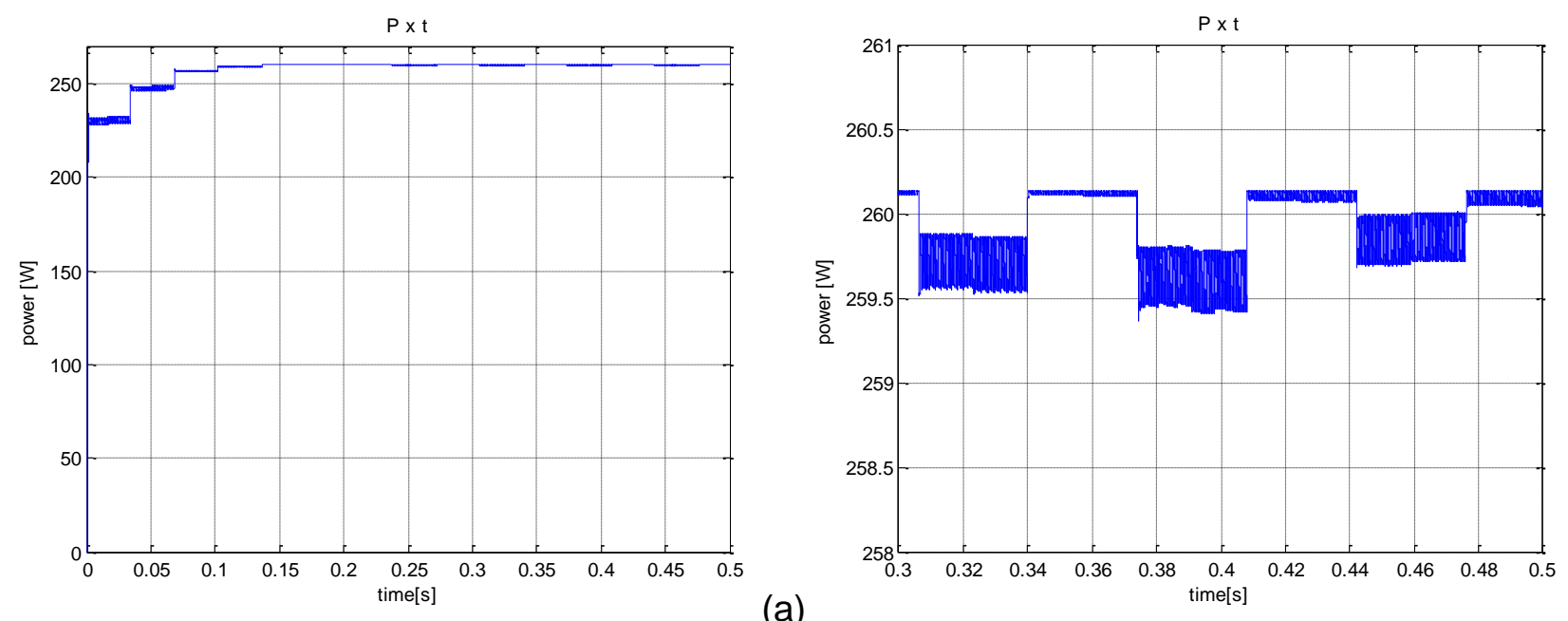

(a) 


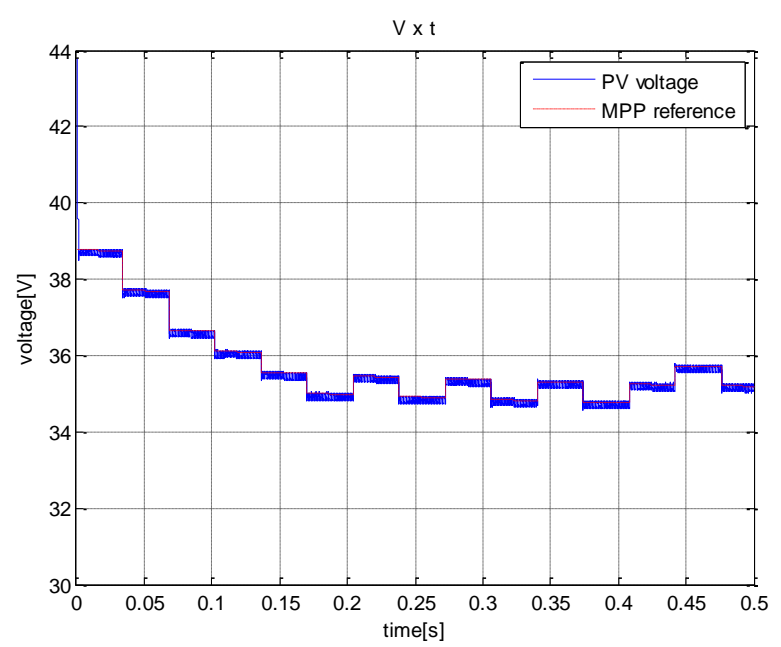

(b)

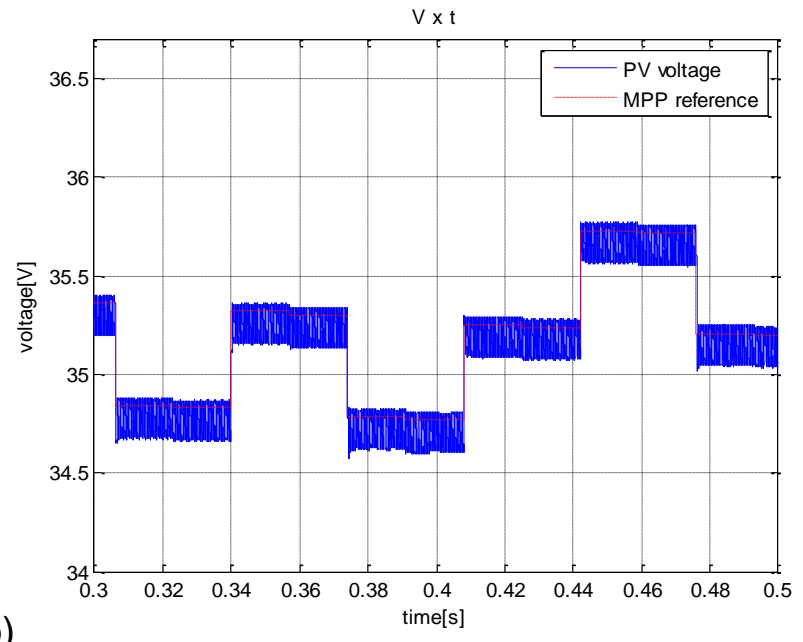

Figura 5.10. Simulações no domínio do tempo para $G=1000 \mathrm{~W} / \mathrm{m}^{2}$ e $T=298,15 \mathrm{~K}$, com passo variável $=\left[\begin{array}{lll}5,0 & 1,0 & 0,5\end{array}\right] \mathrm{V}, T_{\alpha}=17 \mathrm{~ms}$. (a) Curva de potência (b) Curva de tensão.

\subsubsection{Rápidas Mudanças nas Condições de Irradiação e Temperatura}

Em dias parcialmente nublados ocorrem rápidas mudanças na irradiação, o que leva o algoritmo P\&O a confundir-se, diminuindo a sua eficiência na busca do PMP. Esta situação ocorre se a variação da irradiação $\Delta G$ produzir uma variação de potência $\Delta P_{G}$ maior do que a gerada pelo passo do algoritmo do MPPT $\Delta P_{\text {passo }}$ (FEMIA et al., 2005). As simulações apresentadas nas Figuras 5.11 e 5.12 demonstram que $\Delta G$ afeta, significativamente, $P$ ao contrário da variação gerada por $\Delta T$. 


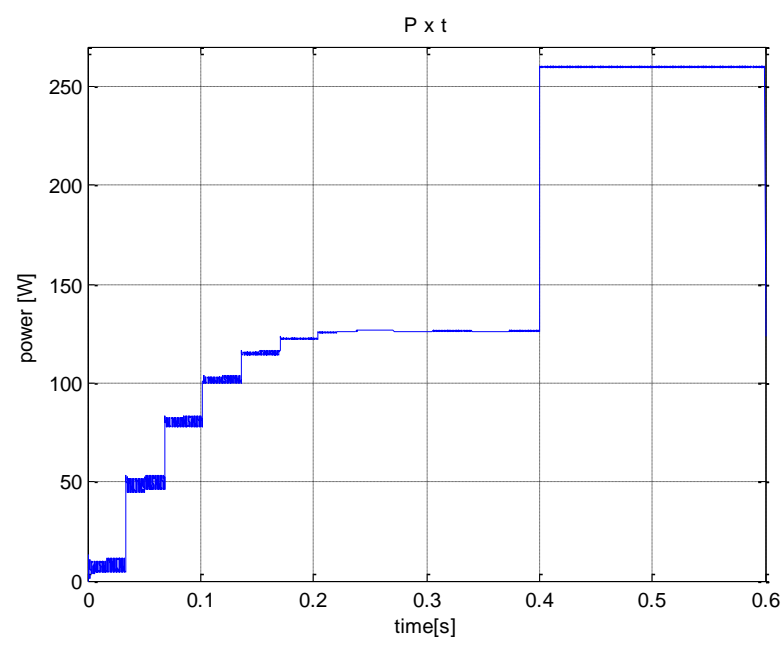

(a)

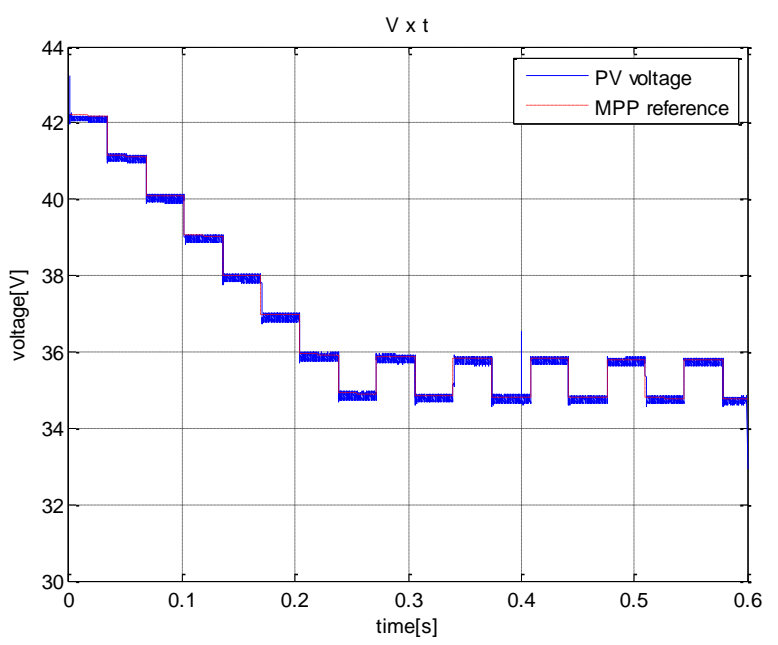

(b)

Figura 5.11. Rápidas mudanças na irradiação no instante 0,4 s, $G=500 \mathrm{~W} / \mathrm{m}^{2}$ (antes de 0,4 s) e $G=1000 \mathrm{~W} / \mathrm{m}^{2}$ (depois de 0,4s), $T=298,15 \mathrm{~K}, T_{\alpha}=17 \mathrm{~ms}$ : (a) Curva de potência (b) Curva de tensão.

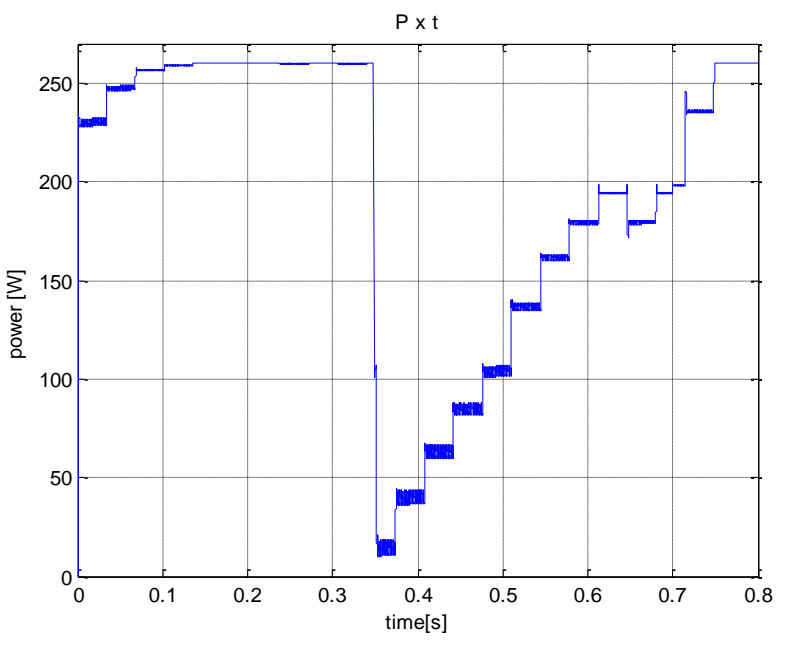

(a)

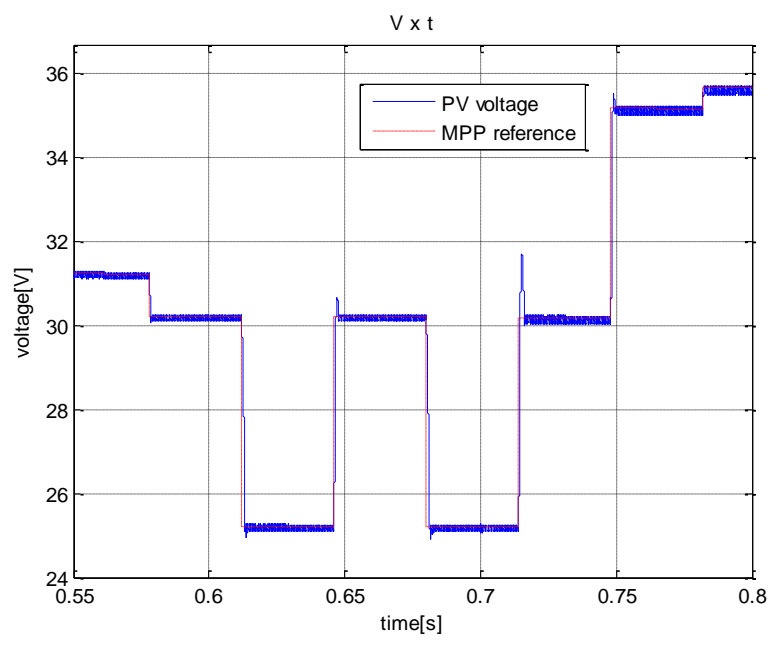

(b)

Figura 5.12. Rápidas mudanças na temperatura no instante $0,35 \mathrm{~s}, t=25^{\circ} \mathrm{C}$ (antes de $0,35 \mathrm{~s}$ ) e $t=75^{\circ} \mathrm{C}$ (depois de 0,35 s), $G=1000 \mathrm{~W} / \mathrm{m}^{2}, T_{\alpha}=17 \mathrm{~ms}$ : (a) Curva de potência (b) Curva de tensão. 
102

\subsubsection{Perturbações na Carga}

O sistema fotovoltaico estudado neste trabalho foi projetado para trabalhar associado a um carregador de bateria. No entanto, em muitas aplicações em geração distribuída o sistema fotovoltaico está conectado com a rede através de um inversor. $\mathrm{Na}$ Figura 5.13 é simulado o sistema fotovoltaico com uma fonte CA de amplitude de $40 V_{p p}$ em série com o link CC com o objetivo de verificar o comportamento do controlador fuzzy PD + PI e do comportamento do sistema fotovoltaico como uma fonte de tensão em geração distribuída.
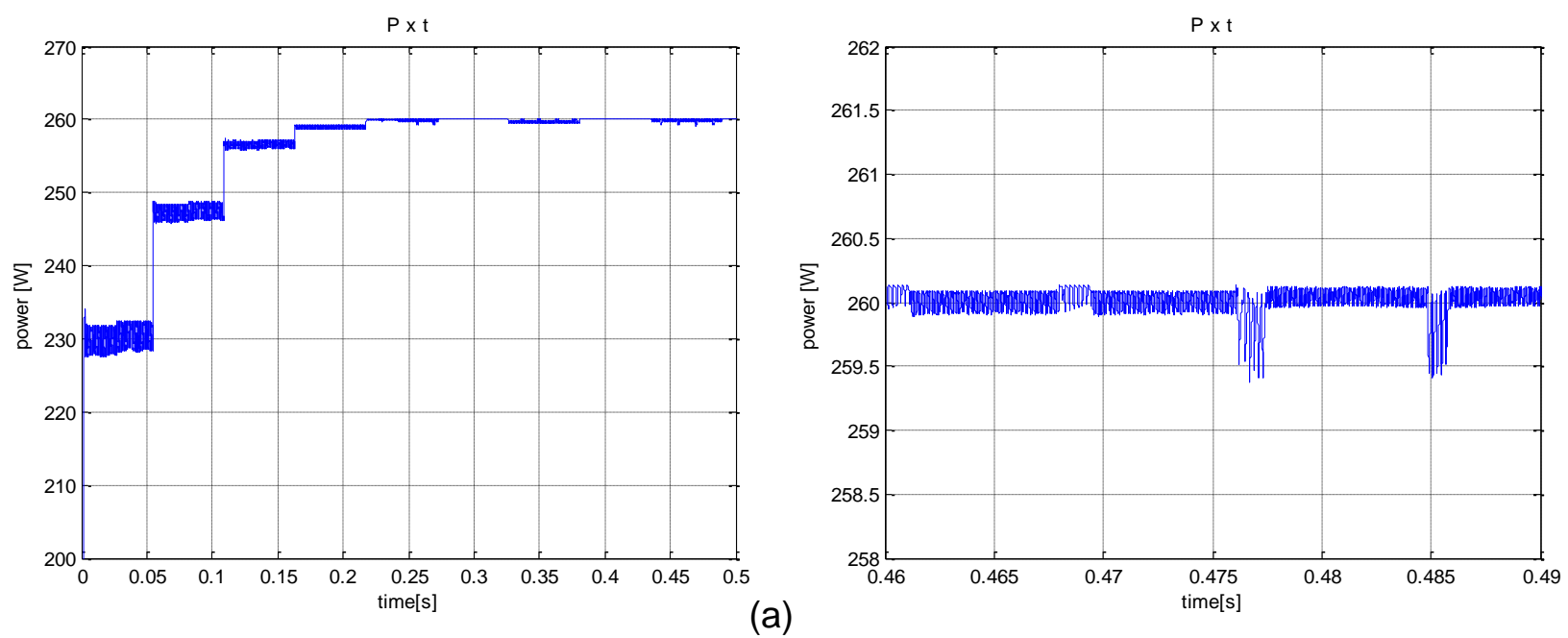

(a) 


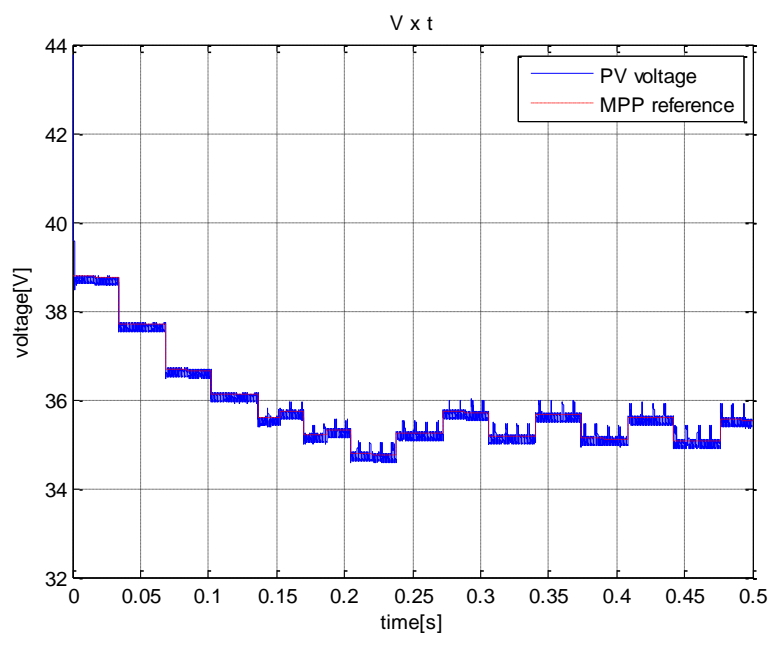

(b)

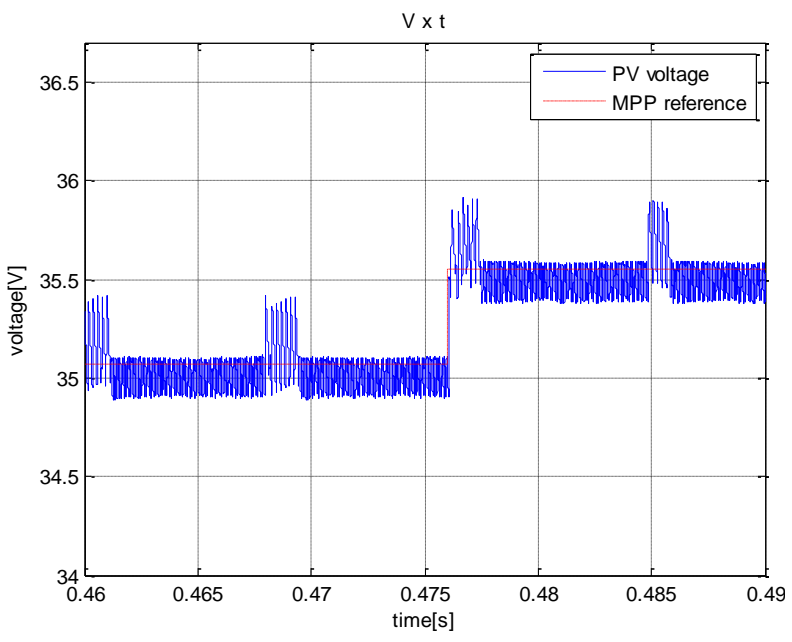

Figura 5.13. Simulação do sistema fotovoltaico com fonte de tensão $A C$ ( $V_{A C}=40 \mathrm{Vpp}$, $\left.f_{A C}=120 \mathrm{~Hz}\right)$ em série com o barramento CC $\left(V_{O}=150 \mathrm{~V}\right)$, para $G=1000 \mathrm{~W} / \mathrm{m}^{2}$, $T=298,15 K, T_{\alpha}=17 \mathrm{~ms}$ : (a) Curva de potência (b) Curva de tensão. 


\subsection{Resultados Experimentais}

Nesta seção são mostrados e analisados os resultados dos testes realizados em laboratório com a fonte SAS e no campo com os painéis fotovoltaicos. Para avaliar o desempenho do sistema fotovoltaico, cada controlador foi testado separadamente ( $P I$, fuzzy $P D$ e fuzzy $P D+P I)$. Além disso, os mesmos foram submetidos a três tipos de buscas: (1) para uma referência fixa, (2) utilizando o algoritmo da perturbação e observação e (3) utilizando o algoritmo da condutância incremental.

\section{Ensaios realizados em laboratório}

Para a realização dos testes em laboratório, primeiramente, determinou-se a resposta em malha aberta do sistema fotovoltaico com o SAS, variando como entrada a razão cíclica do conversor e observando como a tensão e corrente dos painéis se comportava. Este teste foi realizado com o objetivo de verificar e compreender a relação entre a variável de controle (razão cíclica) e a saída da planta (tensão terminal nos painéis fotovoltaicos). Os resultados do teste são apresentados no Apêndice A.

Os experimentos em laboratório foram realizados simulando a condição de irradiação de aproximadamente $630 \mathrm{~W} / \mathrm{m}^{2}$ uma vez que fonte $S A S$ usada tem como corrente de curto circuito $I_{s c}=5,1 \mathrm{~A}$. Desta forma, configurou-se a fonte para operar com os parâmetros $V_{m p}=35,2 \mathrm{~V}, I_{m p}=4,08 \mathrm{~A}$ e $V_{o c}=43,8 \mathrm{~V}$ nestas condições a máxima potência é de $P_{m p} \approx 140 \mathrm{~W}$.

As Figuras 5.14, 5.15 e 5.16, mostram respectivamente, a resposta ao degrau na entrada dos controladores $P I$, fuzzy $P D$ e fuzzy $P D+P I$ para uma tensão de referência $V_{R E F}=35 \mathrm{~V}$. Observa-se que o após o degrau na entrada o sistema utilizando o controlador $P I$ entra em regime permanente em aproximadamente $600 \mathrm{~ms}$, enquanto que utilizando o controlador fuzzy $P D$ e o controlador combinado fuzzy $P D+P I$ o sistema entra em regime permanente em um tempo inferior a $40 \mathrm{~ms}$. Além disso, nota-se que ondulação na tensão - ripple - utilizando somente o controlador $\mathrm{Pl}$ é de aproximadamente $0,8 \mathrm{~V}$ enquanto que o ripple utilizando 
separadamente o controlador fuzzy $P D$ é de aproximadamente $1,2 \mathrm{~V}$, já para 0 controlador fuzzy $P D+P I$ possui um ripple de aproximadamente $1,0 \mathrm{~V}$. Testes adicionais demonstraram que quanto maior à contribuição do controlador fuzzy $P D$, mais rapidamente o sistema estabiliza, no entanto o ripple se torna bastante significativo. Em laboratório, usou-se como ganho de controlador fuzzy $\eta=1,0$.

Nas Figuras 5.17 e 5.18 são mostradas as respostas do controlador $P I$ utilizando o algoritmo de $\mathrm{P} \& \mathrm{O}$ com passo fixo e com passo variável. O intervalo de tempo que o sistema demora a alcançar o PMP é reduzido de aproximadamente $320 \mathrm{~ms}$ com passo fixo, para $128 \mathrm{~ms}$ com passo variável. Nas Figuras 5.19 e 5.20 são mostradas as respostas do sistema com controlador $P I$ com passo fixo e variável empregando o algoritmo de InC, onde se percebe que a tensão se torna mais estável quando comparada a tensão do algoritmo de $\mathrm{P} \& \mathrm{O}$.

Nas Figuras 5.21, 5.22, 5.23 e 5.24 são apresentadas as respostas do sistema utilizando os algoritmos de $\mathrm{P} \& \mathrm{O}$ e InC com passo fixo e variável com 0 controle fuzzy $P D+P I$. Como esperado o ripple aumentou em aproximadamente $20 \%$ em relação ao controlador $P I$, no entanto a magnitude é relativamente baixa, aproximadamente $1,2 \mathrm{~V}$ (3,4\% da tensão nominal de operação). Mediante as figuras anteriores, percebe-se que a resposta com o controlador fuzzy $P D+P I$ se assemelha em grande parte à resposta com controlador $P I$, a principal diferença está na rápida estabilização, característica importante que permite 0 uso de tempos de amostragens $T_{\alpha}$ inferiores aos do controlador linear. Esta característica é determinante quando os painéis estão parcialmente sombreados. Nestas circunstâncias, surgem vários máximos locais (PMPs) e a determinação do $P M P$ global é feita através de algoritmos específicos (VILLALVA, 2010), sendo necessários tempos de respostas menores. Adicionalmente, em dias parcialmente nublados ocorrem frequentes variações na luz incidente sobre os painéis, assim, um controle que estabilize, rapidamente, o sistema é de grande interesse.

Resultados adicionais dos testes apresentados anteriormente e utilizando-se somente 0 controlador fuzzy $P D$ são apresentados no Apêndice $B$. 
Referência Fixa

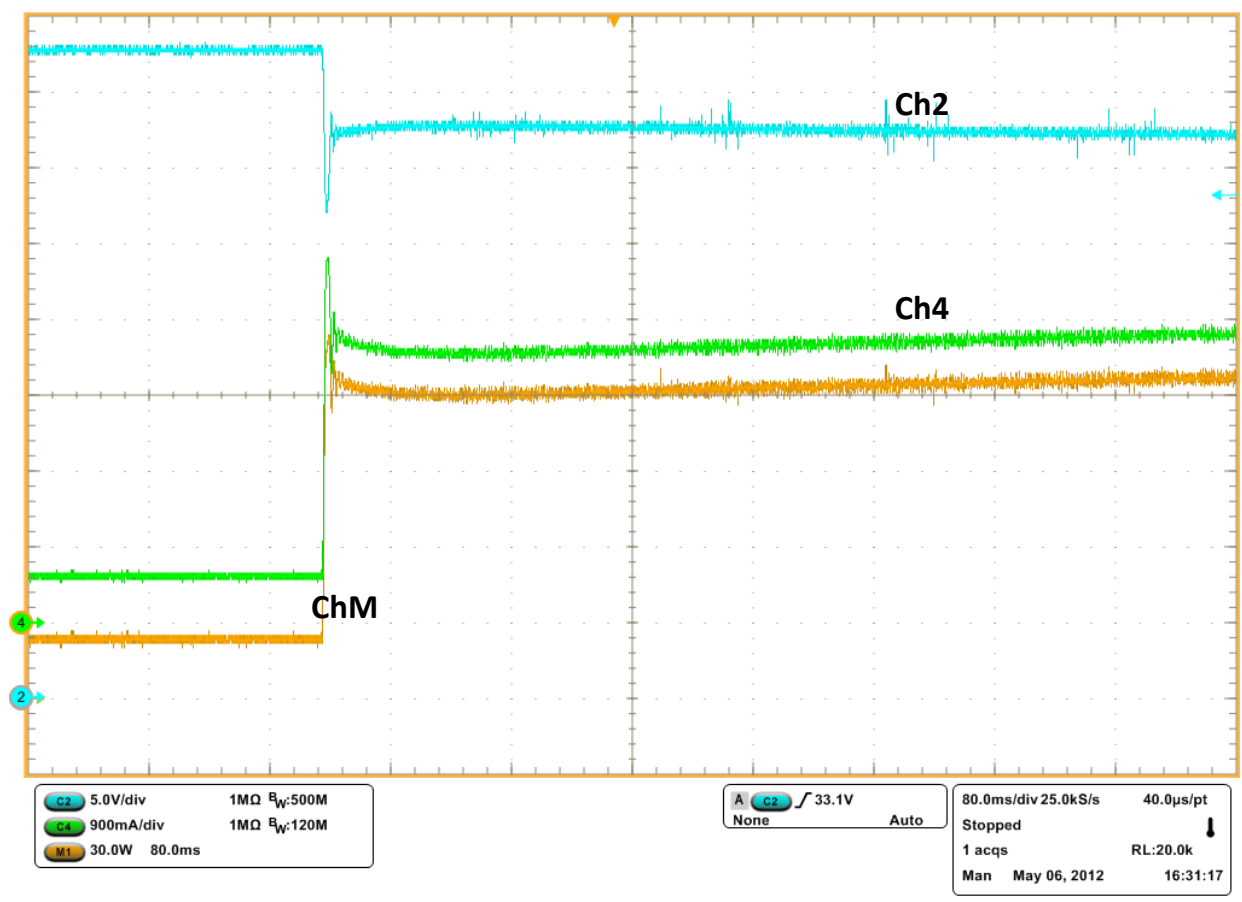

Figura 5.14. Resposta ao degrau na entrada com controlador PI. Ch2: tensão da fonte (5 V/div). Ch4: corrente injetada pela fonte (900 mA/div). ChM: potência gerada pela fonte (30 W/div).

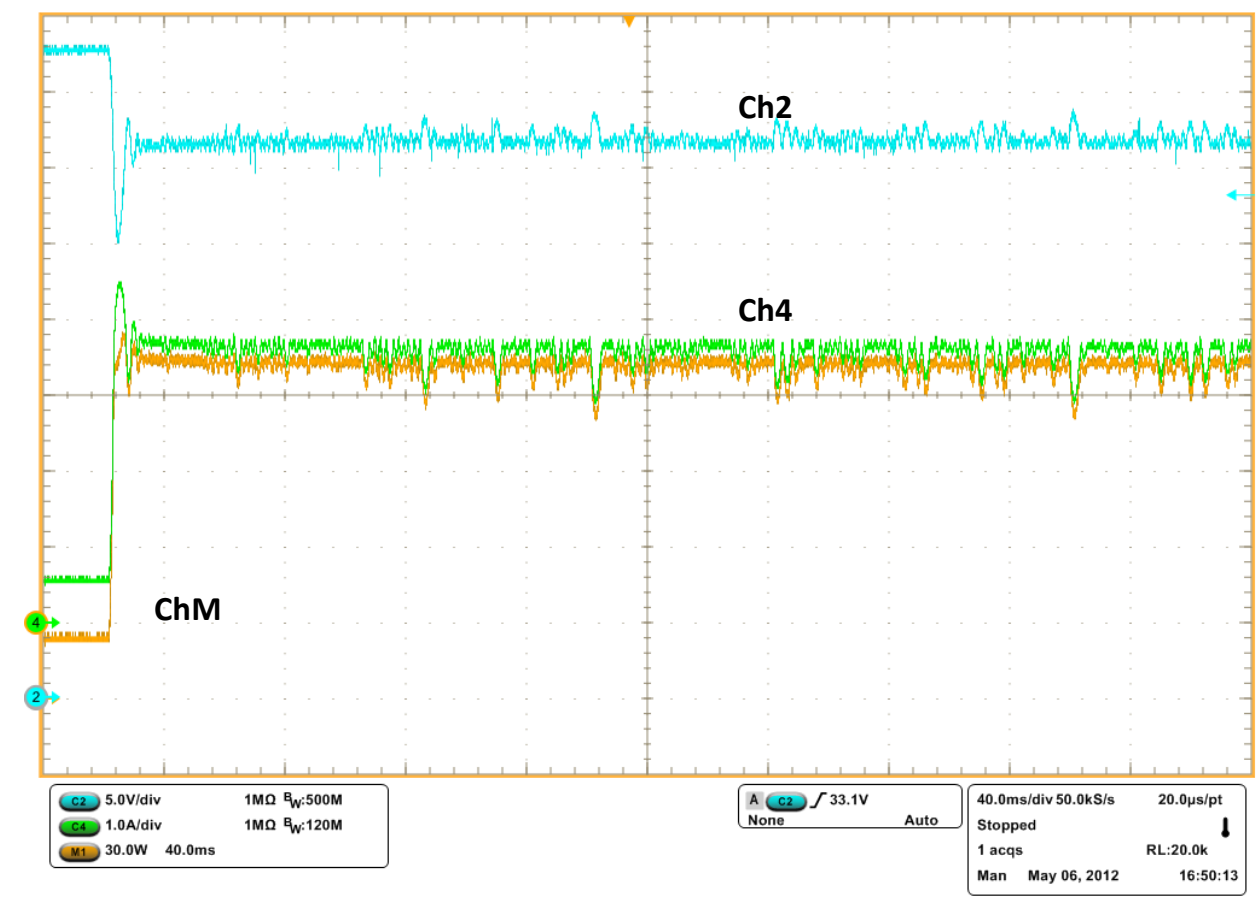

Figura 5.15. Resposta ao degrau na entrada com controlador fuzzy. Ch2: tensão da fonte (5 V/div). Ch4: corrente injetada pela fonte (1 A/div). ChM: potência gerada pela fonte (30 W/div). 


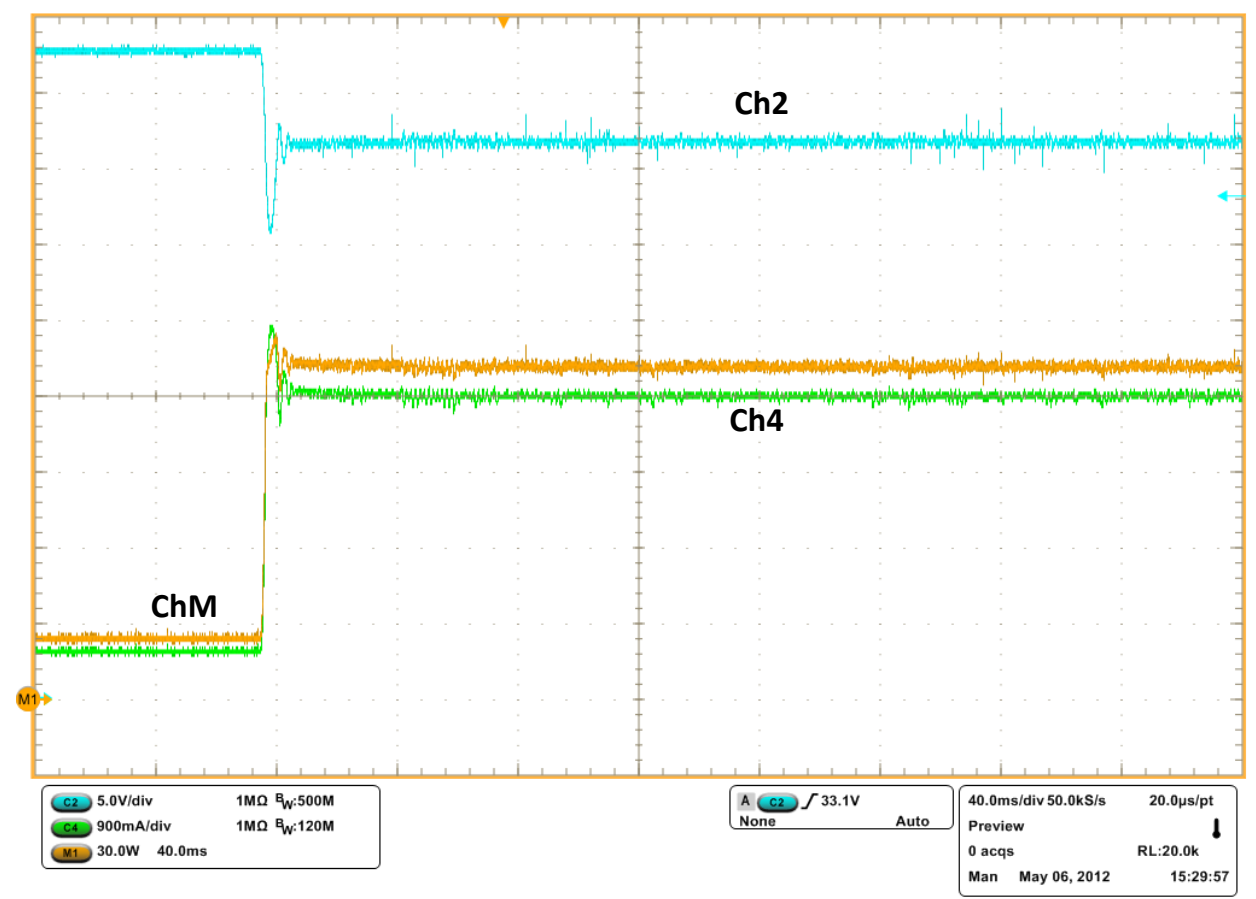

Figura 5.16. Resposta ao degrau na entrada com controlador fuzzy $P D+P I$. Ch2: tensão da fonte (5 V/div). Ch4: corrente injetada pela fonte (1 A/div). ChM: potência gerada pela fonte (30 W/div).

\section{Perturbação e Observação}

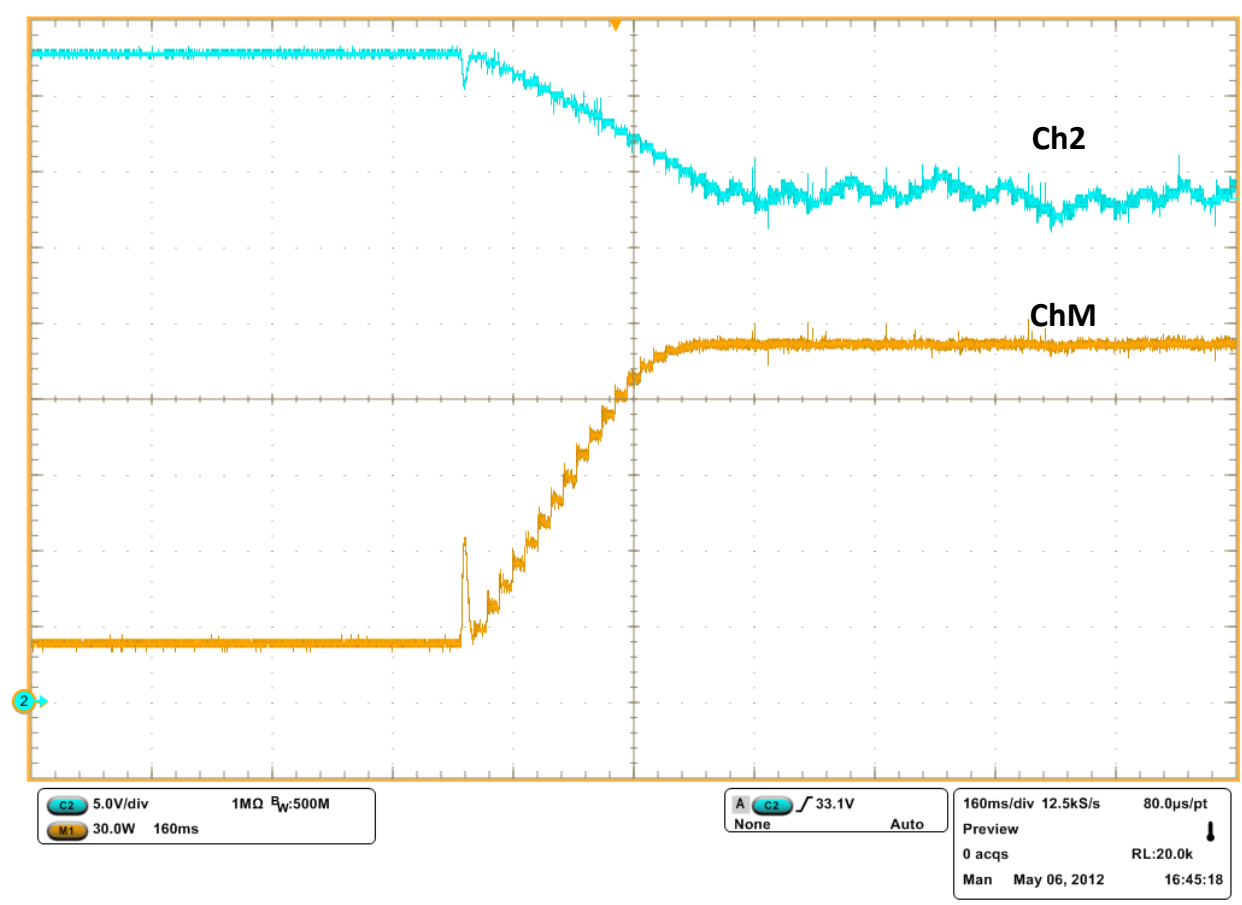

Figura 5.17. Algoritmo P\&O com passo fixo de $0,5 \mathrm{~V}$ : sistema com controlador Pl. Ch2: tensão da fonte (5 V/div). ChM: potência gerada pela fonte (30 W/div). $T_{\alpha}=17 \mathrm{~ms}$. 


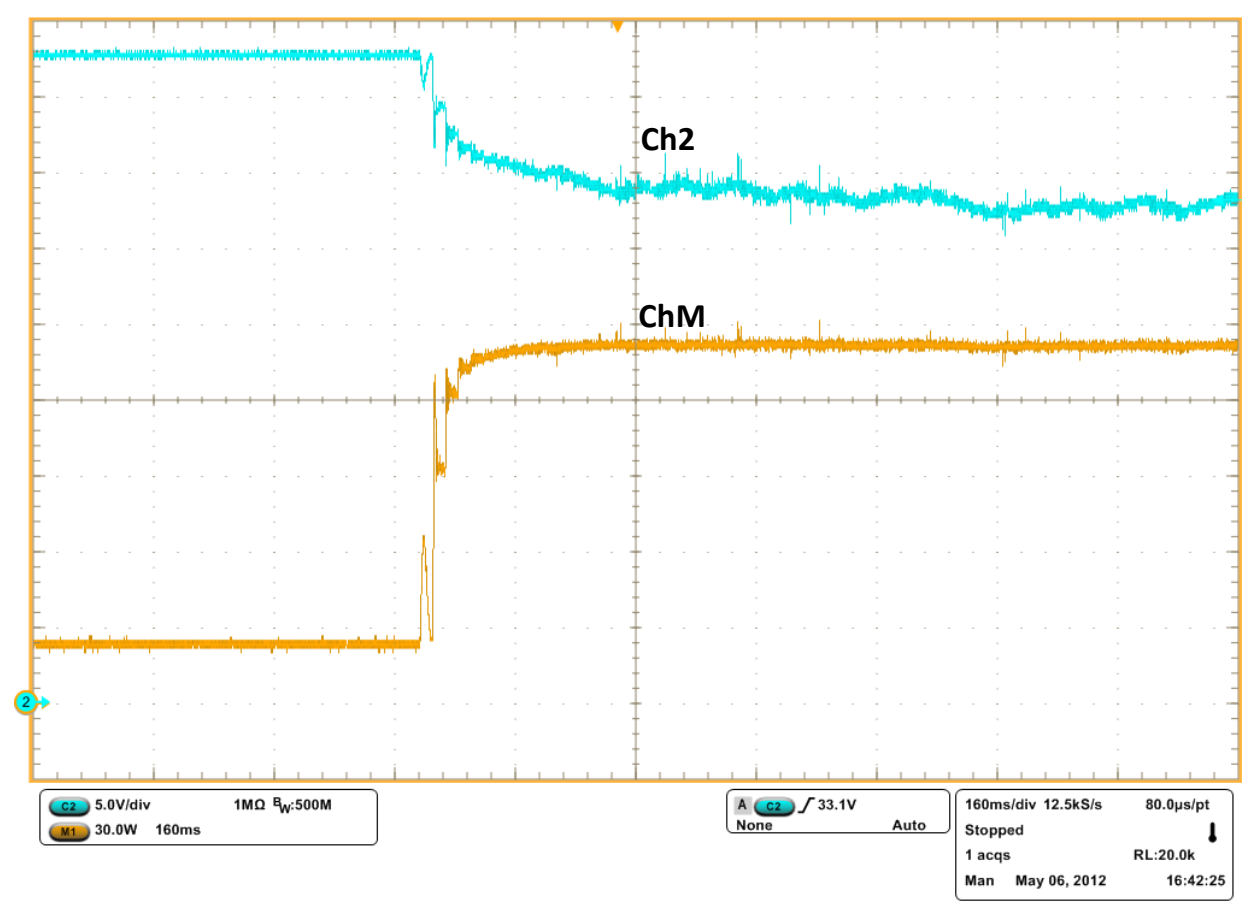

Figura 5.18. Algoritmo P\&O com passo variável [4,0 2,0 1,0 0,5 0,25] V: sistema com controlador Pl. Ch2: tensão da fonte (5 V/div). ChM: potência gerada pela fonte (30 W/div). $T_{\alpha}=17 \mathrm{~ms}$.

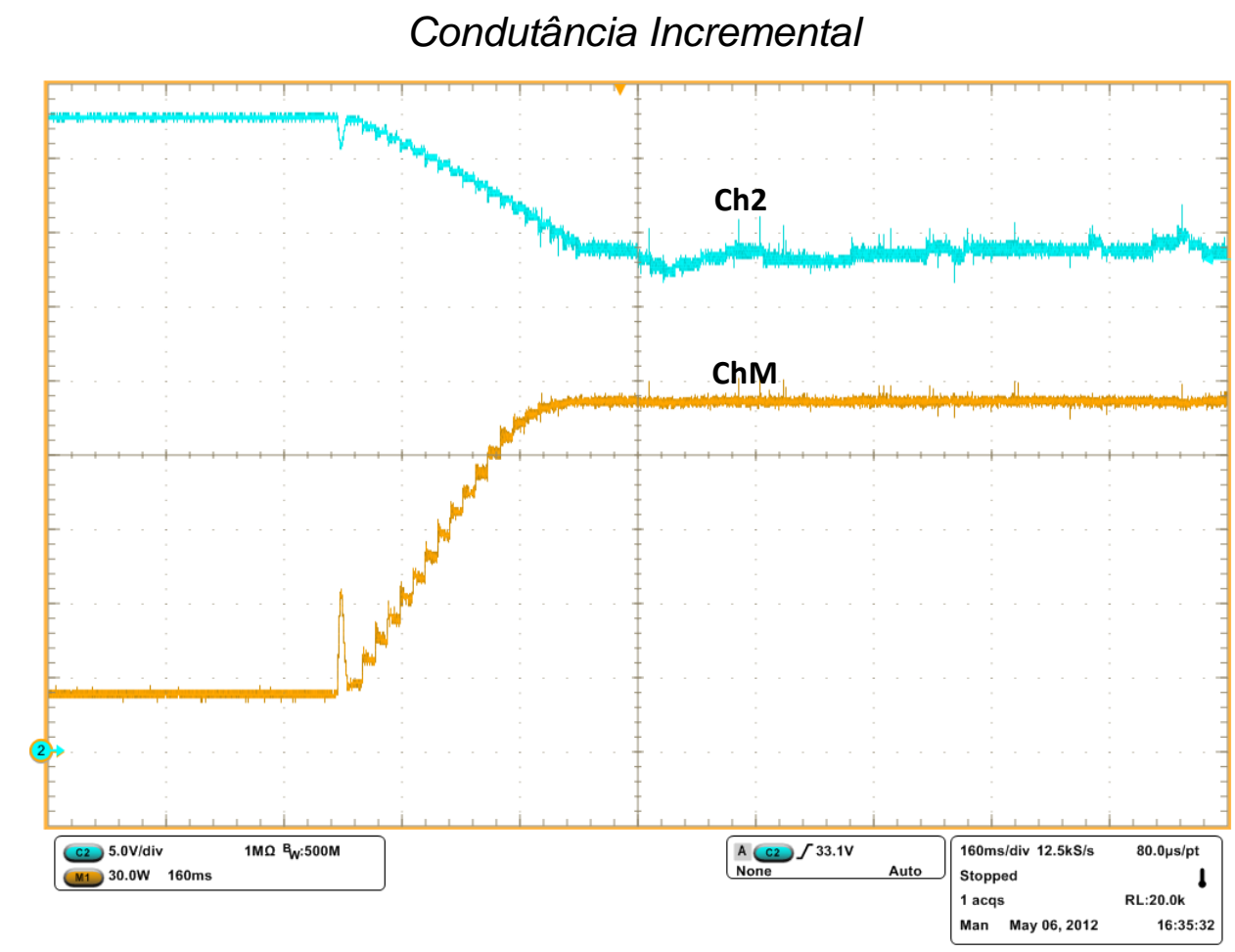

Figura 5.19. Algoritmo InC com passo fixo de 0,5 V: sistema com controlador Pl. Ch2: tensão da fonte (5 V/div). ChM: potência gerada pela fonte (30 W/div). $T_{\alpha}=17 \mathrm{~ms}$. 


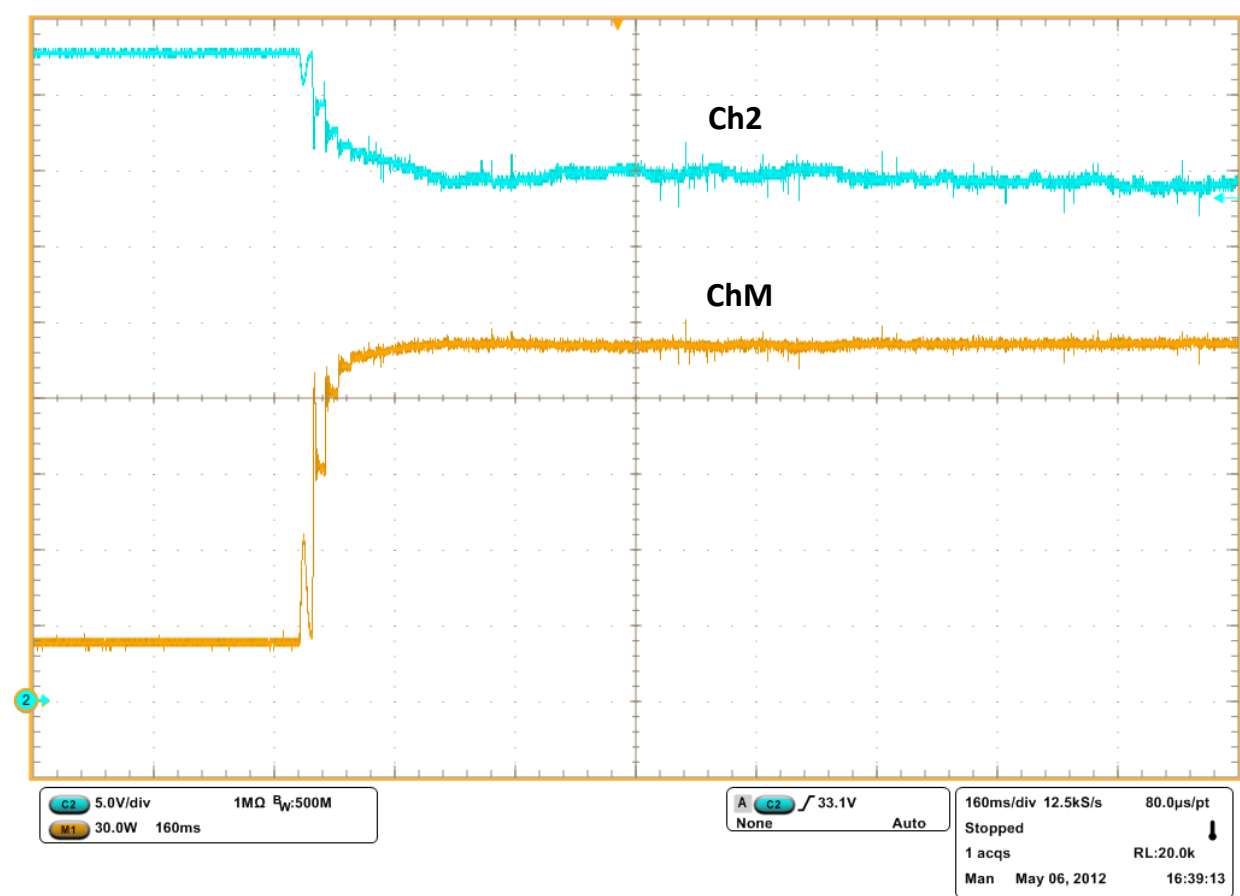

Figura 5.20. Algoritmo InC com passo variável [4,0 2,0 1,0 0,5 0,25] V: sistema com controlador Pl. Ch2: tensão da fonte (5 V/div). ChM: potência gerada pela fonte (30 W/div). $T_{\alpha}=17 \mathrm{~ms}$.

Perturbação e Observação

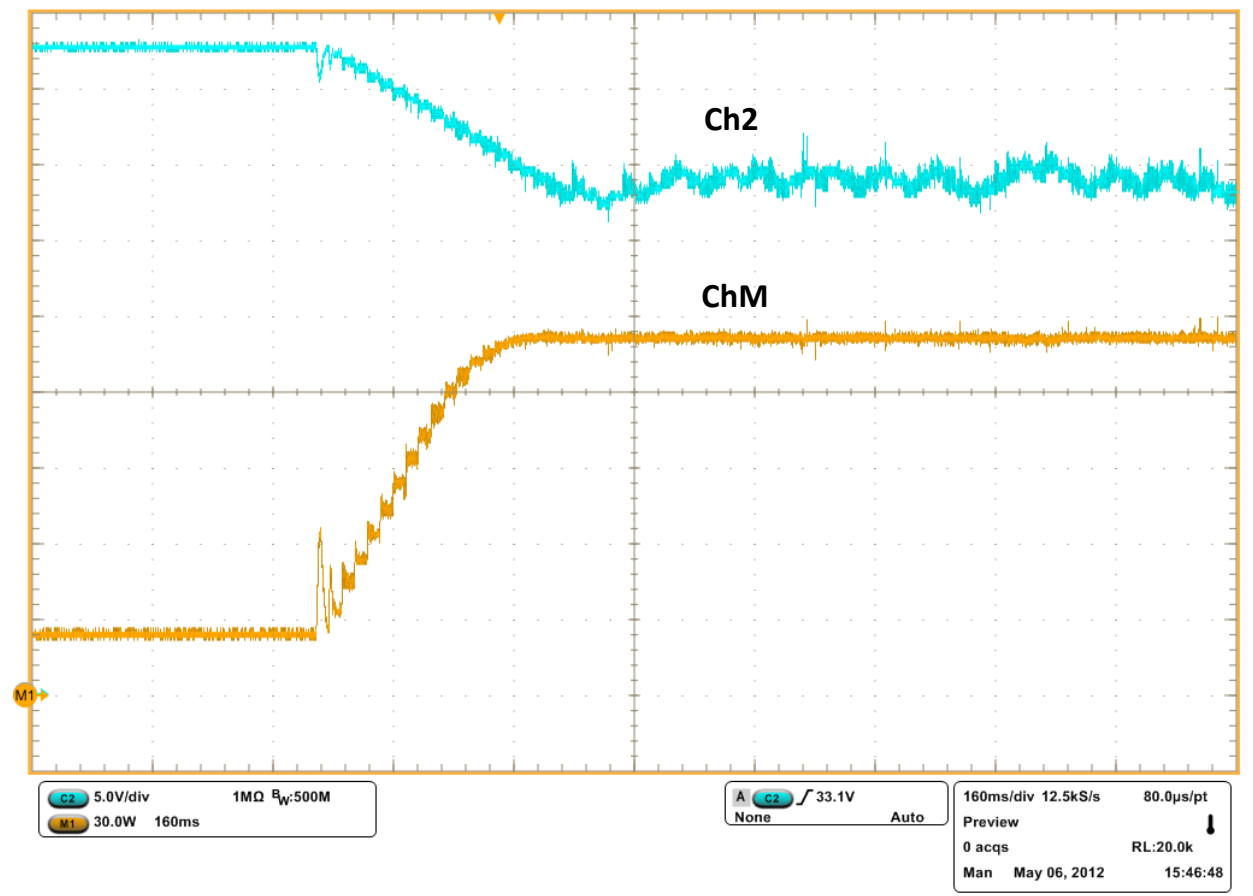

Figura 5.21. Algoritmo P\&O com passo fixo de $0,5 \mathrm{~V}$ : sistema com controlador fuzzy $P D+$ Pl. Ch2: tensão da fonte (5 V/div). ChM: potência gerada pela fonte (30W/div). $T_{\alpha}=17 \mathrm{~ms}$. 


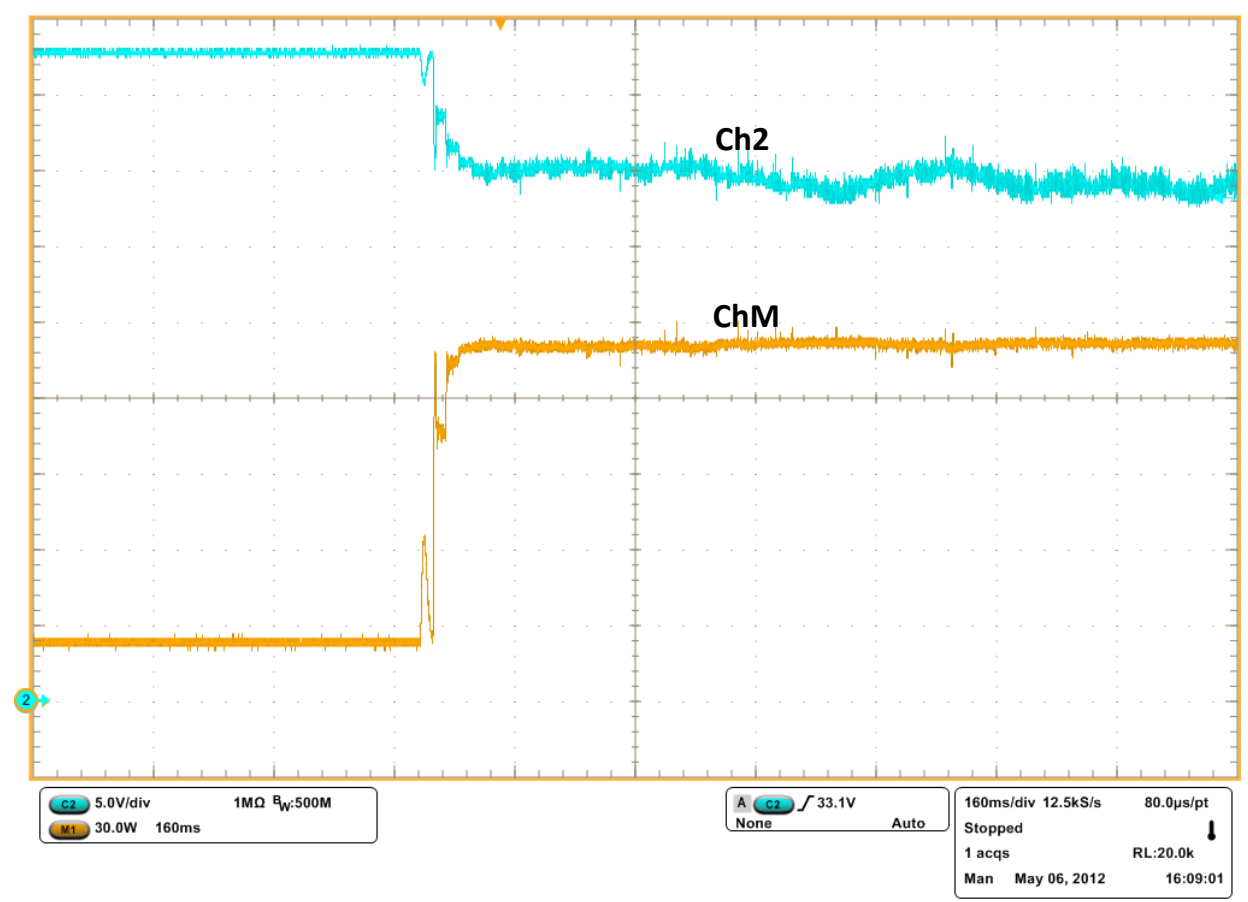

Figura 5.22. Algoritmo P\&O com passo variável [4,0 2,0 1,0 0,5 0,25] V: sistema com controlador fuzzy PD+PI. Ch2: tensão da fonte (5 V/div). ChM: potência gerada pela fonte (30 W/div). $T_{\alpha}=17 \mathrm{~ms}$.

Condutância Incremental

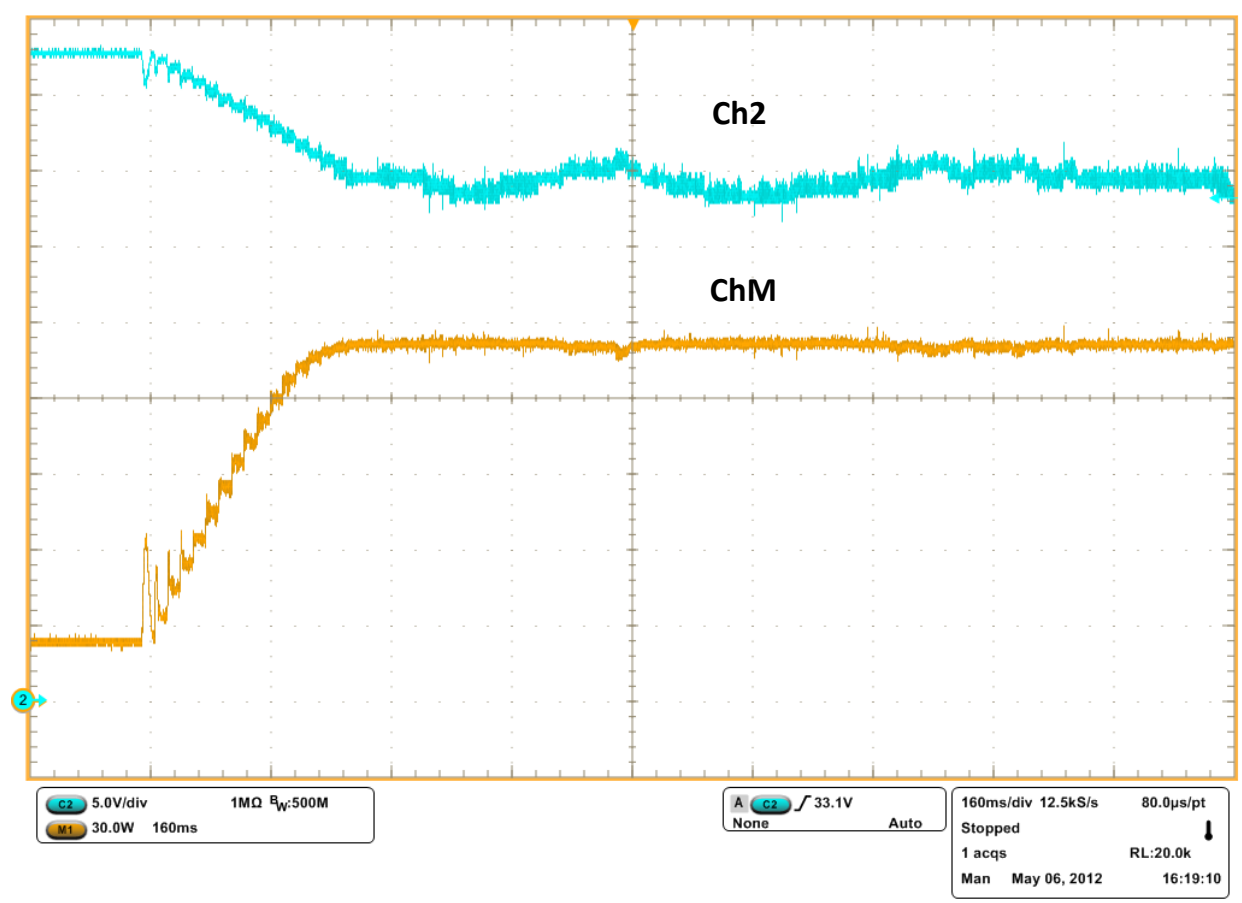

Figura 5.23. Algoritmo InC com passo fixo de 0,5 V: sistema com controlador fuzzy Pl+PD. Ch2: tensão da fonte (5 V/div). ChM: potência gerada pela fonte $(30 \mathrm{~W} / \mathrm{div}) . T_{\alpha}=17 \mathrm{~ms}$. 


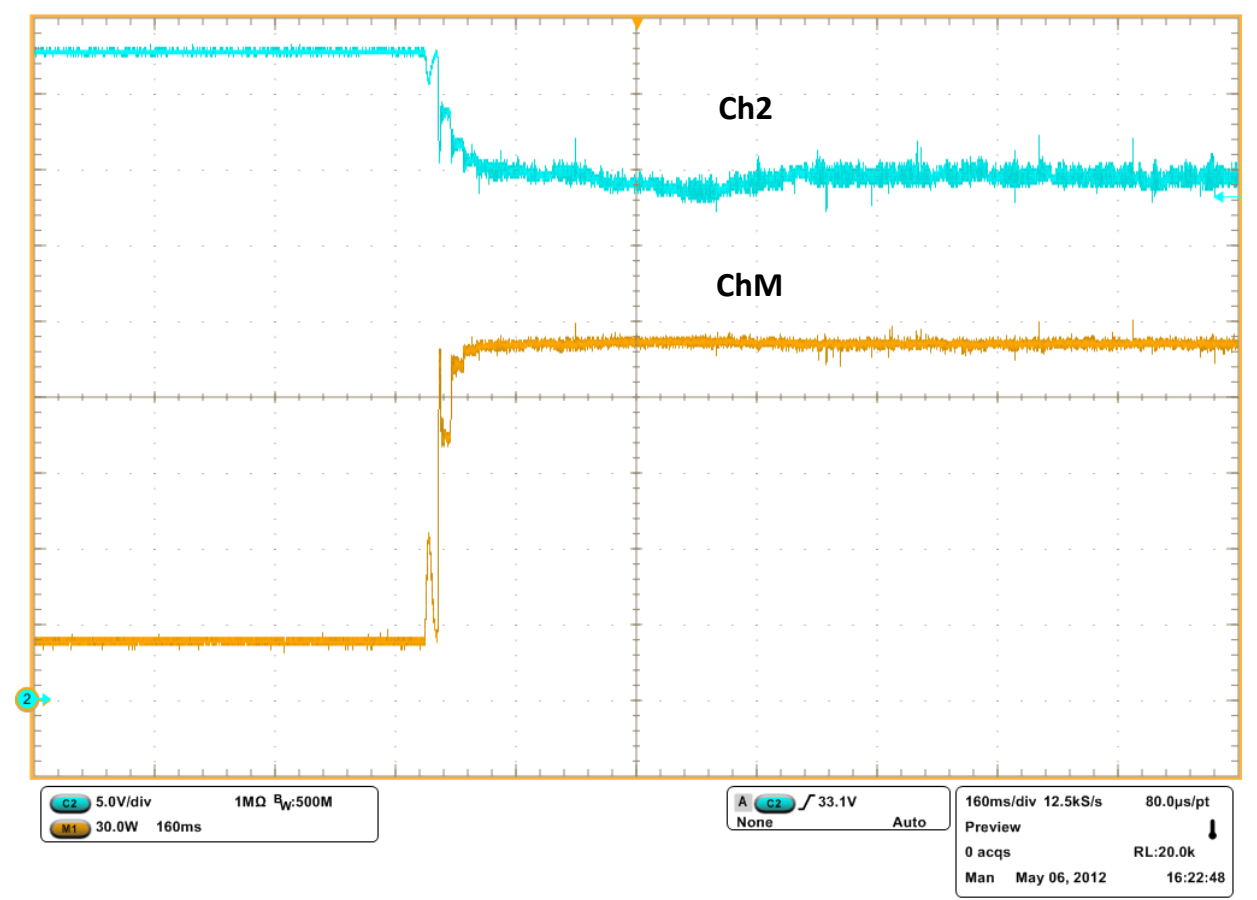

Figura 5.24. Algoritmo InC com passo variável [4,0 2,0 1,0 0,5 0,25] V: sistema com controlador fuzzy PD+PI. Ch2: tensão da fonte (5 V/div). ChM: potência gerada pela fonte (30 W/div). $T_{\alpha}=17 \mathrm{~ms}$.

\section{Ensaios realizados com os painéis fotovoltaicos}

Os ensaios com os painéis fotovoltaicos foram realizados nas proximidades do Departamento de Engenharia Elétrica da Escola de Engenharia de São Carlos USP, em dias parcialmente nublados e com céu claro. Os painéis foram direcionados ao Sol e inclinados aproximadamente a $37^{\circ} \mathrm{em}$ relação à horizontal (AM1.5).

Durante os testes no campo, tiraram-se fotos dos painéis com a câmera infravermelha Ti10 IR Fusion Technology da FLUKE (Figura 5.25). As fotos permitem observar a distribuição térmica nos painéis e podem ser usadas para estimar em que faixa de temperatura nas quais as células fotovoltaicas se encontram (vide Figura 5.26 a 5.29). Constatou-se, com relativa surpresa, que em dias ensolarados e parcialmente nublados, a distribuição térmica não é tão uniforme quanto se podia prever, inclusive nas células pertencentes ao mesmo painel fotovoltaico. A variação térmica máxima nas células do mesmo painel foi de $\approx 6{ }^{\circ} \mathrm{C}$. Esta condição pode acarretar em maiores dificuldades dos algoritmos de busca baseados em treinamento que utilizam medidas de irradiação e de temperatura para calcular o ponto de máxima potência. 

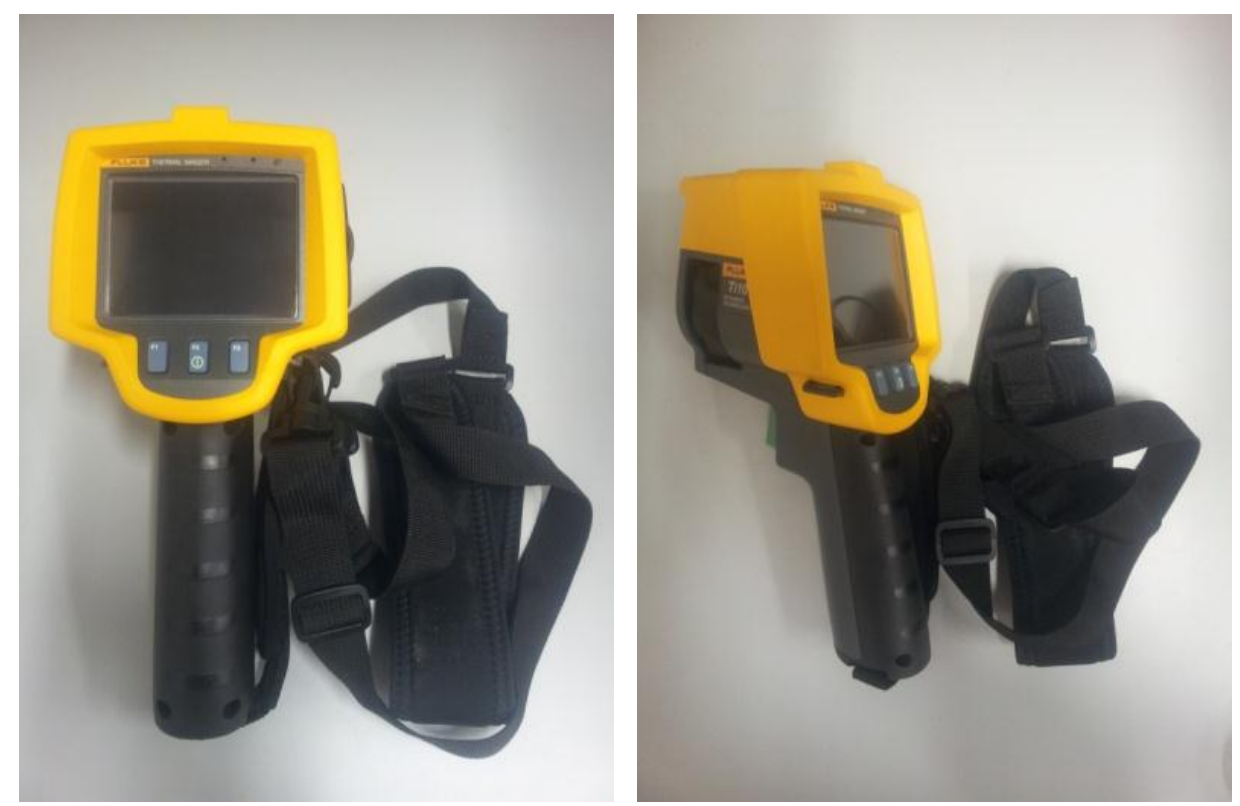

Figura 5.25. Câmera infravermelha Ti10 IR Fusion Technology da FLUKE.

Nas Figuras 5.30, 5.31 e 5.32, são apresentados os resultados utilizando-se os painéis fotovoltaicos da resposta ao degrau na entrada dos controladores $P I$, fuzzy $P D$ e fuzzy $P D+P I$ para uma tensão de referência $V_{R E F}=30 \mathrm{~V}$. As respostas obtidas em campo são semelhantes às obtidas em laboratório, se por um lado o sistema utilizando o controlador fuzzy isoladamente e o combinado fuzzy $P D_{+} P I$ entram em regime em um intervalo de tempo menor ( $50 \mathrm{~ms}$ ), já o sistema utilizando o controlador Pl, o tempo para o regime permanente é cerca de $800 \mathrm{~ms}$. As ondulações na tensão foram similares às obtidas em laboratório para os três sistemas de controle, sendo de $\approx 1,0 \mathrm{~V}$.

Aplicando os algoritmos de busca por perturbação e observação, mostrados nas Figuras 5.33 e 5.34, e de condutância incremental, mostrados nas Figuras 5.35 e 5.36, as respostas com o controlador fuzzy $P D+P I$ apresentaram um ripple $(\approx 2,5 \mathrm{~V})$ com aproximadamente uma unidade a mais do que o ripple com 0 controlador $P I(\approx 1,2 V)$, isto ocorreu por que se aumentou o ganho do controlador fuzzy (utilizou-se $\eta=1,5$ ) com o objetivo de tornar a resposta transitória mais rápida. 


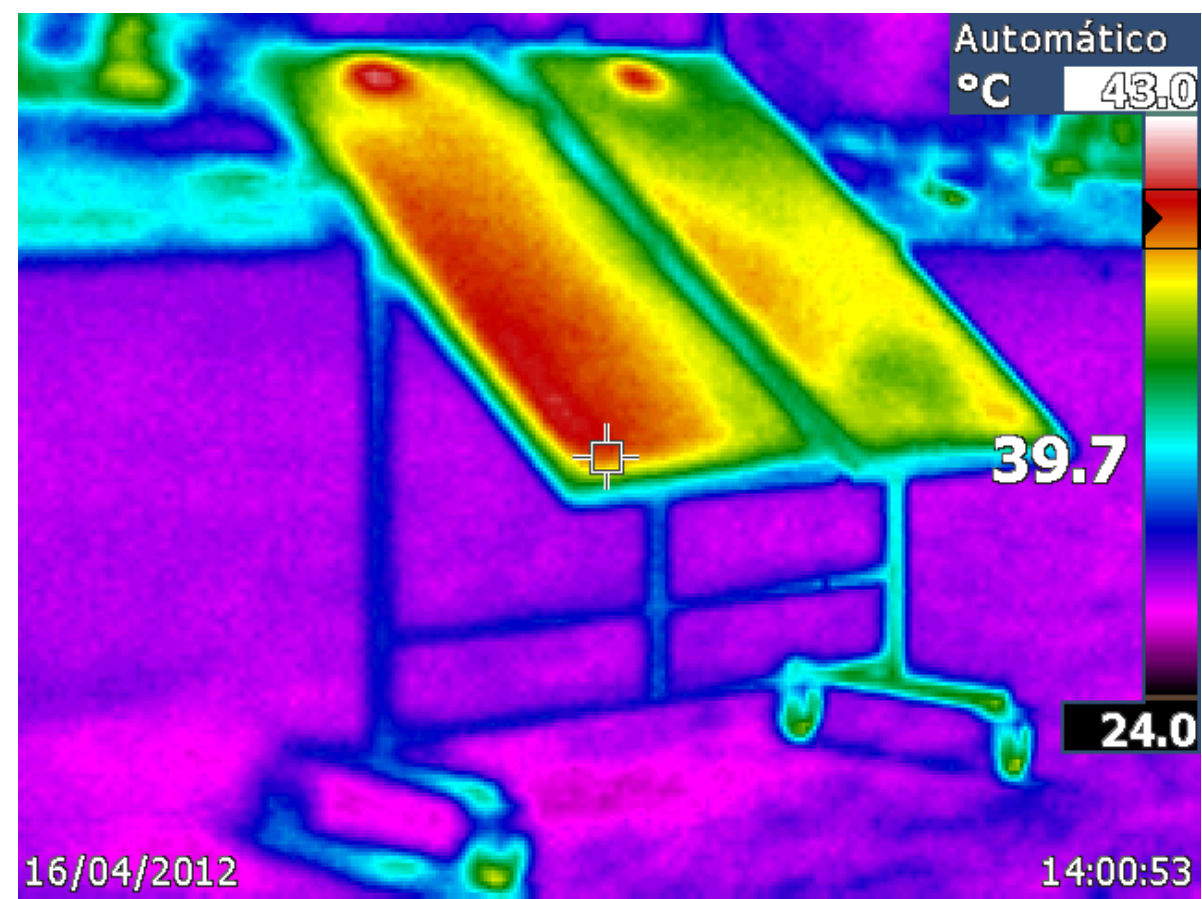

Figura 5.26. Distribuição térmica dos painéis fotovoltaicos em dia parcialmente nublado. (Vista 1).

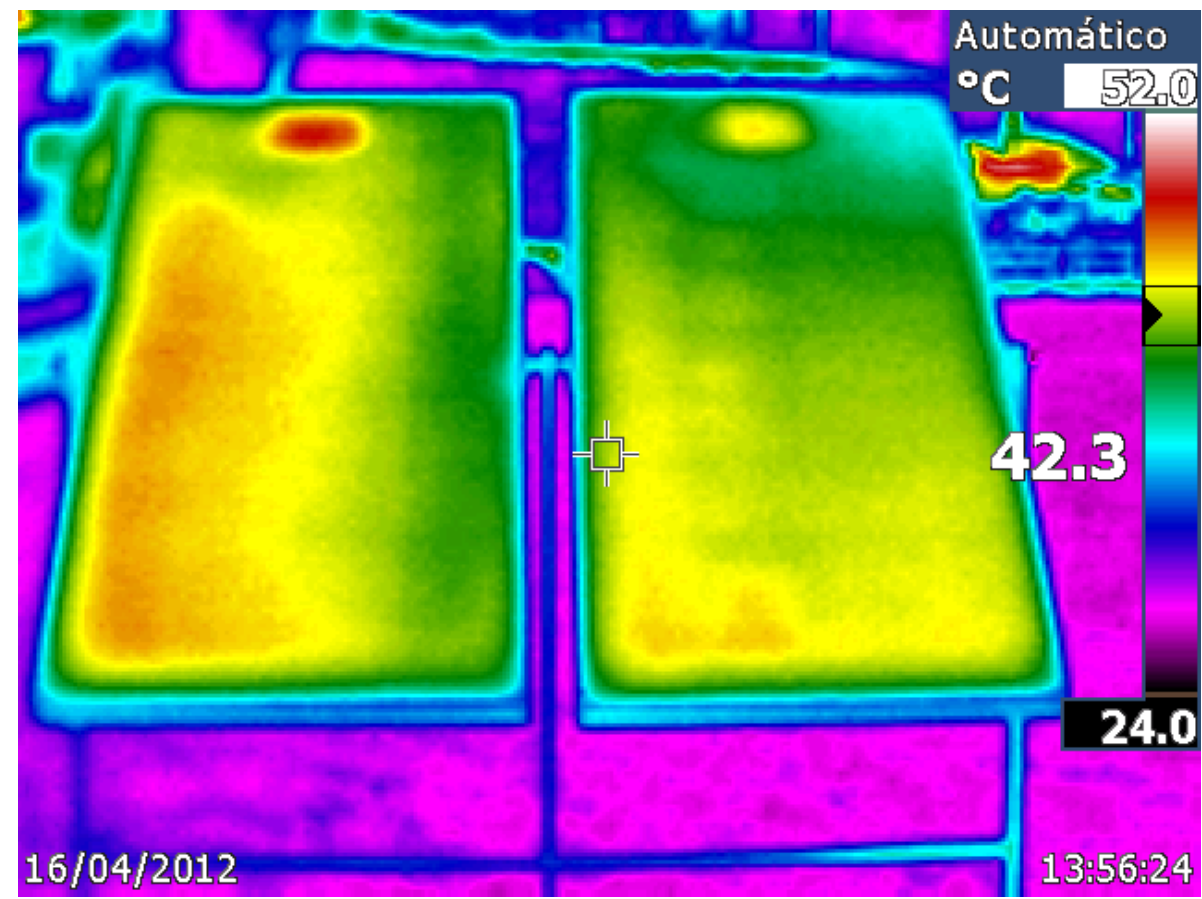

Figura 5.27. Distribuição térmica dos painéis fotovoltaicos em dia parcialmente nublado. (Vista 2). 


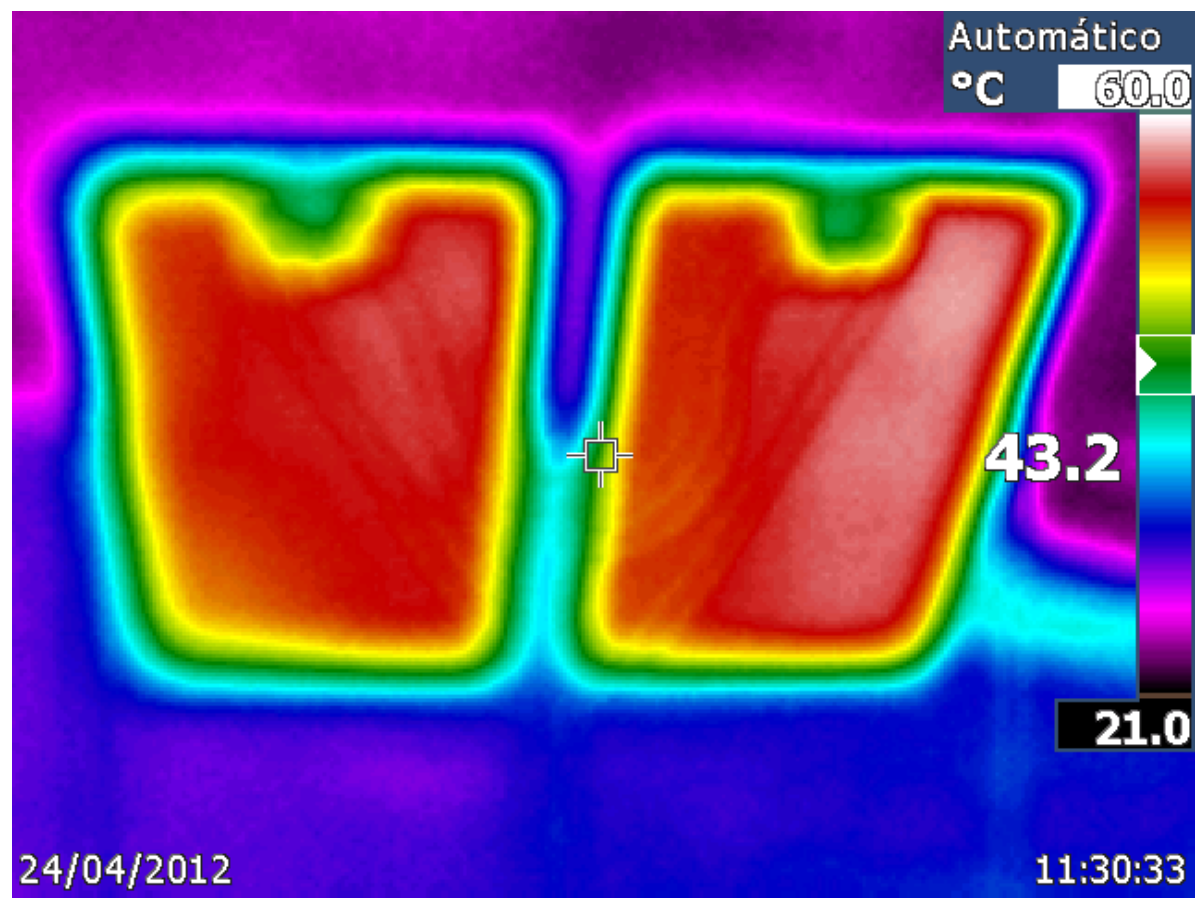

Figura 5.28. Distribuição térmica dos painéis fotovoltaicos em dia com céu claro.

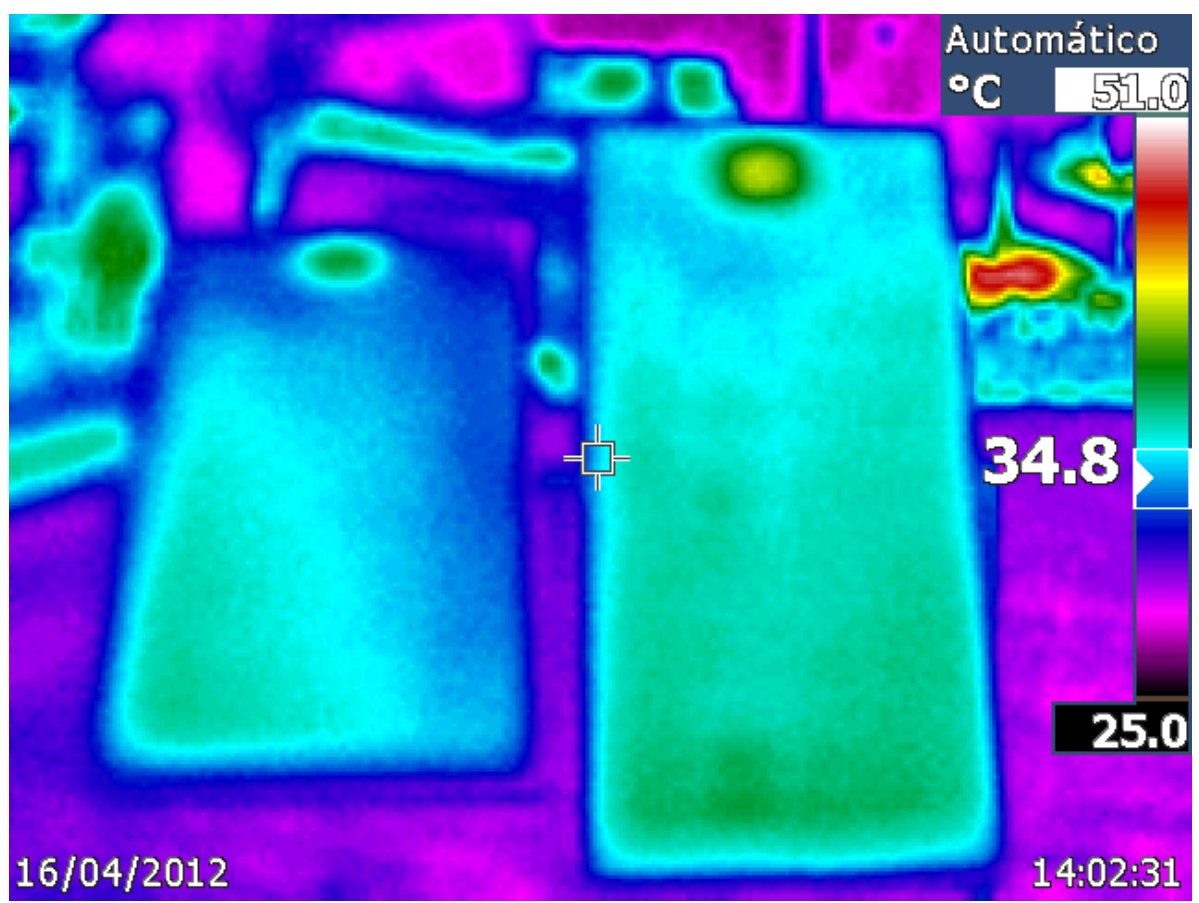

Figura 5.29. Distribuição térmica dos painéis fotovoltaicos com inclinações diferentes em um dia parcialmente nublado. 
Referência Fixa

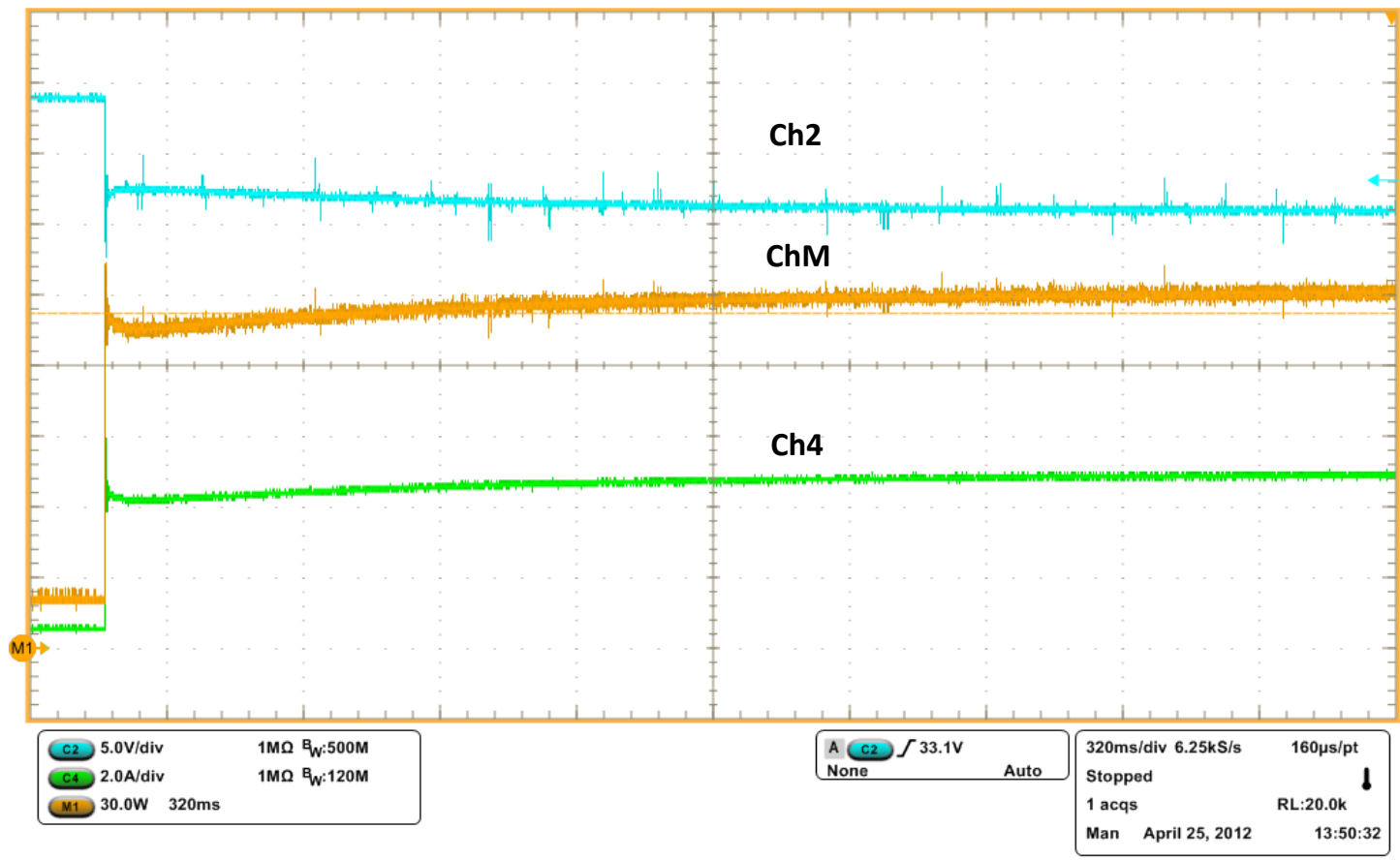

Figura 5.30. Resposta ao degrau na entrada com controlador PI. Ch2: tensão da fonte (5 V/div). Ch4: corrente injetada pela fonte (2 A/div). ChM: potência gerada pela fonte (30 W/div).

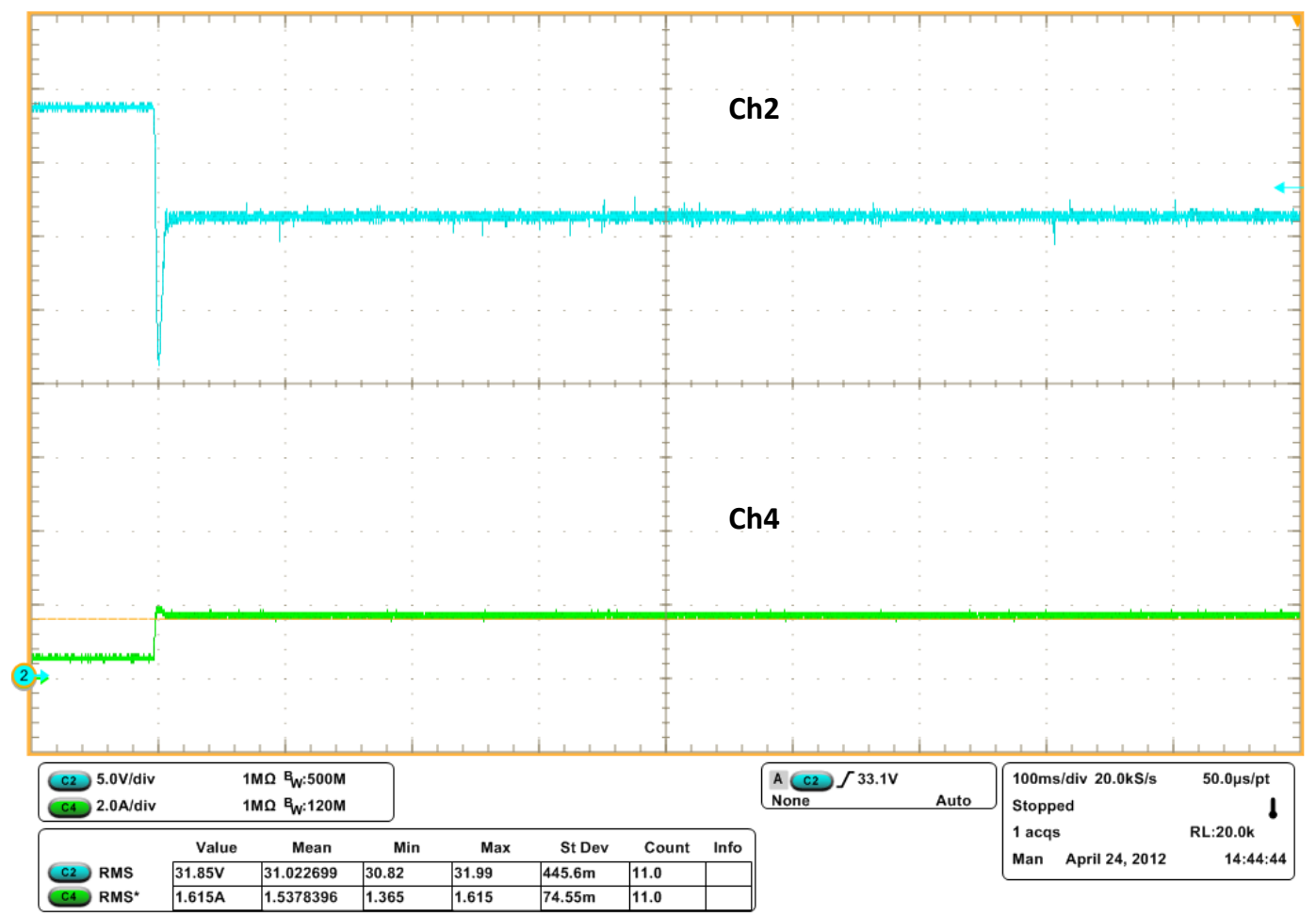

Figura 5.31. Resposta ao degrau na entrada com controlador fuzzy. Ch2: tensão da fonte (5 V/div). Ch4: corrente injetada pela fonte (2 A/div). ChM: potência gerada pela fonte (30 W/div). 


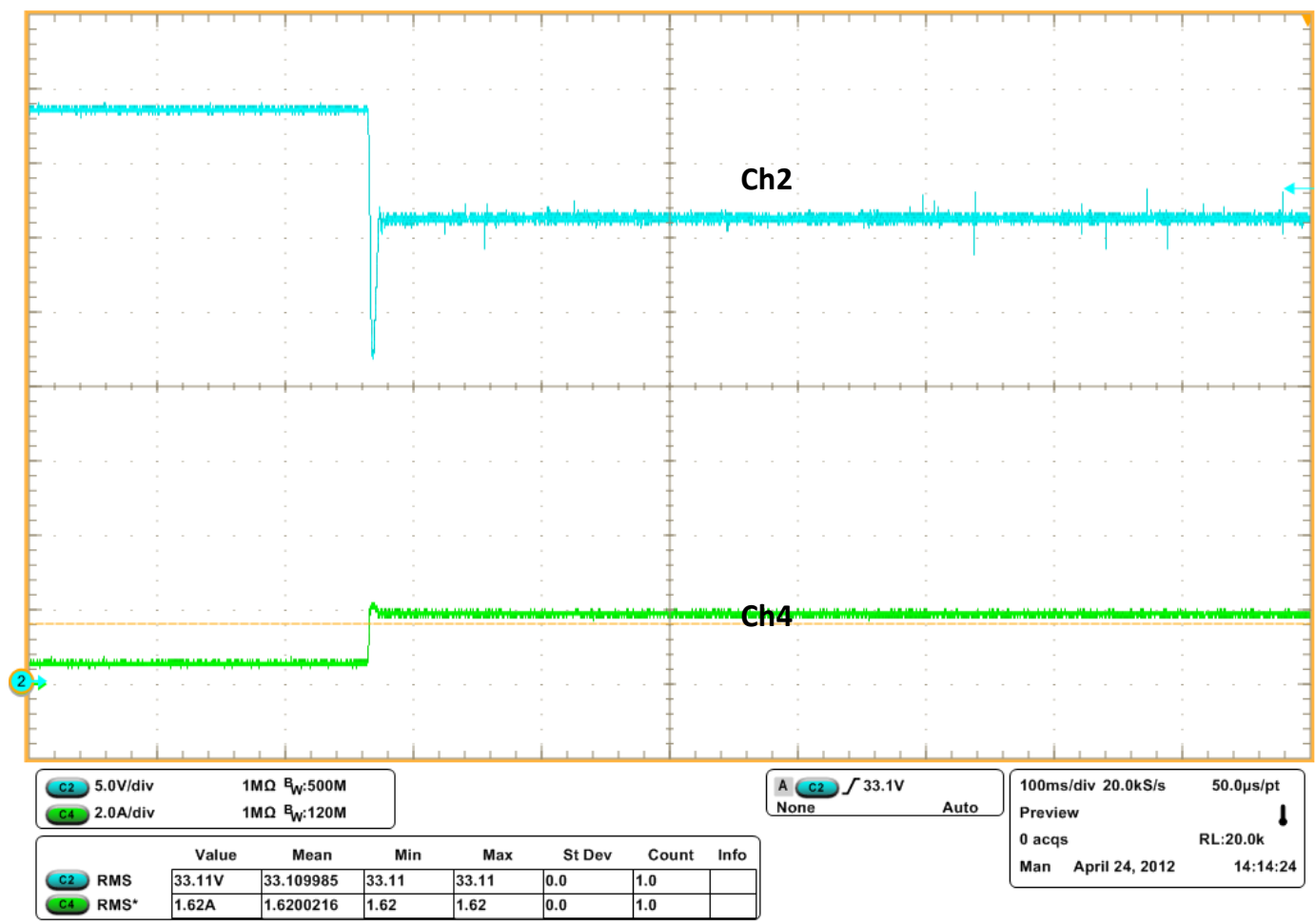

Figura 5.32. Resposta ao degrau na entrada com controlador fuzzy PD + PI. Ch2: tensão da fonte (5 V/div). Ch4: corrente injetada pela fonte (2 A/div). ChM: potência gerada pela fonte (30 W/div).

\section{Perturbação e Observação}

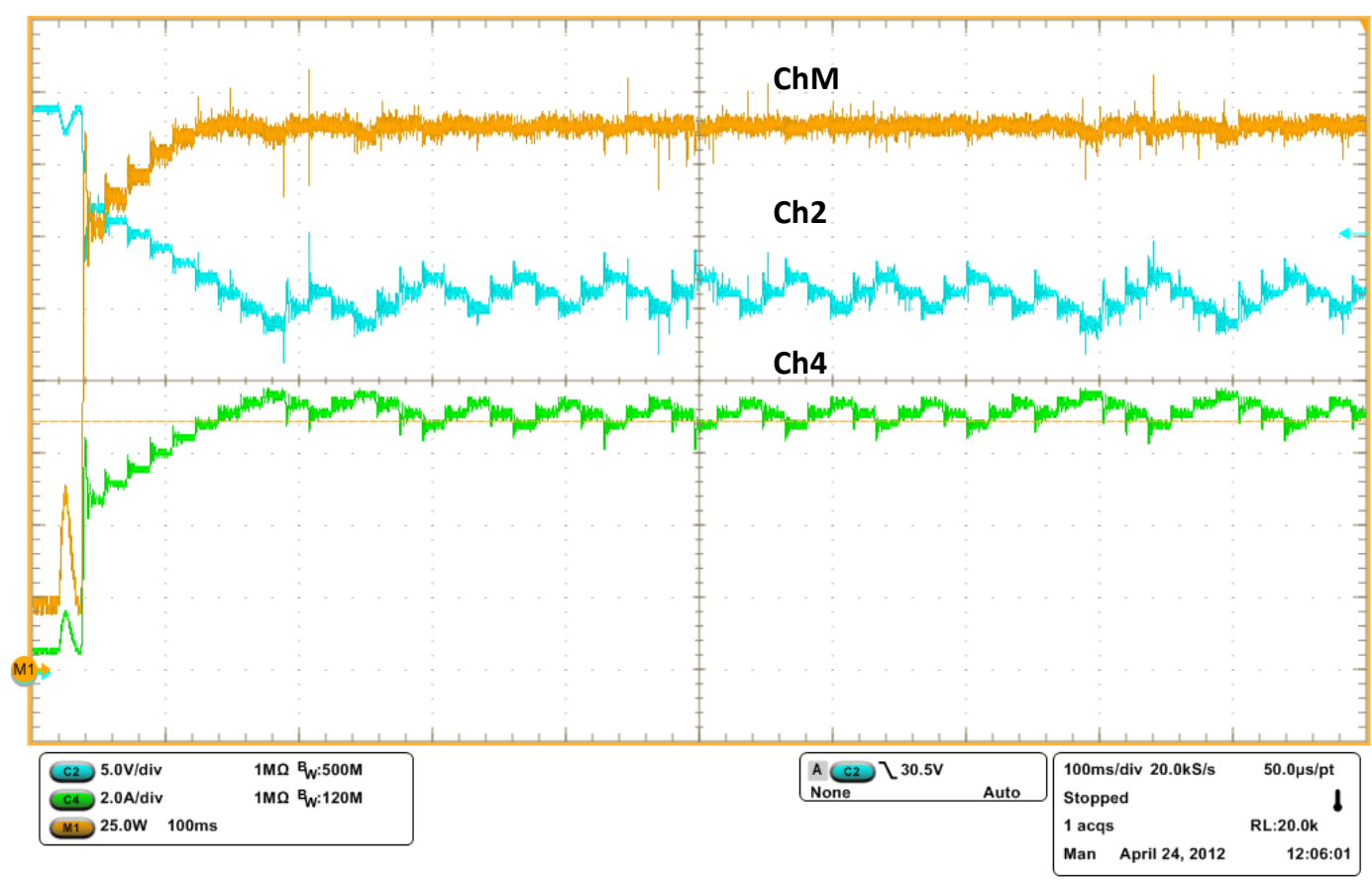

Figura 5.33. Algoritmo P\&O com passo fixo de 1,0 V: sistema com controlador Pl. Ch2: tensão da fonte (5 V/div). Ch4: corrente injetada pela fonte (2 A/div). ChM: potência gerada pela fonte (30 W/div). $T_{\alpha}=17 \mathrm{~ms}$. 


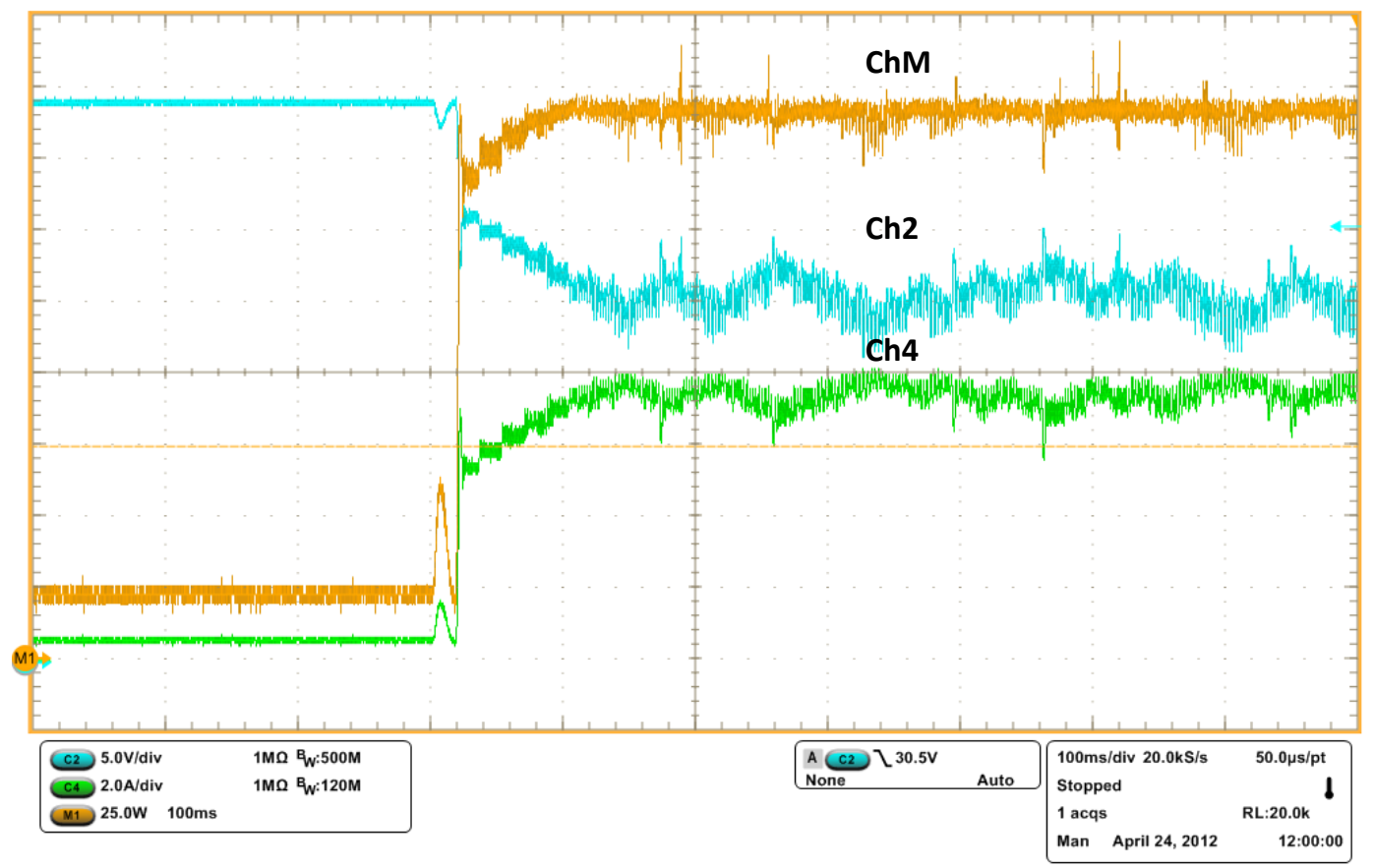

Figura 5.34. Algoritmo P\&O com passo fixo de 1,0 V: sistema com controlador fuzzy PD + PI. Ch2: tensão da fonte (5 V/div). Ch4: corrente injetada pela fonte (2 A/div). ChM: potência gerada pela fonte (30 W/div) $T_{\alpha}=17 \mathrm{~ms}$.

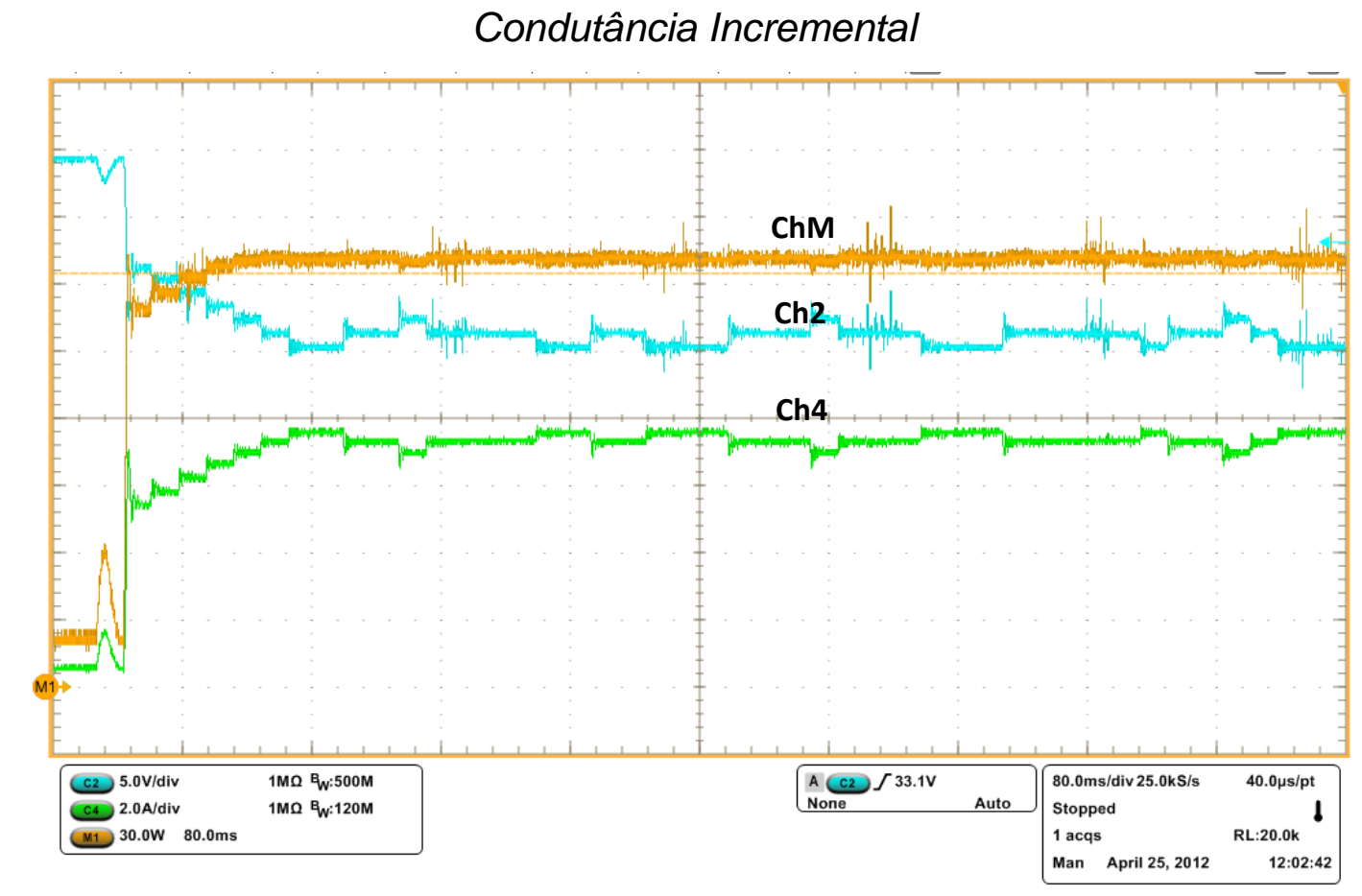

Figura 5.35. Algoritmo InC com passo fixo de 1,0 V: sistema com controlador PI. Ch2: tensão da fonte (5 V/div). Ch4: corrente injetada pela fonte (2 A/div). ChM: potência gerada pela fonte $(30 \mathrm{~W} /$ div $) . T_{\alpha}=17 \mathrm{~ms}$. 


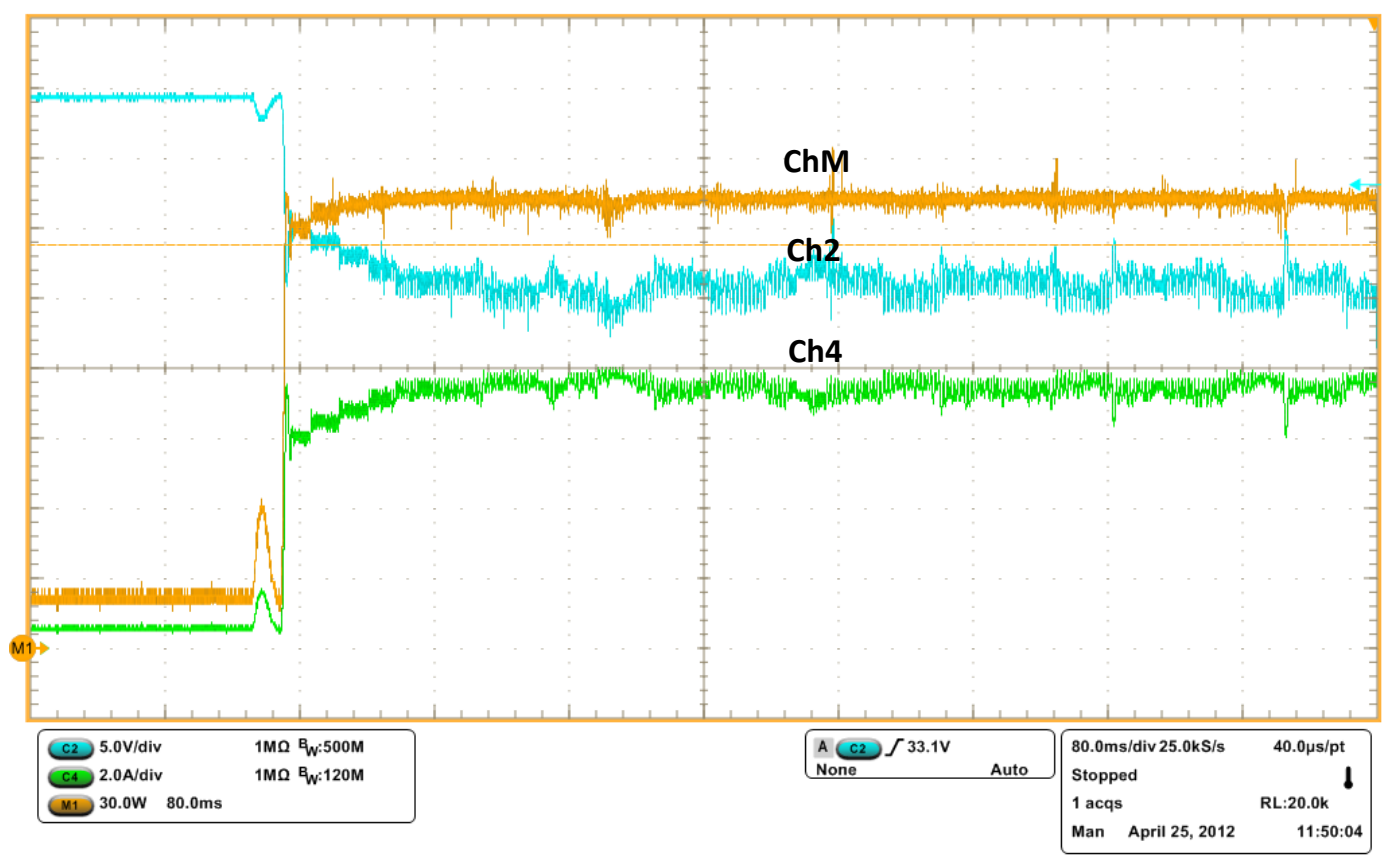

Figura 5.36. Algoritmo P\&O com passo fixo de 1,0V: sistema com controlador fuzzy $P D+P I$. Ch2: tensão da fonte (5 V/div). Ch4: corrente injetada pela fonte (2 A/div). ChM: potência gerada pela fonte (30 W/div) $T_{\alpha}=17 \mathrm{~ms}$.

\subsection{Considerações Finais}

Este capítulo apresentou os resultados de simulação e experimentais do sistema fotovoltaico constituído por painéis fotovoltaicos que alimentam um conversor elevador de tensão. O sistema foi testado em laboratório com níveis de potência de até $140 \mathrm{~W}$ e posteriormente testado em campo com níveis de potencia de $200 \mathrm{~W}$.

A modelagem desenvolvida no Capítulo 3 permitiu o projeto do sistema de controle da tensão de entrada estudado no Capítulo 4. Assim, este capítulo focou na implementação prática do sistema e na análise dos resultados.

Os resultados experimentais tanto em laboratório como em campo, assemelharam-se aos obtidos em simulação, permitindo validar as considerações teóricas e identificar os gargalos para trabalhos futuros. 


\section{Conclusões e Trabalhos futuros}

\subsection{Conclusões Gerais}

Este trabalho é uma contribuição ao projeto de pesquisa voltado às fontes alternativas desenvolvidas pelo Laboratório de Fontes Alternativas e Processamento de Energia e pelo Laboratório de Controle da EESC/USP envolvendo fontes renováveis de energia, controle digital de conversores de potência, qualidade de energia e filtros ativos.

O principal propósito era o de desenvolver um sistema de controle capaz de melhorar a resposta transitória de uma planta constituída por painéis fotovoltaicos conectados a um conversor CC.

Algumas limitações surgiram no decorrer do trabalho, tais como, os recursos disponíveis, o tempo limitado e o estágio ainda inicial do grupo no tema pesquisado. Apesar disso, obtiveram-se bons resultados e identificaram-se diverSAS áreas de pesquisa a serem estudadas futuramente.

\subsection{Contribuições do Trabalho}

Os resultados obtidos nesta dissertação reforçam a necessidade de controlar a tensão do painel fotovoltaico para a melhoria do desempenho dos algoritmos de busca do ponto de máxima potência, uma vez que a tensão de referência varia constantemente em função do MPPT e das condições ambientais.

O sistema de controle proposto obteve uma resposta dinâmica significativamente mais rápida, com um tempo de estabilização abaixo de $10 \mathrm{~ms}$. Esta condição permite a utilização do MPPT com tempos de amostragem menores se comparado ao controle direto da razão cíclica ou quando utilizado somente reguladores lineares, aumentando a eficiência na geração inclusive em situações de sombreamento parcial. 
A aplicação do Teorema do Elemento Extra de Middlebrook permitiu analisar e determinar os critérios para compensar os efeitos de elementos parasitas nos painéis fotovoltaicos e demonstrou ser uma abordagem simples e eficiente, embora pouco explorada, a ser utilizada em outros estudos.

No projeto do controlador fuzzy embarcado desenvolveu-se uma metodologia no processo de defuzzificação que proporcionou uma economia no recurso de memória, aumento da precisão e rápido tempo de execução apesar do leve aumento no custo computacional, se comparado ao método tradicional de indexação por memória ou utilizando laços de repetição ("for", "while" ou "do while").

Apesar dos baixos níveis de potência utilizados neste trabalho, os resultados obtidos e as considerações propostas podem ser estendidos a outras técnicas de controle não lineares e a outros conversores usados em sistemas fotovoltaicos.

\subsection{Trabalhos Futuros}

No decorrer desta dissertação identificaram-se como trabalhos futuros a:

- Elaboração de um algoritmo de busca do ponto de máxima potência baseado em rede neural aplicável inclusive em situações de sombreamento parcial;

- Elaboração de um método que determine o melhor ponto de operação de um sistema fotovoltaico com determinado arranjo de painéis em série e/ou paralelo, mas que está limitado no número de chaves. Esta abordagem visa o baixo custo da instalação fotovoltaica, uma vez que para grandes aplicações é, praticamente, infactível que cada módulo da planta possua individualmente um conversor e uma unidade de processamento digital;

- Generalização da metodologia empregada no processo de defuzzificação, inclusive para outros métodos de implicação (Zadeh, Larsen e aritmético);

- Aplicação do Teorema do Elemento Extra de Middlebrook na análise do sistema fotovoltaico atrelado á outros sistemas, tais como, carregadores de bateria e conversores $\mathrm{CC} / \mathrm{CA}$ conectados à rede. 


\section{Apêndice A}

\section{A.1 Curva Estática do Processo com Conversor Elevador de Tensão e Fonte SAS}

Neste apêndice é apresentado a resposta em malha aberta do conversor elevador de tensão conectado a fonte $S A S$, com o objetivo de se obter a característica estática do processo. A caracterítica estática do processo é a curva que estabelece a relação em regime permanente entre a variável de entrada do processo (razão cíclica $D$ ) e variável de saída (tensão terminal da fonte $V$ ) (ASTROM; HAGGLUND, 1995). É utilizada na determinação do intervalo do sinal de controle necessária para variar a saída do processo em um intervalo específico, no dimensionamento dos atuadores e calibração dos sensores (ASTROM; HAGGLUND, 1995).

No experimento em malha aberta, definiu-se um valor constante para a entrada $D$ e mediu-se a saída $V$ após atingir o regime permanente, obtendo-se um ponto da curva. Repetiu-se o mesmo procedimento para cobrir todo o intervalo da entrada.

Os resultados do experimento são apresentados na Tabela A.1 e Figura A.1. Para razões cíclicas acima de $80 \%$ a proteção de sobrecorrente da fonte foi acionada, o que não permitiu a extração dos resultados. Entretanto, nesta condição a tensão dos painéis estaria abaixo dos $28 \mathrm{~V}$, razoavelmente distante do ponto de interesse (35 $V$ ) na qual foi feita linearização.

Observa-se em (I) da Figura A.1 que a razão cíclica que gera a potência máxima é de aproximadamente 70\%. Já mediante (II e III) da Figura A.1 percebe-se que a relação entre a entrada e a saída é não linear e inversa, ou seja, o aumento da razão cíclica diminui a tensão de entrada. Além disso, é observado que na faixa de 35 à $37 V$ a curva pode ser linearizada sem ocasionar erros significativos. 
Tabela A.1. Dados obtidos em experimento laboratorial para validação da fonte SAS.

\begin{tabular}{|c|c|c|c|}
\hline Duty Cycle & $\mathbf{V}$ ( $\mathbf{V}_{\text {RMS }}$ ) & I ( $\left.\mathbf{A}_{\text {RMS }}\right)$ & P ( $\mathbf{W}_{\text {RMS }}$ ) \\
\hline 0.05 & 42.33 & 0.695 & 2.12 \\
\hline 0.10 & 42.24 & 0.748 & 4.22 \\
\hline 0.15 & 42.12 & 0.821 & 6.32 \\
\hline 0.20 & 41.97 & 0.868 & 8.39 \\
\hline 0.25 & 41.80 & 0.956 & 10.45 \\
\hline 0.30 & 41.61 & 1.07 & 12.48 \\
\hline 0.35 & 41.37 & 1.18 & 14.48 \\
\hline 0.40 & 41.06 & 1.36 & 16.42 \\
\hline 0.45 & 40.67 & 1.57 & 18.30 \\
\hline 0.50 & 40.17 & 1.85 & 20.08 \\
\hline 0.55 & 39.51 & 2.18 & 21.73 \\
\hline 0.60 & 38.67 & 2.66 & 23.20 \\
\hline 0.65 & 37.45 & 3.27 & 24.34 \\
\hline 0.70 & 35.20 & 4.02 & 24.64 \\
\hline 0.75 & 28.88 & 4.67 & 21.66 \\
\hline 0.80 & OVER CURRENT ERROR & OVER CURRENT ERROR & OVER CURRENT ERROR \\
\hline 0.85 & OVER CURRENT ERROR & OVER CURRENT ERROR & OVER CURRENT ERROR \\
\hline 0.90 & OVER CURRENT ERROR & OVER CURRENT ERROR & OVER CURRENT ERROR \\
\hline 0.95 & OVER CURRENT ERROR & OVER CURRENT ERROR & OVER CURRENT ERROR \\
\hline
\end{tabular}

\section{Agilent Technologies Solar Array Simulator}

PARÂMETROS: $V_{M P}: 35.2 \mathrm{~V} \quad \mathrm{I}_{\mathrm{MP}}: 4.08 \mathrm{~A} \quad \mathrm{~V}_{\mathrm{OC}}: 43.8 \mathrm{~V} \quad \mathrm{I}_{\mathrm{SC}}: 5.10 \mathrm{~A}$ OBS: O diodo em série da fonte foi utilizado.

Conversor BOOST

PARÂMETROS: $\quad \mathrm{L}=5 \mathrm{mH} \quad \mathrm{C}=940 \mu \mathrm{F} \quad \mathrm{C}_{0}=1360 \mu \mathrm{F} \quad \mathrm{R}$ (carga) $=100 \Omega$ 

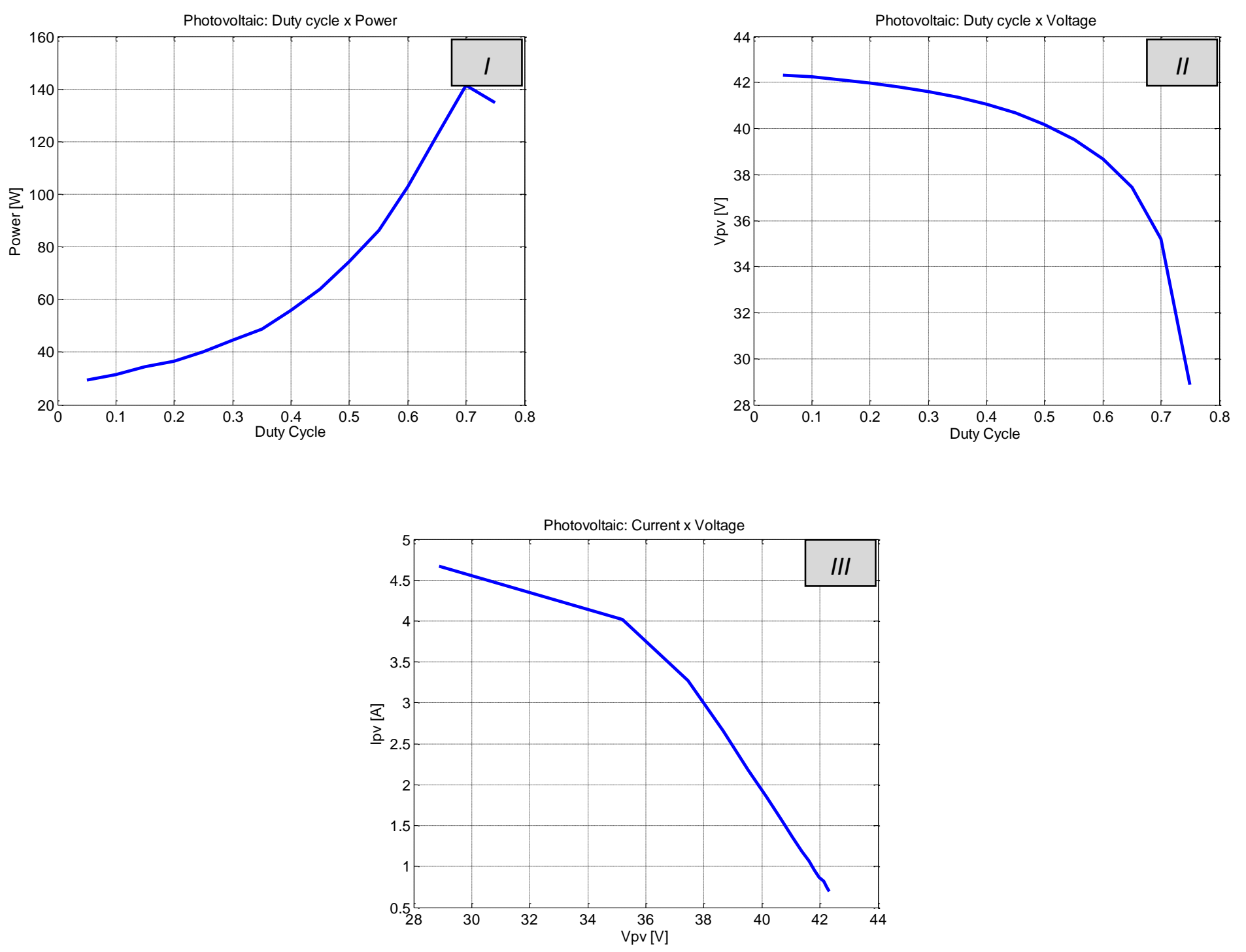

Figura A.1.Curvas geradas por experimento em laboratório da fonte SAS (I): Potência x razão cíclica. (II) Tensão x razão cíclica. (III) e Corrente $x$ Tensão. 


\section{Apêndice B}

Este apêndice apresenta resultados adicionais dos testes realizados em laboratório com o controlador fuzzy $P D+P I$ e o controlador fuzzy $P D$ isoladamente.

Nas Figuras B.1 e B.2 é mostrado o comportamento em regime permanente com o controlador fuzzy $P D+P I$ utilizando os algoritmos de $\mathrm{P} \& \mathrm{O}$ e InC, respectivamente. Observa-se que sob as mesmas condições de teste e em regime, o algoritmo de $\operatorname{InC}$ é mais estável que o algoritmo de P\&O. Isto ocorre porque quando utilizado o algoritmo da $\mathrm{P} \& O$, necessariamente, a tensão de referência é incrementada ou decrementada a cada ciclo. Ao passo que o algoritmo de InC quando atinge o PMP permanece no mesmo ponto a menos $\Delta l$ varie (ESRAM; CHAPMAN, 2007).

Por outro lado, são mostrados os testes realizados isoladamente com o controlador fuzzy $P D$ na Figura B.3. Observa-se que o controlador fuzzy $P D$ quando utilizado com baixo ganho $(<1,0)$ gera ruídos consideráveis na tensão do painel, não sendo recomendável a sua utilização isoladamente. Entretanto, o aumento do ganho do controlador fuzzy não levaria a plena solução do problema, devido ao erro em regime e o aumento do ripple. Uma solução seria um ajuste fino entre o ganho do controlador fuzzy e observando se o ripple e o erro em regime serem compatíveis com as especificações do projeto. 


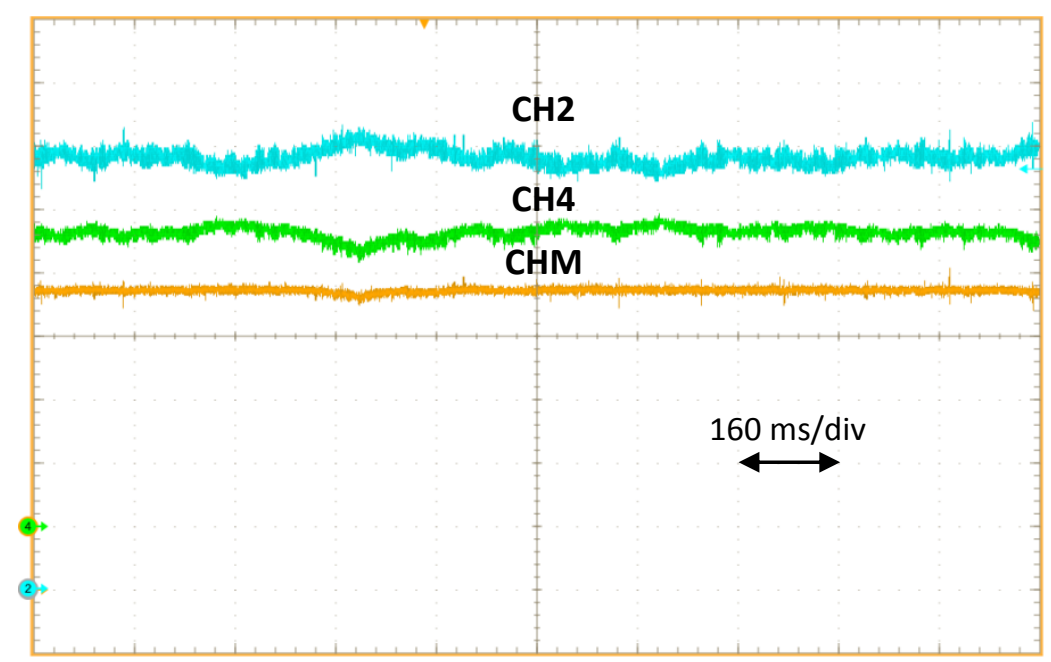

Figura B.1. Teste com o simulador de matriz fotovoltaica, utilizando-se o controlador fuzzy $P D+P I$ e o algoritmo de $P \& O$ em regime. Ch2: tensão da fonte (5 V/div). Ch4: corrente injetada pela fonte (900 mA/div). ChM: potência gerada pela fonte (30 W/div).

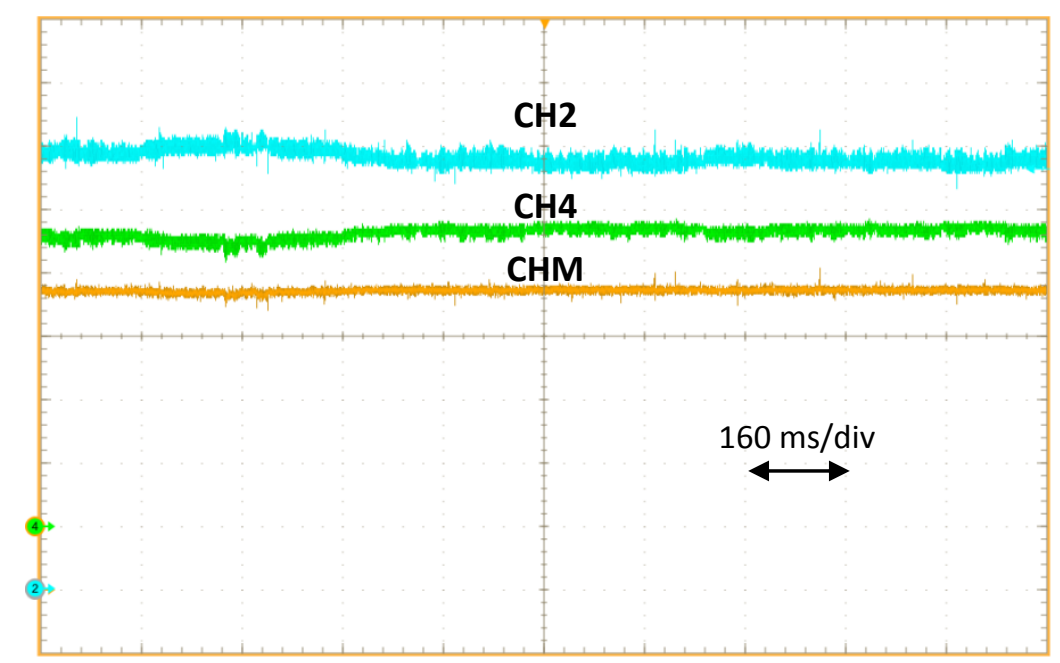

Figura B.2. Teste com o simulador de matriz fotovoltaica, utilizando-se o controlador fuzzy $P D+P I$ e o algoritmo de $\mathrm{InC}$ em regime. Ch2: tensão da fonte (5 V/div). Ch4: corrente injetada pela fonte (900 mA/div). ChM: potência gerada pela fonte (30 W/div). 

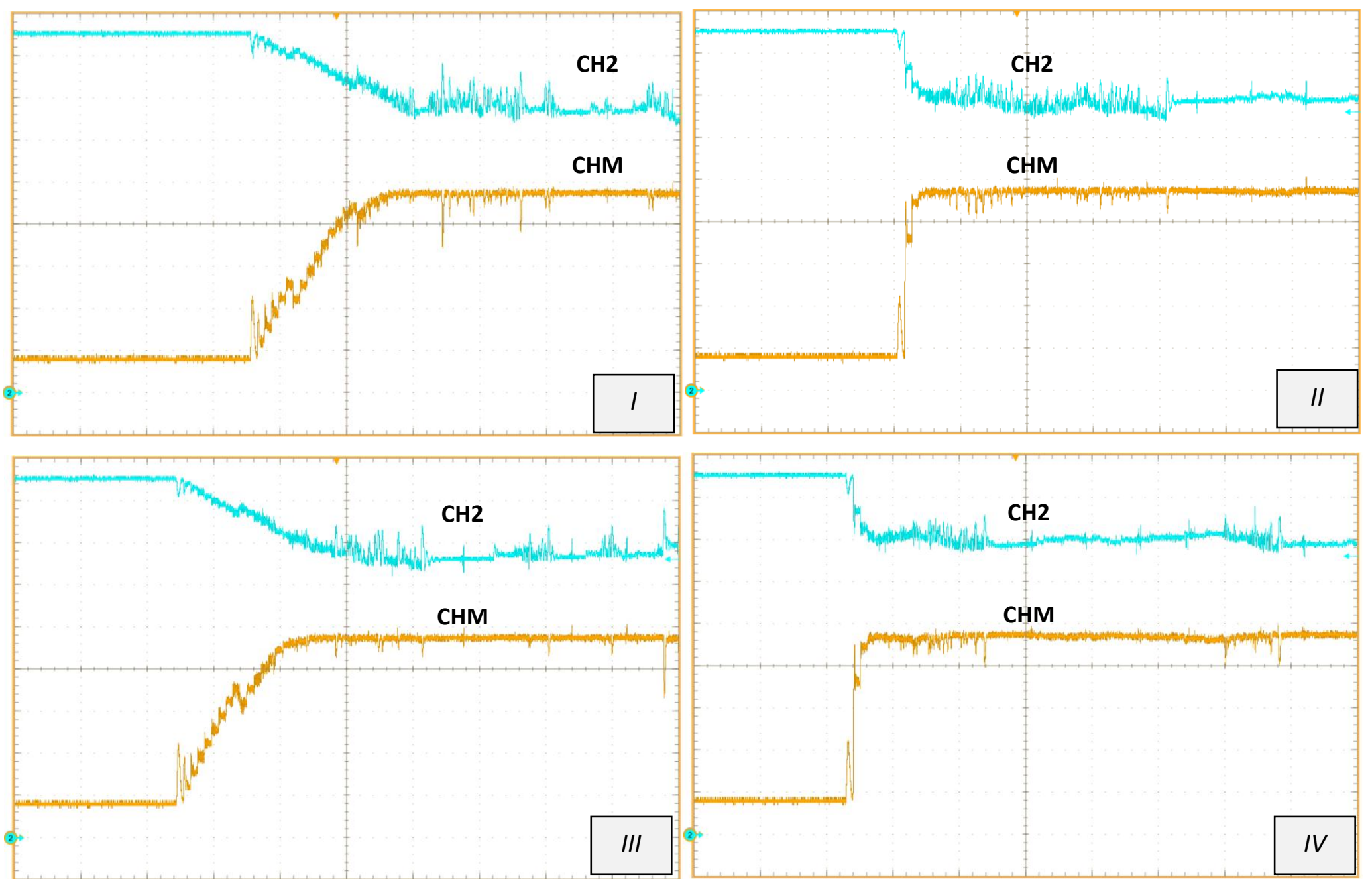

Figura B.3. Controle fuzzy PD testado com o simulador de fonte fotovoltaica nas condições de (I): passo fixo e algoritmo de P\&O. (II): passo variável e algoritmo de P\&O. (III): passo fixo e algoritmo de InC. (IV): passo fixo e algoritmo de InC. Ch2: tensão da fonte (5 V/div). ChM: potência gerada pela fonte (30 W/div). Escala de tempo de $160 \mathrm{~ms} / \mathrm{div}$. 


\section{Referências $^{8}$}

AGÊNCIA NACIONAL DE ENERGIA ELÉTRICA. (2009). Atlas da Energia Elétrica no Brasil, 3. ed. [S.I]: Disponível em: < http://www.aneel.gov.br/arquivos/PDF/atlas_par2_cap5.pdf>. Acesso em: 10 mai.2011.

ALAJMI, B.N. et al. (2011). Fuzzy-Logic-Control Approach of a Modified Hill-Climbing Method for Maximum Power Point in Microgrid Standalone Photovoltaic. In: IEEE Transactions in Power Electronics, v.26, n.4, p.1022-1030, Apr.

AMERICAN SOCIETY FOR TESTING AND MATERIALS (2008). G173 - 03: Standard Tables for Reference Solar Spectral Irradiances: Direct Normal and Hemispherical on $37^{\circ}$ Tilted Surface. Disponível em: <http://enterprise.astm.org/filtrexx40.cgi?+REDLINE_PAGES/G173.htm>. Acesso em 4 mar.2012.

ASTROM, K.; HAGGLUND, T. (1995). PID Controllers: Theory, Design and Tuning, 2nd ed. Research Triangle Park, N.C: International Society for Measurement and Control, p.6-7.

BOER, K.W. (2010). Introduction to Space Charge Effects in Semiconductors Springer Series in Solid-State Sciences, v.160, p.201-218.

CECATI, C.; CIANETTA, F.; SIANO, P. (2010). A Multilevel Inverter for Photovoltaic Systems With Fuzzy Logic Control. In: IEEE Transactions on Industrial Electronics, v. 57, n.12, p.4115-4125, Dec.

CHAOUACHI, A.; KAMEL, R.M.; NAGASAKA, K. (2010). MPPT Operation for PV Grid-connected System using RBFNN and Fuzzy Classification. In: World Academy of Science, Engineering and Technology. Disponível em: < http://www.waset.org/journals/waset/v65/v65-13.pdf>. Acesso em 1 apr.2012.

CHEN, C.-T. (1999). Linear System Theory and Design, 3rd ed. New York: Oxford University Press.

\footnotetext{
${ }^{8}$ De acordo com as alterações da ABNT NBR 6023 adotadas pela Comissão de Pós-Graduação.
} 
CHIU, C.-S.; OUYANG, Y.-L. (2011). Robust Maximum Power Tracking Control of Uncertain Photovoltaic Systems: a Unified T-S Fuzzy Model-Based Approach. In: IEEE Transactions on Control Systems Technology, v.19, n.6, p.1516-1526, Nov.

COELHO, R.F.; CONCER, F.; MARTINS, D.C. (2009). A study of the basic DC-DC converters applied in maximum power point tracking. In: Proceedings of 9th Brazilian Power Electronics Conference, p.673-678.

CRESESB - CENTRO DE REFERÊNCIA PARA ENERGIA SOLAR E EÓLICA SÉRGIO DE SALVO BRITO, CENTRO DE PESQUISA DE ENERGIA ELÉTRICA. (2006). Energia Solar Princípios e Aplicações. (2006). Disponível em: <http://www.cresesb.cepel.br/content.php?cid=tutorial_solar>. Acesso em 3 jan.2011.

DI PIAZZA, M.C. et al. (2008). Fuzzified PI Voltage Control for Boost Converters in Multi-String PV Plants. In: IEC Annual Conference of Industrial Electronics, p.2338-2345.

ELGENDY, M.A.; ZAHAWI, B.; ATKINSON, D.J. (2008). Analysis of the Performance of DC Photovoltaic Pumping Systems with Maximum Power Point Tracking. In: 4th IET Conference on Power Electronics, Machines and Drives Renewable, p.426-430, Apr.

ESRAM, T.; CHAPMAN, P.L. (2007). Comparison of Photovoltaic Array Maximum Power Point Tracking Techniques. In: IEEE Transactions on Energy Conversion, v.22, n.2, p.439-449.

ERICKSON, R.; MAKSIMOVIC, D. (2001). Fundamental of Power Electronics. 2nd ed. Norwell, Mass: Kluwer Academic Publishers.

ESRAM, T. et al. (2006). Dynamic Maximum Power Point Tracking of Photovoltaic Arrays Using Ripple Correlation Control. In: IEEE Transactions On Power Electronics, v.21, n.5, p.1282-1291, Sept.

EUROPEAN PHOTOVOLTAIC INDUSTRY ASSOCIATION. (2012). Market Report 2011, Jan. 2012. Disponível em: < http://www.epia.org>. Acesso em 16 mar.2012. . (fev.2011). Solar Generation 6. Disponível em: < http://www.epia.org>. Acesso em 10 mar.2012.

FARRET, F.A.; SIMÕES, M.G. (2006). Integration of Alternative Sources of Energy, Wiley. 
FEMIA, N. et al. (2005). Optimization of Perturb and Observe Maximum Power Point Tracking Method. In: IEEE Transactions on Power Electronics, 2005, v.20, n.4, p.963-973.

GONZÁLEZ-LLORENTE, J.D. (2009). Analysis Of Optimal Matching Between A CC Motor And Photovoltaic Modules Via CC-CC Power Converters. Thesis (Master Degree) - University of Puerto Rico. Disponível em: < http://search.proquest.com/docview/205436530 >. Acesso em 2 fev.2012.

GOW,J.A.; MANNING, C.D.(1999). Development of a photovoltaic array model for use in power-electronics simulation studies. In: IEE Proceedings of Electrical Power Applications, v.146, n.2, p.193-200.

INTERNATIONAL ENERGY AGENCY. (2009). World Energy Outlook. Disponível em: <http://www.IEA.org/textbase/nppdf/free/2009/weo2009.pdf>. Acesso em: 15 mar.2012.

PHOTOVOLTAIC POWER SYSTEMS PROGRAMME. (2010). Trends Report (low). Disponível em: < http://www.IEA-pvps.org/index.php?id=92>. Acesso em: 15 mar.2012.

. (2006). ANGOLA Towards an Energy Strategy. Disponível em: < http://www.IEA.org/textbase/nppdf/free/2006/angola2006.pdf>. Acesso em 20 mar.2012.

JANUZZI, G.de M.; VARELLA, F.K.de O.M; GOMES, R.D.M. (2009). Sistemas fotovoltaicos conectados à rede elétrica no Brasil: Panorama da atual legislação. out.2009. Disponível em: <http://pt.scribd.com/doc/26823983/RELATORIOPROJETO-2a-FINAL-4>. Acesso em: 20 fev. 2012.

KADRI, R.; GAUBERT, J.-P; CHAMPENOIS, G. (2011). An Improved Maximum Power Point Tracking for Photovoltaic Grid-Connected Inverter Based on Voltage-Oriented Control. In: IEEE Transactions on Industrial Electronics, v.58, n.1, p.66-75, Jan.

KING, D.L.; BOYSON, W.E.; KRATOCHVIL, J.A. (2004). Photovoltaic array performance model. Sandia National Laboratories. Disponível em: < http://photovoltaics.sandia.gov/docs/PDF/King\%20SAND.pdf>. Acesso em 7 mar.2011.

LI, J.; WANG, H. (2009). Maximum Power Point Tracking of Photovoltaic Generation Based on the Fuzzy Control Method. In: IEEE International Conference on Sustainable Power Generation and Supply, p.1-6, Apr. 
LI,Y. et al. (2010). The Optics of Organic Photovoltaics: Fiber - Based Devices. In: IEEE Journal of Selected Topics in Quantum Electronic, v.16, n.6, p.1827-1837.

MASOUM, A.S.; PADOVAN, F.; MASOUM, M.A.S. (2010). Impact of Partial Shading on Voltage - and Current Based Maximum Power Point Tracking of Solar Modules. In: IEEE Power and Energy Society General Meeting, p.1-5.

MAYER, A.C. et al. (2007). Polymer-based solar cells. Materials Today. Disponível em: <http://www.sciencedirect.com/science/article/pii/S1369702107702766>. Acesso em 27 mar.2012.

MIDDLEBROOK, R.D. (1988). Small-Signal Modeling of Pulse-Width Modulated Switched-Mode Power Converters. In: Proceedings of IEEE, v.76, n.4, p.343-354, Apr.

. (1991). Low-Entropy Expressions: The Key to Design-Oriented Analysis. In: IEEE Frontiers in Education Conference, p.399-403. .; VORPÉRIAN, V.; LINDAL, J. (1998). The N Extra Element Theorem. In: IEEE Transactions on Circuits and Systems: Fundamental Theory and Applications, v.45, n.9, p.919-935.

MIYATAKE. M. et al. (2007). A novel maximum power point tracker controlling several converters connected to photovoltaic arrays with particle swarm optimization technique. In: Proceedings of European Conference on Power Electronics and Applications, p.1-10, Sept.

MOHAN, N.; UNDELAND, T.M.; ROBBINS, W.P. (1995). Power Electronics: Converters, Application, 2nd ed. New York: John Willey, Inc, p.324-325.

MUSSER, G. (2010). A solar detective story: explaining how power output varies hour by hour. July 2012. Scientific American. Disponível em: $<$ https://www.scientificamerican.com/blog/post.cfm?id=a-solar-detective-storyexplaining-2010-07-30>. Acesso em 5 abr.2011.

ORTIZ-RIVERA, E.I.; PENG, F.Z. (2004). A Novel Method to estimate the maximum Power for a photovoltaic inverter system", In: 35th Annual IEEE Power Electronics Specialists Conference, v.3, p. 2065-2069, June. . (2005). Analytical Model for a Photovoltaic Module using the Electrical Characteristics provided by the Manufacturer Data Sheet. In: 36th IEEE Power Electronics Specialists Conference, Jun.2005, p.2087-2091. 
PATEL, H.; AGARWAL, V. (2008). MATLAB - Based Modeling to Study the Effects of Partial Shading on PV Array Characteristics. In: IEEE Transactions on Energy Conversion, p.302-310.

RAMAPRABHA, R.; MATHUR, B.L. (2008). Modelling and Simulation of Solar PV Array under Partial Shaded Conditions. In: IEEE International Conference on Sustainable Energy Technologies. p.7-11.

RENEWABLE ENERGY POLICY NETWORK FOR THE $21^{\text {ST }}$ CENTURY. (2011). Renewable Global Status Report. Disponível em: <http://www.ren21.net/Portals/97/documents/GSR/REN21_GSR2011.pdf>. Acesso em: 15 mar.2012.

RIORDAN, C.; HULSTRON, R. (1990). What is an air mass 1.5 spectrum? [solar performance calculations]. In: IEEE Photovoltaic Specialists Conference, v.2, p.1085-1088, May.

RODRIGUEZ, C.; AMARATUNGA, G.A. (2007). Analytic Solution to the Photovoltaic Maximum Power Point Problem. In: IEEE Transactions on Circuits and Systems - I: Regular Papers, v.54, n.9, p.2054-2060.

ROSS, T.J. (2010). Fuzzy Logic with Engineering Applications, 3rd ed. [Singapore]: John Wiley \& Sons.

SPIAZZI, G.; BUSO, S.; MATTAVELLI, P. (2009). Analysis of MPPT Algorithms for Photovoltaic Panels Based On Ripple Correlation Techniques in Presence of Parasitic Components. In: Proceedings of 9th Brazilian Power Electronics Conference, p.88-95.

SUETAKE, M. (2008). Implementação de Sistemas Inteligentes em Processadores Digitais para Controle de Máquinas Elétricas Rotativas. Dissertação (Mestrado) Escola de Engenharia de São Carlos, Universidade de São Paulo.

SYAFARUDDIN; KARATEPE, E.; HIYAMA, T. (2008). Artificial neural network-polar coordinated fuzzy controller based maximum power point tracking control under partially shaded conditions. In: IET Renewable Power Generation, v.3, n.2, p.239-253, July.

UNIVERSITAT KASSEL. (2003). Photovoltaic Systems Technology Technical Report, Disponível em: < http://www.re.e-technik.unikassel.de/photos/documents/29-SKRIPT_Photovoltaic.pdf>. Acesso em 23 mar.2012. 
VILLALVA, M.G.; GAZOLI, J.R.; FILHO, E.R. (2009). Comprehensive approach to modeling and simulation of photovoltaic arrays. IEEE Transactions on Power Electronics, 2009, v.24, n.5, p.1198 - 1208.

(2010). Conversor Eletrônico De Potência Trifásico Para Sistema Fotovoltaico Conectado À Rede Elétrica. Tese (Doutorado) - Faculdade de Engenharia e de Computação, Universidade Estadual de Campinas, Campinas, 2010.

; de SIQUEIRA, T.G.; RUPPERT, E. (2010). Voltage regulation of photovoltaic arrays: small-signal analysis and control design, In: IEEE Transactions in Power Electronics, v.3, n.6, p.869-880.

WANG, Y.-J.; HSU, P.-C. (2011). Modelling of solar cells and modules using piecewise linear parallel branches. In: IET Renewable Power Generation, v.5, n.3, p.215-222, May.

XIAO, W. et al. (2007). Regulation of Photovoltaic Voltage. In: IEEE Transactions on Industrial Electronics, v.54, n.3, p.1365-1374, June. 